\title{
Genetic diversity in sesame (Sesamum indicum L.): molecular markers, metabolic profiles and effect of plant extracts on soil-borne pathogenic fungi
}

\author{
Dissertation \\ to obtain the Ph.D. Degree \\ in the International Ph.D. Program for Agricultural Sciences in Goettingen (IPAG) \\ at the Faculty of Agricultural Sciences, \\ Georg-August-University Göttingen, Germany
}

\author{
presented by \\ Hernán E. Laurentin T. \\ born in Montevideo, Uruguay
}

Göttingen, April 2007 
D7

Name of supervisor: Prof. Dr. Petr Karlovsky

Name of co-supervisor: Prof. Dr. Andreas von Tiedemann

Oral examination date: April, $25^{\text {th }} 2007$ 


\begin{abstract}
\end{abstract}
Sesame (Sesamum indicum L.) is an important crop in tropical and subtropical areas. Sesame seed is traditionally used for direct consumption, because of its high nutritional value $(50 \%$ oil and $25 \%$ protein), and as a source of oil of excellent quality. Potentially beneficial effects of sesame on human health have recently renewed the interest in this ancient crop. Information on the genetic diversity in sesame is limited, only some studies about morphological diversity have been carried out, and generally, these studies have been focused on regional interest. To overcome this gap of knowledge in sesame, this research was achieved to know how diverse is a sesame germplasm collection containing both accessions from different origin regions, and commercial cultivars or experimental lines. Genetic diversity was assessed at three different levels: DNA (by means of amplified fragment length polymorphism or AFLP), metabolic profiles, and functional metabolites (by means of effect of plant extracts on soil-borne pathogenic fungi). Individual outputs for every approach were obtained, but also information about usefulness of AFLP for identifying sesame cultivars, optimal conditions for bioassays, and identification of sesame accessions potentially valuables for breeding and/or production of natural compounds against soil-borne fungi The assessment by means of AFLP resulted in a high level of variability within all diversity centres except Central Asia. No association between geographic origin and AFLP patterns was found. Most of the variation is explained by genetic diversity within origin regions rather than between origin regions. According to the results, conservation strategies do not need to cover all diversity centres as long as they sample a sufficient number of accessions. Similarly, choosing parent genotypes for breeding programs from many diversity centres as compared to sampling just one centre (except Central Asia) is not likely to increase the variability among progeny significantly, whether the objective is breeding for poligenic traits such as yield. AFLP-based fingerprints demonstrated to be useful for identifying unequivocally sesame genotypes, resulting an average and maximum probability of identical match by chance between 2 accessions of $2.7 \times 10^{-7}$ and $5.2 \times 10^{-5}$ respectively. Correlation between AFLP and metabolic profiles was not found, but some important consistencies were reported. Metabolic profiles were obtained from seeds; and indirect selection on some metabolites at seed by farmers and differences in the sampling on the genome of the two methodologies could explain the results. Identification of similarity/dissimilarity relationship between pairs, based on AFLP and seed metabolic profiles, depend on the genotypes under comparison, due to differences in evolutionary history of each genotype. Therefore the assumption that genetic distance between two genotypes is directly proportional to the probability of identifying very different 
levels in some important agronomic or quality trait is not necessarily true, and is not supported by this work. Search in plants of novel compounds with antimicrobial properties requires large screening of accessions, not only at inter-species level, but also within species. Adequate system of screening must be available for this goal. The present study report the standardization of a biosassay to test biological activity of novel compounds on growth of Macrophomina phaseolina. The proposed bioassay has the advantage of being suitable to test small amount of compounds, reducing required laboratory space and therefore being suitable for testing a great amount of sources with several replications. This is especially advantageous for testing natural compounds from plant genetic resources collections, because of the large amount of sources available. The present study shows the importance of large screening within a species when antifungal activity from plants are being searched. Large within-species genetic variation has been originated by evolutionary forces, which can lead to differentiation at metabolite level and therefore, in the effect of plant extracts on fungi growth. Extreme response of fungi before plant extracts from different accessions of sesame are reported in this study: large stimulatory effect or strong growth inhibition. Some accessions have been identified as potentially valuable for breeding and/or production of natural products to control soil-borne fungi, not only from root extracts, also from stem, leaf and seed extracts. Results of the present study suggest that toxic compounds to fungi are present in all the accessions, but final effect on fungi growth depend on its balance respect to other compounds present in the plant organ. 


\section{Table of contents}

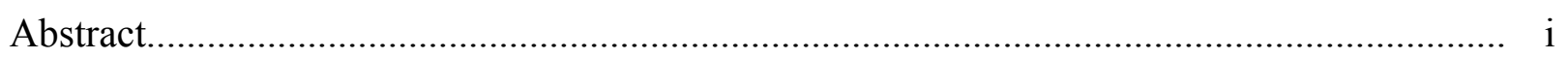

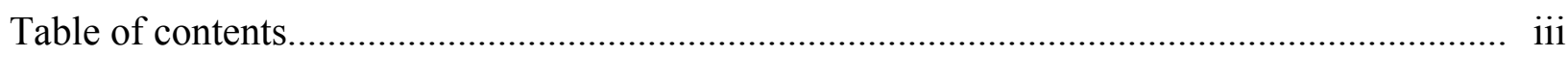

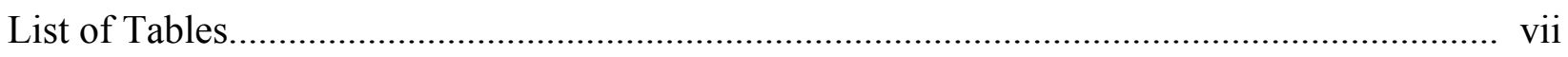

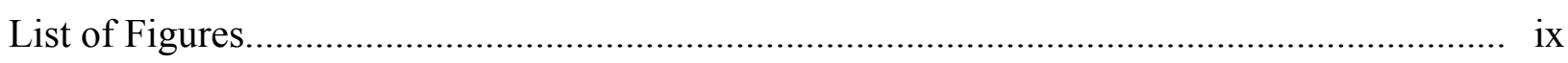

\section{Chapter 1. General Introduction}

1. Sesame importance with emphasis in Venezuela................................................... 1

2. Characterizing plant genetic resources........................................................... 2

2.1. General concepts................................................................................. 2

2.2. Molecular markers with emphasis in AFLP......................................... 3

2.3. Metabolomics................................................................................... 5

2.4. Plant metabolites and pathogens...................................................... 7

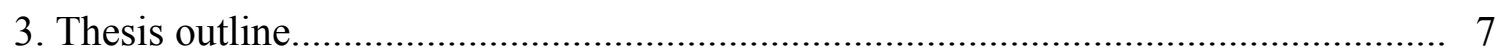

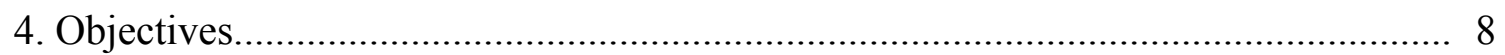

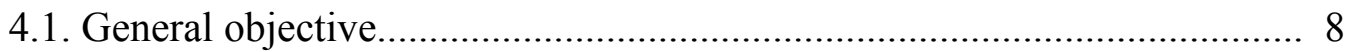

4.2. Specific objectives.......................................................................... 8

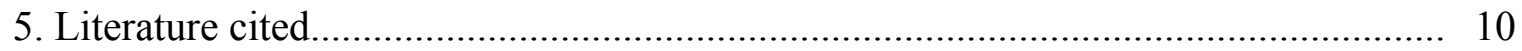

Chapter 2. Genetic relationship and diversity in a sesame (Sesamum indicum L.) germplasm collection using amplified fragment length polymorphism (AFLP)

Abstract.

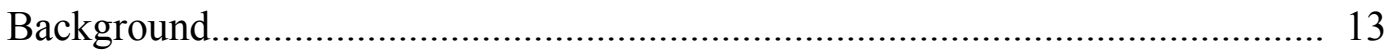

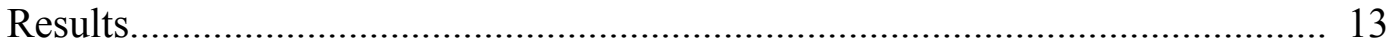

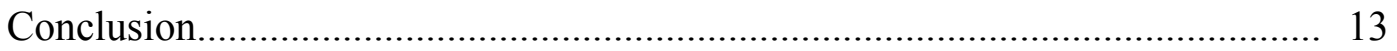

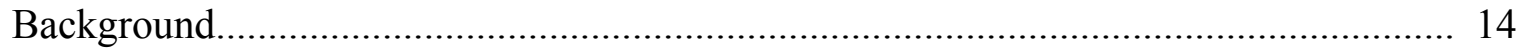

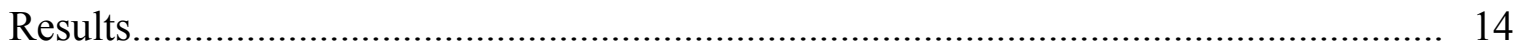

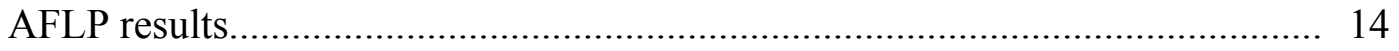

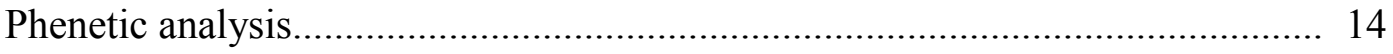

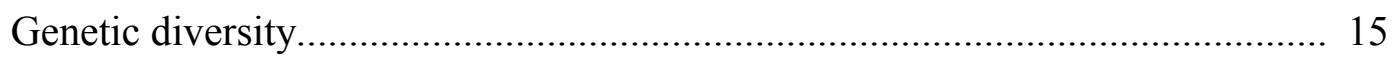

Analysis of molecular variance................................................................... 15

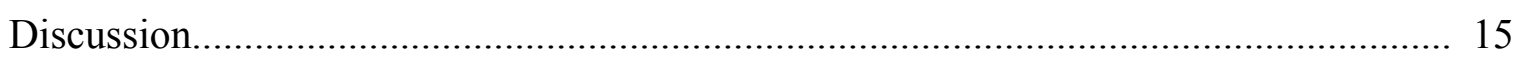

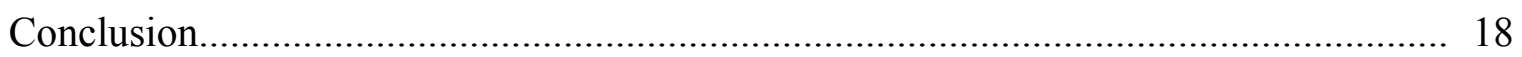




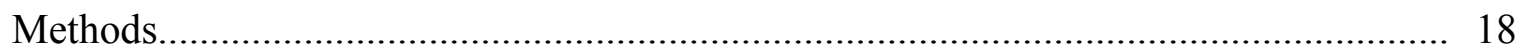

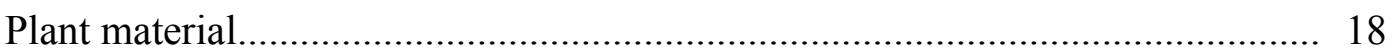

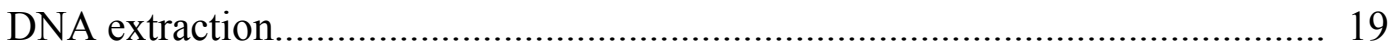

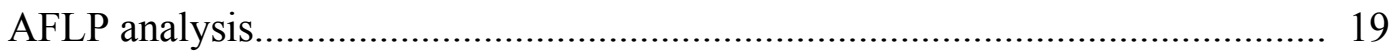

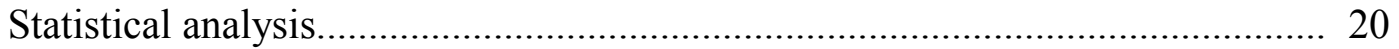

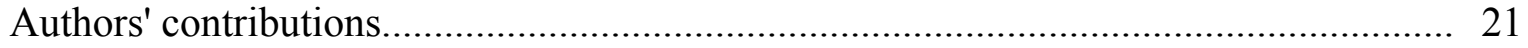

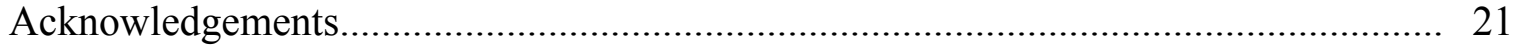

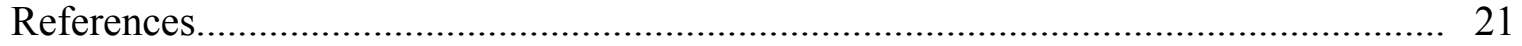

Chapter 3. AFLP fingerprinting of sesame (Sesamum indicum L.) cultivars: identification, genetic relationship and comparison of AFLP informativeness parameters

Introduction

Material and methods.

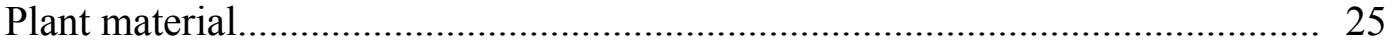

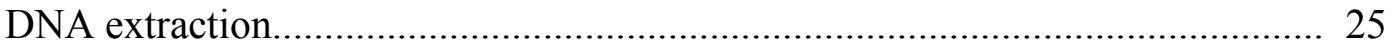

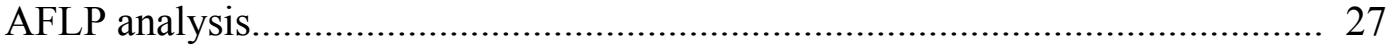

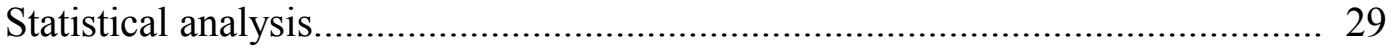

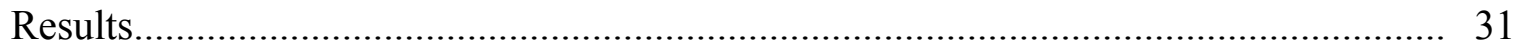

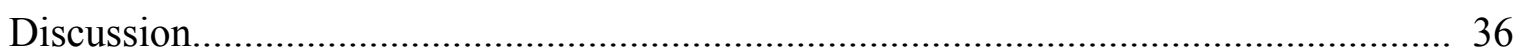

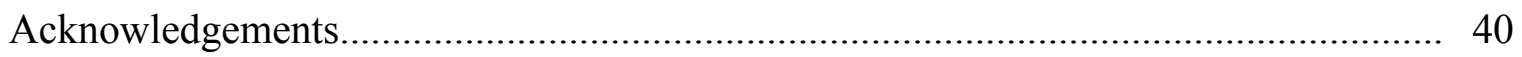

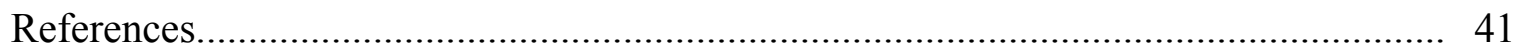

Chapter 4. Analysis of association between seed metabolic profiles and genetic diversity in sesame (Sesamum indicum L.)

Introduction

Material and methods.

Plant material.

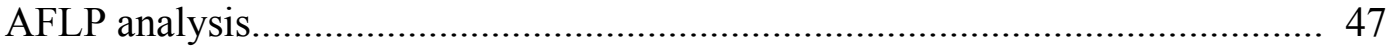

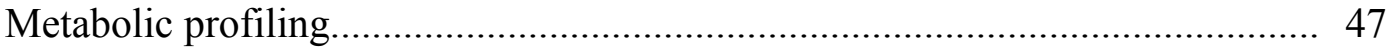

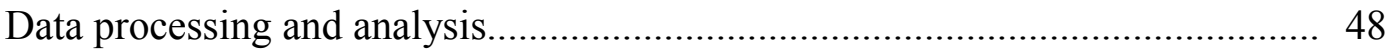

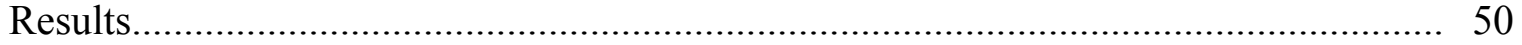

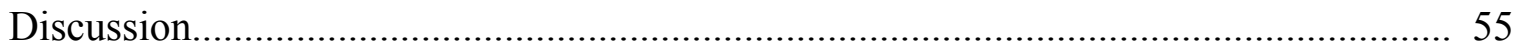

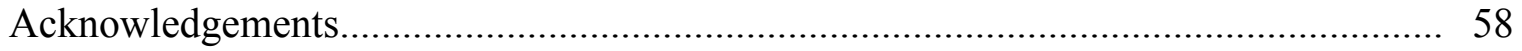

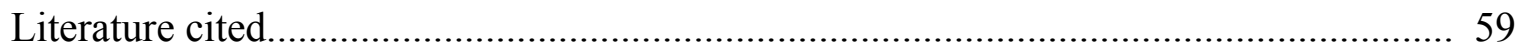


Chapter 5. Standardising bioassays for testing novel compounds against Macrophomina phaseolina (Tassi) Goidanich

Abstract 62

Background. 62

Results. 62

Conclusion. 62

Background 63

Results 64

Fungus growth in Petri dishes 64

Microsclerotia production. 64

Measuring fungus growth in 96-wells microplates. 66

Fungus growth in 96-wells microplates. 66

Fungus growth in presence of Benomyl....................................................... 66

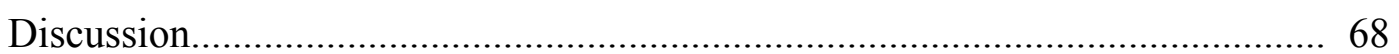

Conclusion 72

Methods 72

Fungus isolates. 72

Fungus growth and microsclerotia production. 72

Fungus growth from different microsclerotia concentration in 96-well microplates. 73

Effect of osmotic potential on fungus growth 74

Fungus growth in presence of antifungal compounds. 74

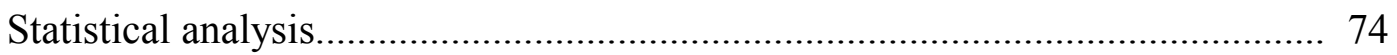

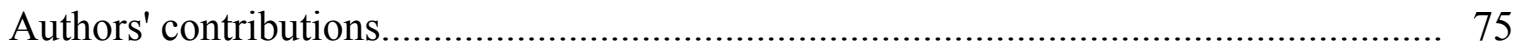

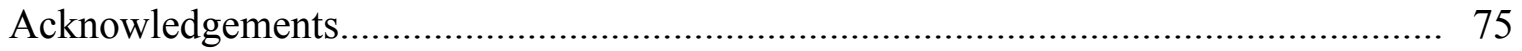

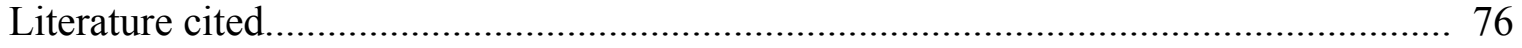

Chapter 6. Effect of plant extracts from a sesame (Sesamum indicum L.) germplasm collection on growth of the soil-borne fungi affecting Venezuelan sesame production

Abstract 78

Introduction.

Material and methods.

Plant material 80

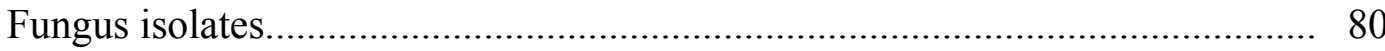

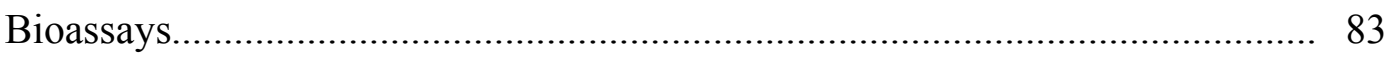

Principal component analysis.................................................................... 84 


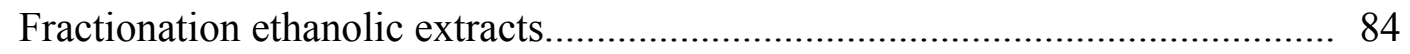

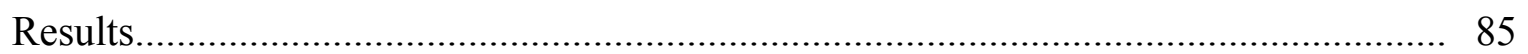

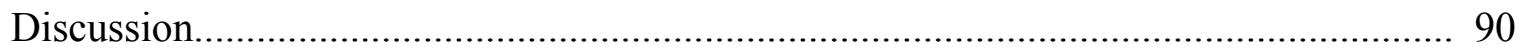

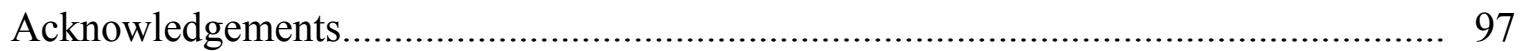

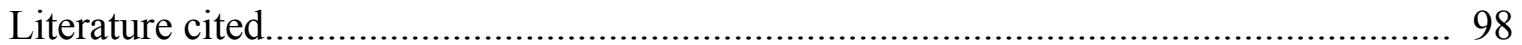

Chapter 7. Concluding summary ................................................................................. 101

Publications and attended conferences.................................................................... 106

Curriculum Vitae........................................................................................................ 107 


\section{List of tables}

Chapter 2. Genetic relationship and diversity in a sesame (Sesamum indicum L.) germplasm collection using amplified fragment length polymorphism (AFLP)

Table 1. List of primer combinations used in the present study and some characteristics of the amplification products.

Table 2. Polymorphic loci and genetic diversity of five groups of sesame accessions, according their geographical distribution.

Table 3. Unbiased measures of identity and genetic distance (Nei, 1978) among groups of sesame accessions.

Table 4. AMOVA for the partitioning AFLP variation in sesame.

Table 5. Pairwise comparison of groups of sesame accessions by AMOVA

Table 6. Accessions from CENIAP Germplasm Bank (Venezuela) and their respective origin country and diversity centre.

Table 7. Primer sequences used in preamplification and amplification.

Chapter 3. AFLP fingerprinting of sesame (Sesamum indicum L.) cultivars: identification, genetic relationship and comparison of AFLP informativeness parameters

Table 1. Commercial cultivars used in the present study and their respective origin.

Table 2. Primer sequences used in the first and second amplification.

Table 3. Number of bands (NB), number of polymorphic bands (NPB), number of exclusive bands (NEB), number of haplotypes $(\mathrm{NH})$, number of genotypes with exclusive haplotype (NGEH), polymorphic information content (PIC), resolving power (Rp) and marker index (MI) obtained per AFLP primer combination.

Table 4. Minimum, maximum and average of probability of identical match by chance for each primer combination.

Table 5. Minimum, maximum and mean of Jaccard's similarity coefficients of 20 sesame cultivars based on 339 AFLP markers. 
Chapter 4. Analysis of association between seed metabolic profiles and genetic diversity in sesame (Sesamum indicum L.)

Table 1. Accessions from CENIAP Germplasm Bank (Venezuela) and their respective origin country and diversity centre.

Table 2. Total number of bands, number of polymorphic bands, percentage of polymorphic bands and number of unique bands obtained per AFLP primer combination..

Table 3. Signals detected in sesame extracts by HPLC-MS.

Chapter 5. Standardising bioassays for testing novel compounds against Macrophomina phaseolina (Tassi) Goidanich

Table 1. Number of microsclerotia per petri dish (20 $\mathrm{ml}$ of medium) for two isolates of $M$. phaseolina in six culture media (PDA4+FP is modified PDA (4\% of agar) and two pieces of filter paper, PDA4 is modified PDA ( $4 \%$ of agar), PDA+FP is normal PDA and two pieces of filter paper, PDA is normal PDA, SNA+FP is low-nutrient agar medium and two pieces of filter paper, and SNA is low-nutrient agar medium) and two temperatures of incubation....

Chapter 6. Biological activity of plant extract from a sesame (Sesamum indicum L.) germplasm collection on growth of the soil-borne fungi affecting Venezuelan sesame production

Table 1. Accessions from Centro Nacional de Investigaciones Agropecuarias (CENIAP) Germplasm Bank (Venezuela) used as source of root, stem, leaf and seed ethanolic extracts... 81

Table 2. Commercial cultivars and experimental lines used as source of root, stem, leaf and seed ethanolic extracts

Table 2. Sesame accessions with plant extracts affecting changes in optical density as consequence of mycelia growth.

Table 3. Eigenvectors of the first two axes of principal component analysis. 


\section{List of figures}

Chapter 2. Genetic relationship and diversity in a sesame (Sesamum indicum L.) germplasm collection using amplified fragment length polymorphism (AFLP)

Figure 1 . Dendrogram for 32 sesame accessions (cophenetic correlation 0.95).

Figure 2. Biplot of principal coordinates analysis for 32 sesame accessions

Chapter 3. AFLP fingerprinting of sesame (Sesamum indicum L.) cultivars: identification, genetic relationship and comparison of AFLP informativeness parameters

Figure 1. Phenogram of 20 sesame cultivars based on Jaccard's similarity coefficients using 339 AFLP markers

Figure 2. Three-dimensional graph from the principal coordinate analysis of 339 AFLP markers of 20 sesame cultivars.

Chapter 4. Analysis of association between seed metabolic profiles and genetic diversity in sesame (Sesamum indicum L.)

Figure 1. Scatter plots comparing ordination performed by AFLP (Jaccard's coefficient and Roger's distance) to ordination performed by metabolic profiles (correlation coefficient, Euclidean distance and simple matching coefficient).

Figure 2. Biplot of principal coordinate analysis. A. Based on AFLP data using Jaccard's coefficient. B. Based on seed metabolic profiles using correlation coefficient......

Chapter 5. Standardising bioassays for testing novel compounds against Macrophomina phaseolina (Tassi) Goidanich

Figure 1. Growth (mean \pm S.E.) of M. phaseolina on 32 petri dishes averaged on 2 isolates and 2 independent experiments, varying temperature of incubation and culture medium.

Figure 2. Growth (mean \pm S.E.) of M. phaseolina in 96-well microplates from microsclerotia, averaged on 3 microsclerotia concentration and 2 independent experiments, varying temperature of incubation and isolate.

Figure 3. Effect of microsclerotia concentration on fungus growth in 96-well microplate in two isolates.

Figure 4. Growth (mean \pm S.E.) of $M$. phaseolina in 96-well microplates from microsclerotia, 
using PDB + different concentration of sorbitol as medium

Figure 5. Growth (mean \pm S.E.) of two isolates of M. phaseolina at different concentration of Benomyl. A. Isolated from Venezuelan soil sample. B. From DSMZ (German Collection of Microorganisms and Cell Cultures).

Chapter 6. Biological activity of plant extract from a sesame (Sesamum indicum L.) germplasm collection on growth of the soil-borne fungi affecting Venezuelan sesame production

Figure 1. Changes in optical density (mean \pm standard error) as consequence of mycelia growth of M. phaseolina in presence of root (A.), stem (B.), leaf (C.) and seed (D.) extracts from sesame accessions. The four with most inhibitory effect and the four with most stimulatory effect on fungus growth are presented.

Figure 2. Changes in optical density (mean \pm standard error) as consequence of mycelia growth of F. oxysporum f.sp. sesami in presence of root (A.), stem (B.), leaf (C.) and seed (D.) extracts from sesame accessions. The four with most inhibitory effect and the four with most stimulatory effect on fungus growth are presented.

Figure 3. Biplot of principal component analysis based on effect of plant extracts of 51 sesame accessions on growth of Macrophomina phaseolina and Fusarium oxysporum f.sp. sesami.

Figure 4. Changes in optical density as consequence of mycelia growth of $M$. phaseolina in presence of fractions of root (A), stem (B), leaf (C) and seed (D) ethanolic extracts from 2 sesame accessions: $\mathrm{O}$ is original ethanolic extract, $\mathrm{AEE}$ is ethanolic extract after extraction with ether, $\mathrm{E}$ is etheric extract.

Figure 5. Changes in optical density as consequence of mycelia growth of $F$. oxysporum in presence of fractions of root (A), stem (B), leaf (C) and seed (D) ethanolic extracts from 2 sesame accessions: $\mathrm{O}$ is original ethanolic extract, $\mathrm{AEE}$ is ethanolic extract after extraction with ether, $\mathrm{E}$ is etheric extract.

Figure 6. Changes in optical density (mean $\pm \mathrm{SE})$ as consequence of mycelia growth of $M$. phaseolina in presence of ether extract and $0.50 \%$ of ether extract from A. Roots of accession Korea 1. B. Stem of accession UCLA1. C. Leaf of accession Greece. D. Seed of accession India 8

Figure 7. Changes in optical density (mean $\pm \mathrm{SE}$ ) as consequence of mycelia growth of $F$. oxysporum f. sp. sesami in presence of ether extract and $0.50 \%$ of ether extract from A. Roots of accession UCLA1. B. Stem of accession Inamar. C. Leaf of accession India 1. D. Seed of accession Korea 1 


\section{Chapter 1. General introduction}

\section{Sesame importance with emphasis in Venezuela}

Sesame (Sesamum indicum L.) is an important crop in tropical and subtropical areas (Ashri, 1998). According to FAO (2006), over seven million of hectares were harvested worldwide in 2005, producing almost three million of tons. India, Sudan, Myanmar, Uganda and China are the greatest sesame producers, covering $75 \%$ of world production. In America the production is about 170.000 tons per year. Mexico, Guatemala, Paraguay and Venezuela cover $80 \%$ of production in the continent, with a little contribution to world production (about $4 \%$ ), however, this production is important in exportation trade, because it covers about $20 \%$. Venezuela is the $16^{\text {th }}$ wold producer (about 30.000 tons per year), and the $7^{\text {th }}$ country in sesame exportations (about 24.000 tons per year). Its sesame is considered of high quality, and its production system unique in the world (Mazzani, 1999).

Some authors use the name Sesamum orientale L. instead Sesamum indicum L. arguing respect to the nomenclature rules (Bedigian, 2003), however Nicolson and Wieserma (2004) propose to conserve Sesamum indicum L. arguing two main reasons: the two names were proposed at the same date like different species, which it is known that is false, and the usage of $S$. indicum L. still significantly predominate in the current overall scientific literature, especially that relating to agriculture. In this research, the scientific name Sesamum indicum L. is used.

Sesame production in Venezuela is very important in the Western Llanos, specifically around Turen town, in Portuguesa state, where all Venezuelan sesame is grown. It is used as a rotation crop to the maize, during the dry season, obtaining needed water from moisture retained in the soils during previous raining season. Venezuelan sesame production has social importance because it is a job source for the people living near Turen, in some steps of production: manual weeds control and mainly in harvest (Laurentin, 2002).

In the early years of Venezuelan sesame production, since 1940, sesame was used as oil 
source for the national market, and a little amount for exportation as oil. At present, since 1990, it is used for exportation as processed grain, and therefore, cultivars used before had to change by cultivars with traits suitable for exportation market, i.e. a big and near white grain (Montilla and Teran, 1996; Mazzani, 1999).

As in any other crop, sesame has abiotic and biotic limitations. Among biotic limitations, the soil borne fungi Macrophomina phaseoli (Tassi) Goid, and Fusarium oxysporum f. sp. sesami Castell have played an important role in Venezuelan sesame production as limiting factors (Pineda, 2002). M. phaseolina causes the disease known as charcoal root rot, and it acts on young plantlets (1-4 weeks old). Fungus survives as microsclerotia in the soil and on infected plant debris. Climatic conditions characterized by high temperature $\left(28-35^{\circ} \mathrm{C}\right)$ and low humidity in the soil, as present in Turen at sesame production season, promote the infection of the fungus. Microsclerotia germinate on the root surface, and mycelia grows through the roots and low stem, where microsclerotia are produced plugging the vascular system. Economic losses in Venezuela have been estimated in about 30\% (Pineda, 1987), but up to $100 \%$ in India (Vyas, 1981). Fusarium wilt disease is currently associated to M. phaseolina infection (Dhingra and Sinclair, 1978; Pineda and Avila, 1988), however, some studies deal to control it as a fungus able to infect sesame plants without previous infections (Ammar et al., 2004). F. oxysporum f. sp. sesami survives as saprophyte in soil. Mycelia penetrate roots, growing intercellulary and reaching the xylem. It grows through the vascular system, affecting the plant water supply. Differential response of sesame cultivars to isolates of $M$. phaseolina (Pineda et al., 1985; Simoza and Delgado, 1991; Rajput et al., 1998; Avila, 2003; ElBramawy and Wahid, 2006) or F. oxysporum (El-Shazly et al., 1999) has been frequently found.

\section{Characterizing plant genetic resources}

\subsection{General concepts}


Plant genetic resources are considered one of the most important world's natural resources (Ramanatha and Hodgkin, 2002). Increasing efforts to conserve them have been done. Plant genetic conservation comprises several activities. Evaluation or characterization is one of the most critical steps because information that the users will have about different accessions, depend on it. For instance breeders will need a correct characterization to know the agronomic value of specific accessions. Access to a wide range of genetic diversity is critical to the success of breeding programs (Hoisington et al. 1999) and the ability to identify genetic variation is indispensable for effective management and use of genetic resources (Rao, 2004), and it depends on characterization.

Germplasm characterization involves, in the first instance, description of variation for morphological traits, it means to measure variation at phenotypic level. This approach has disadvantages such as they are often limited (Rao, 2004), highly heritable traits often show little variation over much of the material studied (Karp et al., 1997), and trait expression, mainly of quantitative traits, is subjected to strong environmental influence (Karp et al., 1997; Rao, 2004). Despite of the limitations, this approach was used for much time, and it is used yet, but it was necessary to get a more reliable way to characterize the plant genetic resources. Thus biochemical methods appeared, they included seed storage proteins, allozymes and isozymes. This approach is effective in a better control of environmental influence, therefore they have been more successful than morphological characterization but they are unable to detect low levels of variation (Rao, 2004) because they screen only a very small genome section of species. These disadvantages are overcome by DNA-based techniques, which have potential to identify polymorphism represented by differences in DNA sequences, because they can be used at any developmental stage of the plant (Ovesná et al., 2002) and they cover the whole genome variability (Ovesná, 2002; Rao, 2004).

\subsection{Molecular markers with emphasis in AFLP}


Karp et al. (1997) classify DNA-based techniques according to two criteria, depending on the technique is PCR-based, and arbitrary/semi-arbitrary primers or specifically designed primers are used. Three categories are considered: the first one includes non-PCR based methods, such as Restriction Fragments Length Polymorphism (RFLP) and Variable Number of Tandem Repeats (VNTRs), the second one includes PCR-based techniques which use arbitrary or semi-arbitrary primers, such as Random Amplified Polymorphic DNA (RAPD) (Williams et al., 1990) and Amplified Fragments Length Polymorphism (AFLP) (Vos et al., 1995), and the third one includes PCR-based techniques which use specifically designed primers such as microsatellites or simple sequence repeats (SSRs). The second category requires no previous sequence knowledge.

AFLP is a technique developed by Vos et al. (1995) that is based on the detection of genomic restriction fragments by PCR amplification. AFLP is considered a robust and reliable technique because stringent reaction conditions are used for primer annealing. AFLP technique, for complex genomes, consists in five steps: DNA digestion with two restriction enzymes, ligation of adapters to the DNA-fragments ends, preamplification of ligated DNA fragments with two primers with one selective nucleotide, amplification of the preamplified DNA fragments with two primers with three selective nucleotide, and electrophoresis on polyacrylamide gels and bands visualization.

Comparisons among DNA-based techniques have been done. Savelkoul et al. (1999) indicate that AFLP is more reproducible and robust than RFLP because signal detection does not depend on hybridization, partial digestion and faint patterns like RFLP, and these are sources of irreproducibility. AFLP technique has advantages on RAPD because it has the possibility of using stringent PCR annealing temperatures. Jones et al. (1997) also indicate an excellent reproducibility of AFLP as compared to RAPD. About the informative power, or efficiency of the markers, Powell et al. (1996) and Russell et al. (1997) found that AFLP had higher values of diversity index or marker index than RAPD, RFLP and SSR, that is to say, AFLP was more 
efficient than these markers because it analyzes simultaneously a large number of bands rather than the levels of polymorphism detected (Russell et al., 1997). Diversity index and marker index are concepts used by these authors to measure the efficiency of one marker. Garcia-Mas et al. (2000) reported that AFLP showed higher efficiency in detecting polymorphism than RAPD and RFLP. Archak et at. (2003) found that AFLP exhibited a maximum discrimination efficiency as compared to RAPD, ISSR and AFLP .

Mueller and LaReesa (1999) used 5 criteria to compare AFLP with RAPD, RFLP, SSR and allozymes, getting that AFLP are similar to RAPD and SSR in sharing the potential to get a high quantity of information, to SSR, RFLP and allozymes in the high reproducibility, to RAPD and allozymes in the short development time, to SSR and RFLP in the high ability to solve genetic difference. AFLP are considered intermediate between easiness of use and development of RAPD and allozymes, and the difficulty of SSR and RFLP.

Reliable information about genetic diversity within a species can be obtained by means of AFLP. These types of studies help designing comprehensive conservation strategies, and maximizing the use of accessions in breeding. Another current use of molecular markers such as AFLP is the cultivar identification, which is a useful tool whether the objective is to contribute to protect intellectual rights of cultivars production.

\subsection{Metabolomics}

Approaches based on genomics (genes) and based on functional genomics (transcriptome, proteome and metabolome) differs basically in the ability to overcome environmental influence. Studies at gene level are not sensitive to environmental influence, can be used at any developmental stage of the organism (Ovesná et al., 2002) and covers the whole genome variability (Ovesná, 2002; Rao, 2004). On the contrary, approaches based on proteome and metabolome are highly dependent on the environmental influence and development stage of the organism, but they can be related with specific agronomic, nutritional or commercial 
meaning.

Most of the studies aimed to determine diversity have been based on morphological characterisation or DNA techniques, however, for a holistic and comprehensive understanding of the species diversity, integration of different approaches is desirable.

Metabolomics is gaining popularity as a functional genomics tool useful in broadening the knowledge of biological systems (Hall, 2006), this is also true for species diversity. Metabolic profiling and metabolic fingerprinting (Fiehn, 2002; Fiehn and Weckwerth, 2003; Dunn and Ellis, 2005; Hall, 2006) could provide valuable information about species diversity, however only few studies have been focussed on this aim (e.g. Murch et al., 2004; Schauer et al., 2005; Overy et al., 2005). In line with the terminology established in genome and transcriptome analysis, metabolic fingerprinting designates procedures generating static profiles of signals (HPLC peaks, TLC spots, mass spectra) representing anonymous metabolites, which are characteristic for a given sample and can be used, for example, to confirm its origin or uncover surrogates. Metabolic profiling, in analogy to transcription profiling, generates profiles of metabolites, either anonymous or identified, and is mostly used for quantitative comparisons among varieties, physiological states or treated/untreated samples. Profiling of metabolite classes defined by their chemical nature (e.g., glucosinolates or oxylipins) is used to quantitatively describe the representation of these substances in the sample. Alternative definitions of metabolic profiling and metabolic fingerprinting (Fiehn, 2002; Fiehn and Weckwerth, 2003) are likely to lead to confusion whenever metabolic analysis, genome fingerprinting and transcription profiling are treated jointly.

Impact on breeding programs could be reached with this approach, because of the quality of crop plants is a direct function of their metabolite content (Memelink, 2005) and quality of plant tissues also determines their commercial value in relation to aspects of flavour, fragrance, shelf life, physical attributes, etc. (Hall, 2006). 


\subsection{Plant metabolites and pathogens}

Plants represent a nearly unlimited source of phytochemicals, metabolites of primary and secondary metabolism (Sudha and Ravishankar, 2002). The secondary metabolites are of major interest because of their different functions and biological activities, among them antimicrobial properties (Stockigt et al., 1995). Plants use constitutive and induced defences to protect themselves from pathogen and herbivore attack, (Walling, 2000), therefore the study of the effect of constitutive plant extracts on fungi-pathogenic growth can be used as approach to study the genetic diversity within a species. This approach would be useful in identifying accessions possessing antimicrobial compounds involved in resistance response, or for obtaining new natural compounds with antifungal activity. This kind of study requires an easy, rapid and high-throughput bioassay to screen the effect of plant extracts from several accessions on the growth of pathogenic-fungi. Metabolic signals correlating with resistance can be used as biomarkers to speed up resistance breeding even before the structure of the compounds have been fully elucidated.

\section{Thesis outline}

The importance of sesame in Venezuela, and the importance of biotic stress on sesame production, are justification enough to carry out the present project. First it was needed to perform a broad screening on several sesame accession from different geographic origin to know the genetic relationships among them; therefore, AFLP was performed for 52 accessions. The chapters 2 and 3 are about the results obtained with this DNA characterization. Chapter 4 deals with the characterization of 10 sesame accessions (chosen based on AFLP characterization) based on metabolomics. The following part of the thesis deals with the bioassays to determine the effect of plant extracts (root, stem, leaf and seed) on pathogenic fungi (Macrophomina phaseolina and Fusarium oxysporum f. sp. sesami), but before, was necessary to standardize the bioassay for $M$. phaseolina because there was not 
any report about the use of this fungus in microplate-format bioassays. Chapter 5 and 6 deal with these aspects of the thesis.

\section{Objectives}

\subsection{General objective}

To study the genetic diversity of a sesame (Sesamum indicum L.) germplasm collection consisting of accessions with different geographical origins and obtained from Venezuelan breeding programs, using molecular markers, metabolomic approach, and effect of plant extracts on growth of the major pathogenic fungi on sesame production in Venezuela.

\subsection{Specific objectives}

- To clarify genetic relationship among 32 sesame accessions from the Venezuelan Germplasm Collection, which represents genotypes from 5 geographical regions (Chapter 2).

- To determine the relationship between geographical distribution and genetic diversity (Chapter 2).

- To determine the genetic relationship among 20 Venezuelan sesame cultivars (Chapter 3).

- To evaluate the ability of AFLP markers for distinguishing 20 Venezuelan sesame cultivars (Chapter 3).

- To estimate the usefulness of parameters currently used to assess the informativeness of molecular markers for genotyping (Chapter 3).

- To evaluate genetic and metabolic diversity on a set of 10 sesame accessions and to discern the relationship between metabolic and genomic data (Chapter 4). 
- To develop a rapid and little-format bioassay adequate for evaluating the effect of small amount of novel compounds, from a large amount of sources, on the growth of Macrophomina phaseolina (Chapter 5).

- To explore the diversity of a sesame germplasm collection based on effect of extracts of root, stem, leaf and seed on growth of the soil-borne pathogenic fungi Macrophomina phaseolina, and Fusarium oxysporum f.sp. sesami (Chapter 6).

- To compare the ordination obtained among the sesame accessions based on effect of plant extract on fungi growth to classifications based on AFLP and metabolomics (Chapter 6). 


\section{Literature cited}

Ammar, S., M. El-Shazly, M. El-Ashry, M. El-Bramawy. 2004. Inheritance of resistance to Fusarium wilt disease in some sesame hybrids. Egyptian Journal of Applied Science 19:36-55

Archak, S., A. Gaikwad, D. Gautam, E.V.V. Rao, K.R. Swamy and J. Kurihaloo. 2003. Comparative assessment of DNA fingerprinting techniques (RAPD, ISSR and AFLP) for genetic analysis of cashew (Anacardium occidentale L.) accessions of India. Genome 46(3):362-369

Ashri, A. 1998. Sesame breeding. Plant Breeding Reviews 16:179-228

Avila, J. 2003. Resistance of white seeded sesame (Sesamum indicum L.) cultivars against charcoal rot (Macrophomina phaseolina) in Venezuela. Sesame and Safflower Newsletter $18: 72-76$

Bedigian, D. 2003. Evolution of sesame revisited: domestication, diversity and prospects. Genetic Resources and Crop Evolution 50:779-787

Dhingra, O. and J. Sinclair. 1978. Biology and pathology of Macrophomina phaseolina. Impresa Universitaria. Universidade Federal de Viçosa. Minas Gerais, Brasil.

Dunn, W. and D. Ellis. 2005. Metabolomics: current analytical platforms and methodologies. Trends in Analytical Chemistry 24:285-294

El-Bramawy, M., and A. Wahid. 2006. Field resistance of crosses of sesame (Sesamum indicum L.) to charcoal root rot caused by Macrophomina phaseolina (Tassi) Goid. Plant Protect Sci 42:66-72

El-Shazly, M., O. A. Wahid, M. A. El-Ashry, S. M. Ammar, M. A. El-Barmawy. 1999. Evaluation of resistance to Fusarium wilt disease in sesame germplasm. International Journal of Pest Management 45:207-210

FAO. 2006. FAOstat Databases. http://apps.fao.org/cgi-bin/nph-db.pl

Fiehn, O. 2002. Metabolomics - the link between genotypes and phenotypes. Plant Molecular Biology 48:155-171

Fiehn, O. and W. Weckwerth. 2003. Deciphering metabolic networks. Eur. J. Biochem. 270:579-588

Garcia-Mas, J., M. Oliver, H. Gomez-Paniagua and M.C. deVicente. 2000. Comparing AFLP, RAPD and RFLP markers for measuring genetic diversity in melon. Theor. Appl. Genet. 101:860-864

Hall, R.D. 2006. Plant metabolomics: from holistic hope, to hype, to hot topic. New Phytologist. 169:453-468

Hoisington, D., M. Khairallah, T. Reeves, J. Ribaut, B. Skovmand, S. Tanba and M. Warburton. 1999. Plant genetic resources: what can they contribute toward increased crop productivity?. Proc. Natl. Acad. Sci. 96:5937-5943 
Jones, C., K. Edwards, S. Castaglione, M. Winfield, F. Sala, C. van de Wiel, G. Bredereneijer, B. Vosman, M. Matthes, A. Daly, R. Brettschneider, P. Bettini, M. Buiatti., E. Maestri, A. Malcevschi, N. Marmiroli, R. Aert, G. Volckaert, J. Rueda, R. Linacero, A. Vasquez and A. Karp. 1997. Reproducibility testing of RAPD, AFLP and SSR markers in plants by a network of European laboratories. Molecular Breeding 3:381-390

Karp, A., S. Kresovich, K. Bhat, W. Ayad and T. Hodgkin. 1997. Molecular tools in plant genetic resources conservation: a guide to the technologie. IPGRI Technical Bulletin No. 2. International Plant Genetic Resources Institute. Rome. Italy

Laurentin H. 2002. Mejoramiento genético del ajonjolí en Venezuela. En: ASOPORTUGUESA, UCLA, INIA (eds.). II Curso de Producción de Ajonjolí y Soya. Araure, estado Portuguesa, Venezuela.

Mazzani, B. 1999. Investigación y tecnología del cultivo del ajonjolí en Venezuela. Ediciones del Consejo Nacional de Investigaciones Cientificas y Tecnológicas. Caracas. Venezuela. 103 pp. http://ajonjoli.sian.info.ve/mazzani.pdf

Memelink, J. 2005. Tailoring the plant metabolome without a loose stitch. Trends in Plant Science 10:305-307

Montilla, D. and H. Terán. 1996. UCLA-1, una nueva variedad de ajonjolí (Sesamum indicum L.) Bioagro 8(1):26-29

Mueller, U. and L. LaReesaWolfenberger. 1999. AFLP genotyping and fingerprinting. Tree $14: 389-394$

Murch, S.J., H.P. Vassantha Rupansinghe, D. Goodenowe and P. Saxena. 2004. A metabolomic analysis of medicinal diversity in Huang-qin (Scutellaria baicalensis Georgi) genotypes: discovery of novel compounds. Plant Cell Rep. 23:419-425

Nicolson, D. and J. Wieserma. 2004. Proposal to conserve Sesamum indicum against Sesamum orientale (Pedaliaceae). Taxon 53(1):210-211

Overy, S.A., H.J. Walker, S. Malone, T.P. Howard, C.J. Baxter, L.J. Sweetlove, S.A. Hill and W.P. Quick. 2005. Application of metabolite profiling to the identification of traits in a population of tomato introgression lines. Journal of Experimental Botany 56:287-296

Ovesná, J., K. Poláková and L. Leisová. 2002. DNA analyses and their applications in plant breeding. Czech J Genet Plant Breed. 38(1):29-40

Pineda, J.B. 1987. Macrophomina phaseolina en Ajonjolí. Evaluación de Daños y Pérdidas. Fonaiap Divulga (Venezuela) 5(25):25-26.

Pineda, J. 2002. Enfermedades en el cultivo del ajonjoli. En: ASOPORTUGUESA, UCLA, INIA (eds.). II Curso de Producción de Ajonjolí y Soya. Araure, estado Portuguesa, Venezuela

Pineda, J. and J. Avila. 1988. Alternativas para el control de Macrophomina phaseolina y Fusarium oxysporum patogenos del ajonjoli (Sesamum indicum L.). Agronomia Tropical 38(4-6):79-84

Pineda, J., H. Nass and H. Rodriguez. 1985. Efecto de la densidad de inoculo de 
Macrophomina phaseolina en la infección de plántulas de ajonjoli. Agronomia Tropical 35(46):133-138

Powell W., M. Morgante, C. Andre, M. Hanafey, J. Vogel, S. Tingey and A. Rafalsky. 1996. The utility of RFLP, RAPD, AFLP and SSR (microsatellite) markers for germplasm analysis. Molecular Breeding 2:225-238

Rajput, M., H. Khan, K. Jafri and J. Fazal Ali. 1998. Field Screening of Sesame Germplasm for Resistance against Charcoal Rot (Macrophomina phaseolina). Sesame Safflower Newsl., 13:63-66.

Rao, N. 2004. Plant genetic resources: advancing conservation and use through biotechnology. African Journal of Biotechnology 3(2):136-145

Ramanatha R., and T. Hodgkin. 2002. Genetic diversity and conservation and utilization of plant genetic resources. Plan Cell, Tissue and Organ Culture 68:1-19

Russell, J., J. Fuller, M. Macaulay, B. Hatz, A. Jahoor, W. Powell, R. Waugh. 1997. Direct comparison of levels of genetic variation among barley accessions detected by RFLPs, AFLPs, SSRs, and RAPDs. Theor. Appl. Genet. 95:714-722

Savelkoul, P., H. Aarts, J. DeHaas, L. Dijkshoorn, B. Duim, M. Otsen, J. Rademaker, L. Schouls and J. Lenstra. 1999. Amplified-fragment length polymorphism analysis: the state of an art. Journal of Clinical Microbiology 37(10):3083-3091

Schauer, N., D. Zamir and A. Fernie. 2005. Metabolic profiling of leaves and fruit of wild species tomato: a survey of the Solanum lycopersicum complex. Journal of Experimental Botany 56:297-307

Simosa, Neyda and M. Delgado. 1991. Virulence of four isolates of Macrophomina phaseolina on four sesame (Sesamum indicum) cultivars. Fitopatología Venezolana 4: 20-23

Stockigt, J., P. Oblitz, H. Falkenhagen, R. Lutterbach and S. Endeß. 1995. Natural products and enzymes from plant cell cultures. Plant Cell Tiss. Org Cult. 43: 97-109

Sudha, G. and G. Ravishankar. 2002. Involvement and interaction of various signaling compounds on the plant metabolic events during defense response, resistance to stress factors, formation of secondary metabolites and their molecular aspects. Plant Cell, Tissue and Organ Culture 71:181-212

Vos, P., R. Hogers, M. Bleeter, M. Reijans, T. van de Lee, M. Hornes, A. Frijters, J. Pot, J. Peleman, M. Kuiper and M. Zabeau. 1995. AFLP: a new technique for DNA fingerprinting. Nucleic Acids Res. 23:4407-4414

Vyas, S. 1981. Diseases in Sesamum in India and their control. Pesticides 15:10

Walling, L. 2000. The myriad plant responses to herbivores. J Plant Growth Regul 19:195216

Williams, J.G.K., A.R. Kubelik, K.J. Livak, J.A. Rafalski and S.V. Tingey. 1990. DNA polymorhism amplified by arbitrary primers are useful as genetic markers. Nucleic Acid Res 18:6531-6535 


\title{
Genetic relationship and diversity in a sesame (Sesamum indicum L.) germplasm collection using amplified fragment length polymorphism (AFLP) Hernán E Laurentin*1 and Petr Karlovsky ${ }^{2}$
}

\author{
Address: 'Biologic Sciences Department, Agronomy Faculty, Universidad Centroccidental Lisandro Alvarado, Barquisimeto, Venezuela and \\ IInstitute of Phytopathology and Plant Protection, Georg-August-University, 37077 Goettingen, Germany \\ Email: Hernán E Laurentin* - hlaurentin@uda.edu.ve; Petr Karlovsky - karlovsky@web.de \\ * Corresponding author
}

Published: 16 February 2006

BMC Genetics2006, 7:10 doi:10.1186/1471-2156-7-10

This article is available from: http://www.biomedcentral.com/147/-2156/7/10

Q) 2006Laurentin and Karlorsky, licensee BioMed Central Ltd.

This is an Open Access article distributed under the terms of the Creative Commons Attribution License (bttp://creativecommons-org/licenses/by/2.0). which permits unrestricted use, distribution, and reproduction in any medium, provided the original work is properly cited.
Received: 13 September 2005 Accepted: 16 February 2006

\begin{abstract}
Background: Sesame is an important oil crop in tropical and subtropical areas. Despite its nutritional value and historic and cultural importance, the research on sesame has been scarce, particularly as far as its genetic diversity is concerned. The aims of the present study were to clarify genetic relationships among 32 sesame accessions from the Venezuelan Germplasm Collection, which represents genotypes from five diversity centres (India, Africa, China-Korea-Japan, Central Asia and Western Asia), and to determine the association between geographical origin and genetic diversity using amplified fragment length polymorphism (AFLP).

Results: Large genetic variability was found within the germplasm collection. A total of 457 AFLP markers were recorded, $93 \%$ of them being polymorphic. The jaccard similarity coefficient ranged from 0.38 to 0.85 between pairs of accessions. The UPGMA dendrogram grouped 25 of 32 accessions in two robust clusters, but it has not revealed any association between genotype and geographical origin. Indian, African and Chinese-Korean-Japanese accessions were distributed throughout the dendrogram. A similar pattern was obtained using principal coordinates analysis. Genetic diversity studies considering five groups of accessions according to the geographic origin detected that only $20 \%$ of the total diversity was due to diversity among groups using Nei's coefficient of population differentiation. Similarly, only $5 \%$ of the total diversity was attributed to differences among groups by the analysis of molecular variance (AMOVA). This small but significant difference was explained by the fact that the Central Asia group had a lower genetic variation than the other diversity centres studied.
\end{abstract}

Conclusion: We found that our sesame collection was genetically very variable and did not show an association between geographical origin and AFLP patterns. This result suggests that there was considerable gene flow among diversity centres. Future germplasm collection strategies should focus on sampling a large number of plants. Covering many diversity centres is less important because each centre represents a major part of the total diversity in sesame, Central Asia centre being the only exception. The same recommendation holds for the choice of parents for segregant populations used in breeding projects. The traditional assumption that selecting genotypes of different geographical origin will maximize the diversity available to a breeding project does not hold in sesame. 


\section{Background}

Sesame (Sesamum indicum L.) is one of the most ancient crops [1]. It is grown in tropical and subtropical areas [2] on 6.5 million hectares worldwide, producing more than three million tons of seed [3]. India, Sudan, Myanmar and China are the most important sesame producers with 68 $\%$ of the world production. Sesame seed, which is highly nutritive ( $50 \%$ oil and $25 \%$ protein), is traditionally used for direct consumption and as a source of oil of excellent quality due to the presence of natural antioxidants such as sesamin and sesamol [4]. Potentially beneficial effects of sesame on human health have recently renewed the interest in this ancient crop.

Despite the nutritional value and historic and cultural importance of sesame, the research on sesame has been scarce. For example, no international CGIAR (Consultative Group on International Agricultural Research) agency is mandated to study sesame [5]. Information on the genetic diversity in sesame is limited as well. Sesame diversity centres have been identified as India, China, Central Asia, Near East and Abysinia in classical studies $[6,7]$. More recently, a high level of variability of morphological characters within different sesame collections was reported $[8,9]$. Genetic variability in sesame has also been studied by molecular techniques, including isozymes $[10,11]$, RAPD [12,13] and ISSR [14]. Amplified fragment length polymorphism (AFLP) has only been used in linkage analysis [15]. AFLP is a promising technique for the characterization of genetic diversity in sesame because it possesses a high degree of reproducibility and discriminatory power [16]. It has been successfully applied to many cultivated and wild plants, including faba bean (Vicia faba L.) [17], grapevine (Vitis vinifera L.) [18], adzukibean (Vigna angularis Willd.) [19], squash (Cucurbita pepo L.) [20], Nicotiana attenuata [21], plantain (Musa spp.) [22], sorghum (Sorghum bicolor L.)[23], alfalfa (Medicago sativa L.) [24] wheat (Triticum turgidum L. subsp. Durum (Desf.) Husn) [25], and coffee (Coffea arabica L.) [26].
The aim of the present study was to clarify genetic relationships among 32 sesame accessions from the Venezuelan Germplasm Collection, which represents genotypes from 5 geographical regions, and to determine the relationship between geographical distribution and genetic diversity.

\section{Results \\ AFLP results}

A total of 457 AFLP markers were recorded using 8 primer combinations on 32 sesame accessions. Ninety-three percent of markers were polymorphic (Table 1). Fifty-nine percent of the markers ranged from 100 to 300 nucleotides in size. Forty-seven bands $(10.3 \%)$ were unique, 25 belonging to African accessions, 10 to Indian accessions, 8 to China-Korean-Japan accessions, 3 to Central-Asian accessions and 1 to Western-Asian accession.

\section{Phenetic analysis}

Jaccard's similarity coefficients ranged from 0.38 (between one accession from India and one from Korea) to 0.85 (between one accession from Turkey and one from Syria), with an average of 0.65 . Within each geographical region sampled similarity coefficients were 0.59 for Africa, 0.61 for China-Korea-Japan, 0.63 for India, 0.68 for Western Asia and 0.80 for Central Asia.

Figure 1 displays a UPGMA dendrogram obtained using similarity coefficients. Two robust groups were identified at a similarity value of 0.65 by bootstraping (bootstrap values $90 \%$ and $93 \%$ ). These clusters included 25 of 32 accessions used in the analysis. The cophenetic correlation coefficient (0.95) indicated little distortion between the original similarity values from the similarity matrix and the values used to construct the dendrogram. Furthermore, the standard deviation for the two main clusters was less than $4 \%$ (see legend to Figure 1). Figure 2 displays the location of the same 32 accessions on a bidimensional space of principal coordinates analysis, which represented $74 \%$ of total variation among accessions.

Table I: List of primer combinations used in the present study and some characteristics of the amplification products. Bands were considered polymorphic if the frequency of one of its states (present or absent) is less or equal to 0.97 (present or absent in at least 31 from 32 accessions)

\begin{tabular}{lccc}
\hline Primer combination & Total number of bands & Polymorphic bands & \% of polymorphic bands \\
\hline (Cy5)E_ACA+M_CTCA & 48 & 43 & 90 \\
(Cy5)E_ACA+M_CAA & 68 & 66 & 97 \\
(Cy5)E_ACA+M_CCA & 52 & 52 & 100 \\
(Cy5)E_ACA+M_CGAA & 45 & 38 & 84 \\
(Cy5)E_ACA+M_CAT & 93 & 56 & 92 \\
(Cy5)E_ACA+M_CAG & 57 & 56 & 98 \\
(Cy5)E_ACA+M_CCC & 56 & 32 & 93 \\
(Cy5)E_ACA+M_CAC & 40 & 83
\end{tabular}




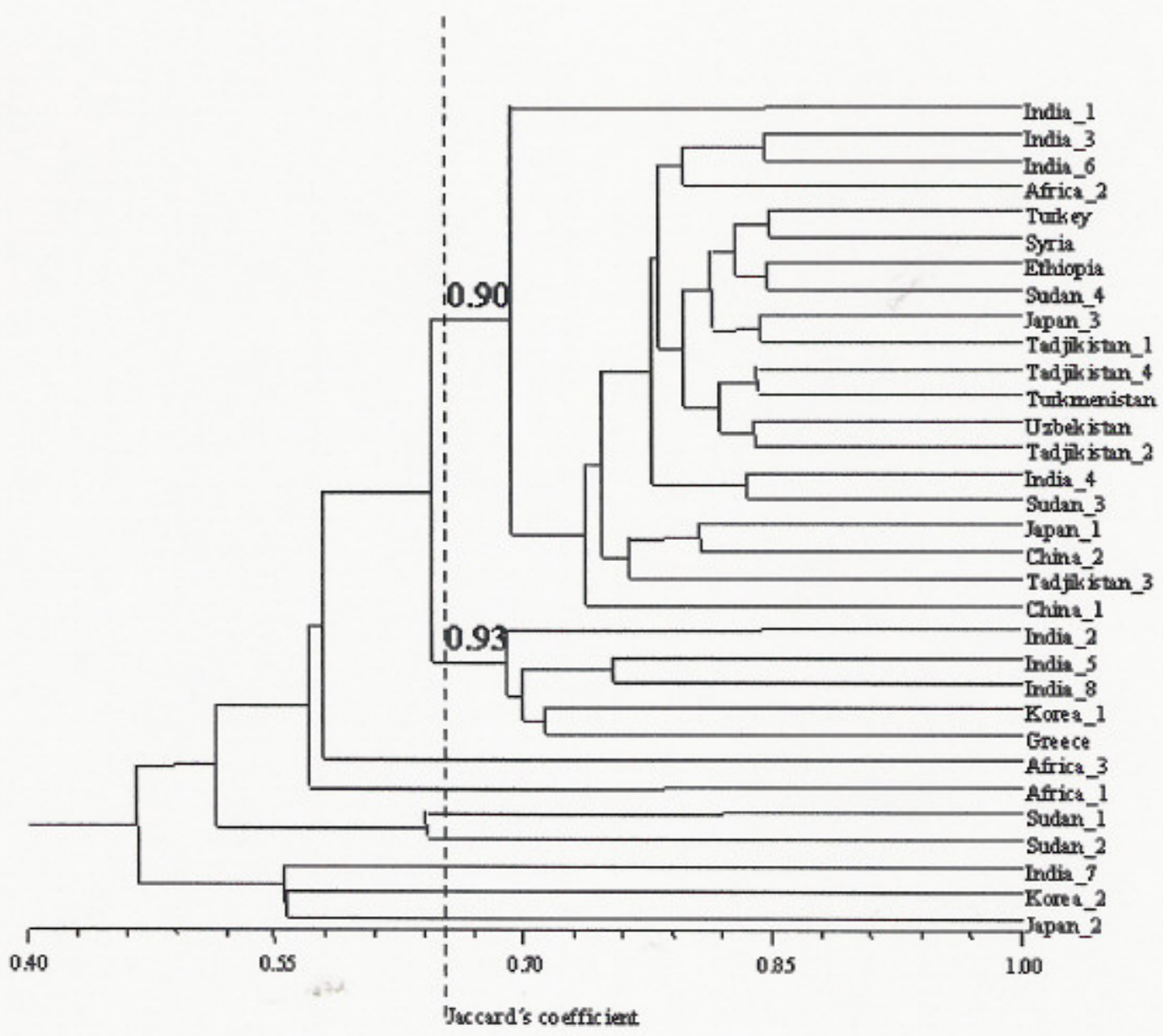

Figure I

Dendrogram for 32 sesame accessions (cophenetic correlation 0.95 ). Values from bootstraping analysis are indicated. Two groups are clearly identified, and these nodes have a similarity average and standard deviation of $69.2 \pm 2.6$ (the upper) and $69.0 \pm 1.2$. (the lower)

\section{Genetic diversity}

Table 2 summarises estimated Nei's parameters related to genetic diversity, showing that only $20 \%$ of the total variation in allele frequencies corresponds to differences among groups. Average diversity within groups $\left(\mathrm{H}_{\mathrm{ST}}\right)$ ranged between 0.14 for Central Asia and 0.21 for Africa. Genetic distances among groups are very low (Table 3 ). Central Asia accessions had the lowest probability of sharing the same allele frequencies in all sampled loci with the other geographical regions.

\section{Analysis of molecular variance}

Table 4 shows the analysis of molecular variance. It indicates that $5 \%$ of the variance among the 32 AFLP patterns was due to differences among groups and $95 \%$ was due to differences within groups. However, despite the small value for variation among groups, it was statistically significant $(\mathrm{P}<0.05)$. Table 5 displays that this finding can be explained by a large difference between the variation of Central Asia accessions with respect to the other diversity centres, since all of them, and only they, were significant $(\mathrm{P}<0.05)$.

\section{Discussion}

Sesamum indicum $\mathrm{L}$. has a large genetic variability, which should be taken into account when planning conservation strategies or when sesame variability is used in breeding programs. This high level of polymorphism in sesame has been reported before for its morphology [8,9]. Early molecular studies have not confirmed this. Isozyme studies concluded that cultivated sesame has a narrow genetic base $[10,11]$, However, the number of loci sampled in 


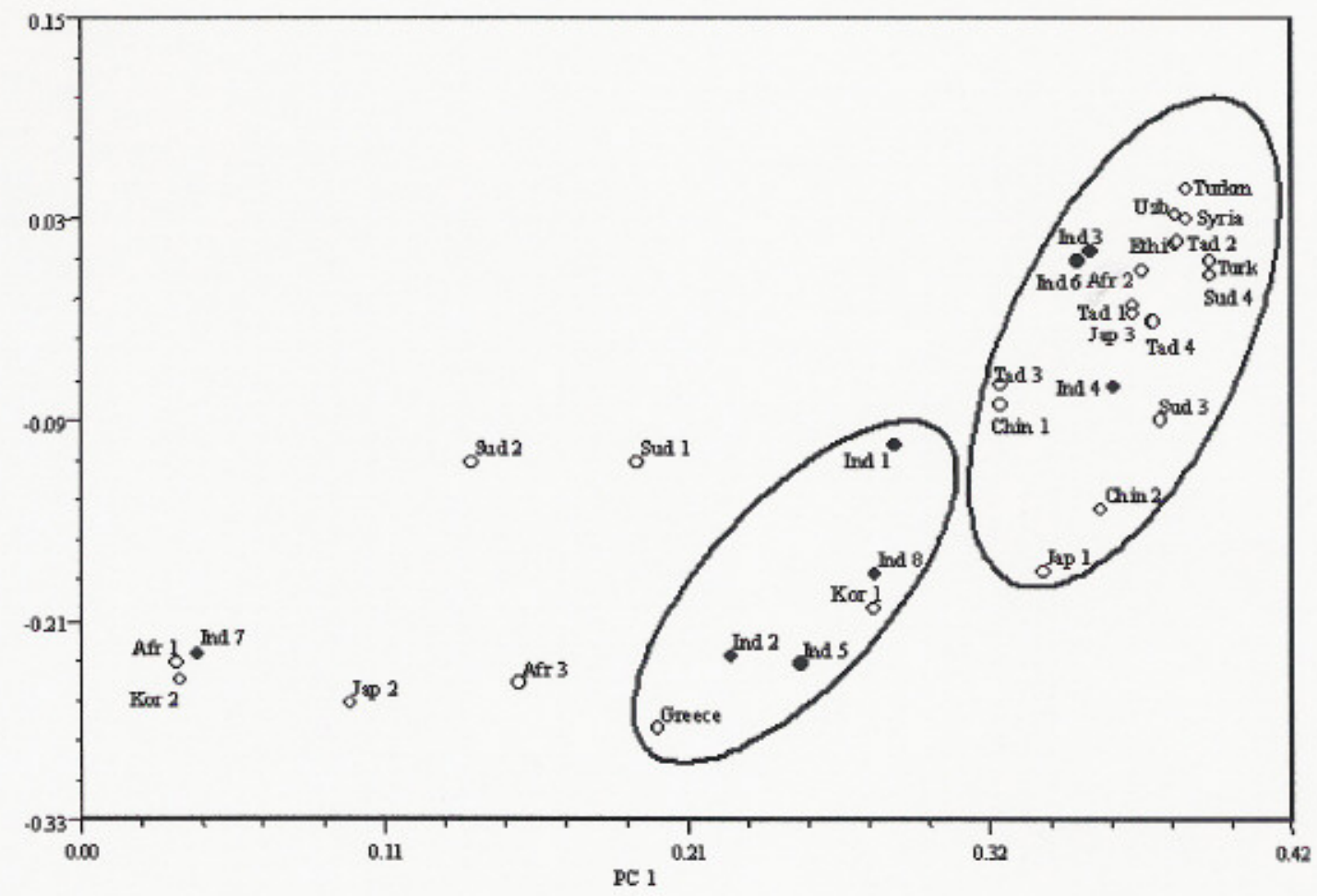

Figure 2

Biplot of principal coordinates analysis for 32 sesame accessions.

these studies were limited and enzymes represent merely coding sequences. Furthermore, all synonymous and many non-synonymous mutations are not detected with isozyme analysis [27].

A RAPD-based study on sesame carried out on 36 Indian accessions and 22 accessions from other countries [12] and a study on a Turkish sesame collection [13] concluded that sesame has a high level of genetic variability. An ISSR-based study on Korean accessions and cultivars from 12 countries found a low level of polymorphism in this particular marker, but the authors cautioned that their method had low resolution and problems with visualization [14]. Generally, methods based on arbitrarily primed PCR tend to reveal a higher degree of genetic variability as compared to other methods [28].

Figures 1 and 2 allow assessment of the genetic relationship among accessions. There is no obvious relationship between geographical origin and grouping based on genetic similarities. Particularly Indian, African and Chinene-Japanese-Korean accessions are distributed throughout clusters in UPGMA analysis and the whole two-dimensional space in PCA. Nei's parameters dis- played in Table 2 and 3, especially the $\mathrm{G}_{\mathrm{ST}}$ value of 0.20 , support the lack of association between geographical origin and population differentiation. Due to AFLP are dominant markers, heterozygocity cannot be directly observed. Therefore three methods are available for the calculation of allele frequencies from dominant marker data: a classical approach based on Hardy-Weinberg assumption, which we used in this work (see Material and Methods for details), a modification of the classical approach by the exclusion of loci with three or less recessive homozygotes [29], and a Bayesian approach [30]. Comparison of allele frequencies calculations from these three methods on AFLP data resulted essentially identical; furthermore potential biases in the estimation of null allele frequency are largely eliminated in highly polymorphic dominant marker data [31]. Confidence in our calculations of Nei's parameters are supported by this finding.

However, the interpretation of results obtained using Nei's parameters should be used cautiously. $\mathrm{H}_{\mathrm{T}}$ is called "average heterozygosis" when it is calculated from data on co-dominant markers and "average genetic diversity" or "heterogeneity" when it is calculated from data on dominant markers. Heterogeneity values might overestimate 
Table 2: Polymorphic loci and genetic diversity of five groups of sesame accessions, according their geographical distribution

\begin{tabular}{|c|c|c|c|}
\hline Population & Polymorphic loci & $\%$ & $\mathrm{Hs}$ \\
\hline India & 313 & 63 & 0.1957 \\
\hline Africa & 352 & 71 & 0.2129 \\
\hline Western Asia & 187 & 38 & 0.1516 \\
\hline Central Asia & 199 & 40 & 0.1445 \\
\hline \multirow[t]{4}{*}{ China-Korea-Japan } & 292 & 59 & 0.1916 \\
\hline & & \multicolumn{2}{|c|}{ Average $\mathrm{Hs}=0.1793 \pm 0.0266$} \\
\hline & & \multicolumn{2}{|c|}{$\mathrm{Ht}=0.2244 \pm 0.0325$} \\
\hline & & \multicolumn{2}{|c|}{ Gst $=0.2013$} \\
\hline
\end{tabular}

the number of real loci, whereas the number of alleles per locus is underestimated. Thus, heterogeneity measures have only relative value and cannot be compared with values obtained from other molecular markers [32]. Additionally, reliable estimation of average heterozygosis with small number of individual are based on large number of loci $(>50)$ and low average heterozygosis $(<0.1)$ [33]. Our results indicate a heterogeneity higher than 0.1 , however, we are more interested in the partition of variation (within and between groups of accessions) than in the value by itself.

AMOVA results shown in Table 4, support the lack of association between geographical origin and population differentiation as well. AMOVA reported differences among geographical regions, which were significant but represented only $5 \%$ of the total variation. Table 5 shows that the differences between Central Asian accessions and the other centres were responsible for this part of the variation. These results, together with the fact that all Central Asian accessions were grouped in one cluster, indicate a narrow variation within this centre as compared to the variance in AFLP patterns of the whole germplasm collection. Furthermore, Central Asian accessions had the lowest $\mathrm{H}_{\mathrm{ST}}$ value (0.14) though it had more polymorphic loci than Western Asia accessions. A possible explanation of this result is that allele frequencies in Central Asia were close to 0 or 1 , which could be a consequence of genetic drift. If a strong genetic flow was the cause of the lack of association between geographical origin and genetic differences in sesame, the genetic flow to Central Asia in recent time was limited.
This lack of association between geographical distribution and classification based on molecular markers in sesame was explained by the exchange of sesame among widely separated locations [14]. However, this study used predominantly commercial cultivars, which resulted from a systematic selection process on material of unreported origin, while the origin of material used in our study is known.

The genetic variability in Indian accessions of sesame is high [6], as shown both for molecular [12] and morphological markers [9]. Sesame seems to have been domesticated in India [5], which could explain the high genetic variability among Indian accessions. In our study, African and Chinese-Korean-Japanese accessions showed as high a genetic variability as Indian accession.

Africa has also been considered the origin of sesame $[2,34]$, based on the fact that most of the wild Sesamum species are endemic there. Reports on the variability of cultivated sesame in Africa are controversial, claiming both low [12] and high [[35] and our results] level of variability. Some authors consider Abysinia (Ethiopia) as the basic diversity centre for sesame $[6,7]$.

Accessions from China, Korea and Japan, which we grouped into one diversity centre, have been studied separately by some authors. A unique allele was found in Chinese-Japanese accessions in a study on isozymes [11]. China is considered a secondary centre of diversity for sesame [7]. Genetic variability among Korean landraces is higher than among Korean cultivars [14].

Table 3: Unbiased measures of identity and genetic distance (Nei, 1978) among groups of sesame accessions. Nei's genetic identity is shown above diagonal, genetic distance below diagonal.

\begin{tabular}{|c|c|c|c|c|c|}
\hline & India & Africa & Western Asia & Central Asia & China-Korea-Japan \\
\hline India & & 0.978 & 0.956 & 0.925 & 0.979 \\
\hline Africa & 0.023 & & 0.950 & 0.933 & 0.989 \\
\hline Western Asia & 0.045 & 0.051 & & 0.928 & 0.951 \\
\hline Central Asia & 0.078 & 0.069 & 0.075 & & 0.926 \\
\hline China-Korea-Japan & 0.021 & 0.011 & 0.051 & 0.077 & \\
\hline
\end{tabular}


Table 4: AMOVA for the partitioning AFLP variation in sesame

\begin{tabular}{lcccc}
\hline Source of variation & Degree of freedom & SS & CV & \% total \\
\hline Among geographical areas & 4 & 328.37 & 3.32 & 5.14 \\
Within geographical areas & 27 & 1654.47 & 61.28 & 9.02 \\
Total & 31 & 1982.84 & & 94.86 \\
\hline
\end{tabular}

Fixation index $\left(F_{s t}\right)=0.0514$

Central Asia and Western Asia accessions had the lowest genetic variability in our study. Reports on the genetic variability of Western Asia accessions are scarce and no information has been published so far about Syrian and Greek sesame. Turkish landraces have been compared to each other with RAPD recently [13], but the relationship to accessions from other geographical region has not been investigated. We analysed only three accessions from Western Asia. Remarkably, the highest similarity found among all 32 accessions corresponded to similarity values between two of these accessions (one from Syria and one from Turkey). The third accession was not closely related to these.

Distribution of genetic diversity in a plant species depends on its evolution and breeding system, ecological and geographical factors and often on human activities [36]. Cross-pollination may play a role, because it can reach up to $60 \%$ in sesame, depending on the presence of suitable insects at flowering time [12]. Ecological and geographical factors obviously have not played an important role in the evolution of sesame since we have not found any association between genetic diversity and accession origin.

Sesame growers have been manipulating the crop due to migration and trade for centuries, causing a steady gene flow among different geographical areas. The oldest remnants of sesame, found in the Harappa valley in the Indian subcontinent [1], date the origin of these activities to at least $5500 \mathrm{BP}$. Therefore, we believe that the most important factor affecting the current genetic structure in sesame were human activities.

\section{Conclusion}

AFLP analysis revealed a high degree of genetic polymorphism in sesame accessions within all diversity centres except Central Asia. Phenetic analysis has not shown any association between geographic origin and AFLP patterns. According to Nei's diversity indexes, $80 \%$ of the total genetic diversity in sesame is represented within diversity centres. This result was corroborated by analysis of molecular variance (AMOVA) which indicated that $95 \%$ of the variation among accessions were due to variation within diversity centres. These results suggest that conservation strategies do not need to cover all diversity centres as long as they sample a sufficient number of accessions. Similarly, choosing parent genotypes for breeding programs from many diversity centres as compared to sampling just one centre (except Central Asia) is not likely to increase the variability among progeny significantly. Regardless of how many diversity centres are sampled, both conservation strategies and breeding programs would benefit from using AFLP or another genome fingerprinting technique to maximise the genetic variability covered by the selected genotype set.

\section{Methods \\ Plant material}

Thirty-two accessions from Centro Nacional de Investigaciones Agropecuarias (CENIAP) Germplasm Bank (Table 6) were grown in the greenhouse. These accessions originate from five different geographical regions representing the proposed diversity centres for sesame $[6,7]$, and the geographical areas included in the germplasm bank; they were chosen randomly within each geographical region, using more accessions for the two proposed origin centres

Table 5: Pairwise comparison of groups of sesame accessions by AMOVA. Genetic distance ( $F_{S T}$ ) between groups of sesame accessions is shown below diagonal. Probability of random distance $\left(F_{\mathrm{ST}}\right)$ larger than the observed distance after 1000 permutations is shown above diagonal.

\begin{tabular}{llllr}
\hline & Indla & Africa & China-Korea-Japan & Western Asia \\
\hline India & & 0.161 & 0.233 & 0.367 \\
Africa & 0.027 & & 0.455 & 0.540 \\
China-Korea-Japan & 0.014 & -0.003 & & 0.005 \\
Western Asia & 0.000 & -0.022 & 0.014 & 0.005 \\
Central Asica & 0.141 & 0.098 & 0.132 & 0.012 \\
\end{tabular}


Table 6: Accessions from CENIAP Germplasm Bank (Venezuela) and their respective origin country and diversity centre

\begin{tabular}{|c|c|c|c|}
\hline Accessions & Country of Origin & Working code & Diversity Centre \\
\hline $93-22223$ & India & India I & India \\
\hline $95-465$ & India & India 2 & India \\
\hline $95-469$ & India & India 3 & India \\
\hline $95-447$ & India & India 4 & India \\
\hline $89-007$ & India & India 5 & India \\
\hline $93-2224$ & India & India 6 & India \\
\hline $95-464$ & India & India 7 & India \\
\hline $92-2918$ & India & India 8 & India \\
\hline $92-3091$ & Korea & Korea I & China-Japan-Korea \\
\hline $92-3093$ & Korea & Korea 2 & China-Japan-Korea \\
\hline $92-2922$ & Turkey & Turkey & Western Asia \\
\hline $92-3125$ & Greece & Greece & Western Asia \\
\hline $93-2022$ & Syria & Syria & Western Asta \\
\hline $93-2113$ & Sudan & Sudan 1 & Africa \\
\hline $92-310$ & Sudan & Sudan 2 & Africa \\
\hline $93-2010$ & Ethiopia & Ethiopia & Africa \\
\hline $95-272$ & Unknown & Africa I & Africa \\
\hline $92-2872$ & Sudan & Sudan 3 & Africa \\
\hline $93-2105$ & Sudan & Sudan 4 & Africa \\
\hline $95-234$ & Unknown & Africa 2 & Africa \\
\hline $95-223$ & Unknown & Africa 3 & Africa \\
\hline $92-2856$ & Japan & Japan 1 & China-Japan-Korea \\
\hline $92-3030$ & Japan & Japan 2 & China-Japan-Korea \\
\hline $92-3031$ & Japan & Japan 3 & China-Japan-Korea \\
\hline $92-3108$ & China & China I & China-Japan-Korea \\
\hline $95-383$ & China & China 2 & China-Japan-Korea \\
\hline $92-2930$ & Tadjikistan & Tadjikistan I & Central Asia \\
\hline $92-2947$ & Uzbekistan & Uzbekistan & Central Asia \\
\hline $92-2952$ & Turkmenistan & Turkmenistan I & Central Asia \\
\hline $92-2955$ & Turkmenistan & Turkmenistan 2 & Central Asia \\
\hline $92-2950$ & Tadjikistan & Tadjikistan 2 & Central Asia \\
\hline $92-2917$ & Tadjikistan & Tadjikistan 3 & Central Asia \\
\hline
\end{tabular}

(India and Africa). The accessions were grouped into one of the following diversity centres: India, Africa, ChinaKorea-Japan, Central Asia and Western Asia.

\section{DNA extraction}

Three grams of apical young leaves from 6 plants per accession were collected and used for DNA extraction. Leaves were ground in liquid nitrogen and tissue powder was dispersed in CTAB buffer $(2.3 \mathrm{~g}$ sorbitol, $1 \mathrm{~g} \mathrm{~N}$-laurylsarcosine, $0.8 \mathrm{~g}$ CTAB, $4.7 \mathrm{~g}$ sodium chloride, and $1 \mathrm{~g}$ polyvinylpolypyrolidone in total volume of $100 \mathrm{ml}$ of $20 \mathrm{mM}$ EDTA, $10 \mathrm{mM}$ Tris, pH set to 8.0 ) containing $0.4 \mathrm{mg}$ proteinase $\mathrm{K}$ and $20 \mu \mathrm{L}$ mercaptoethanol. The homogenates were incubated for $10 \mathrm{~min}$ at $42^{\circ} \mathrm{C}$ and $10 \mathrm{~min}$ at $65^{\circ} \mathrm{C}$, cooled to room temperature and extracted with $8 \mathrm{ml}$ of chloroform-isoamylalcohol (24:1). Phases were separated by centrifugation for $10 \mathrm{~min}$ at $12000 \mathrm{RCF}$ (relative centrifugal force or $\mathrm{g}$ value). Polyethyleneglycol (PEG6000, SERVA Electrophoresis, Germany) stock solution (30\%) was added to the aqueous phase to a final concentration of $6 \%$, mixed, and after $30 \mathrm{~min}$ of incubation at room temperature the precipitated DNA was sedimented by centrifugation for $20 \mathrm{~min}$ at $12,000 \mathrm{RCF}$. Pellets were washed twice with $70 \%$ ethanol and dissolved in $200 \mu \mathrm{L}$ TE buffer ( $10 \mathrm{mM}$ Tris/HCl pH 8.0, $0.1 \mathrm{mM}$ EDTA). 500 $\mu \mathrm{L}$ of $5 \mathrm{M}$ ammonium acetate solution were added and samples were kept at $0^{\circ} \mathrm{C}$ for $30 \mathrm{~min}$, centrifuged for 30 min at $4^{\circ} \mathrm{C}$ and $18000 \mathrm{RCF} .500 \mu \mathrm{L}$ of isopropanol were added to the supernatant and DNA was precipitated for 10 min at room temperature. Samples were centrifuged at $18000 \mathrm{RCF}$ at room temperature for $10 \mathrm{~min}$; pellets were washed twice with $70 \%$ ethanol, dried and dissolved in $200 \mu \mathrm{L}$ of TE buffer. DNA concentration was determined by electrophoresis in a $0.8 \%$ agarose gel with lambda DNA standard.

\section{AFLP analysis}

AFLP analysis was performed as originally proposed [37] with minor modifications [38]. $250 \mathrm{ng}$ of DNA were used for each reaction. DNA was digested with $10 \mathrm{U}$ EcoRI and $3 \mathrm{U}$ of Tru1I (both entzymes from MBI Fermentas, Germany) in buffer recommended by the manufacturer in a total volume of $15 \mu \mathrm{l}$ at $37^{\circ} \mathrm{C}$ for $90 \mathrm{~min}$, followed by 90 min at $65^{\circ} \mathrm{C} .10 \mu \mathrm{l}$ of a solution with a final concentration 
Table 7: Primer sequences used in preamplification and amplification

\begin{tabular}{ll}
\hline Primer & Sequence \\
\hline Primer & Sequence \\
(Cy5)AFL_E_ACA & (Cy5)GACTGCGTACCAATTCACA \\
AFLP_M_C & GATGAGTCCTGAGTAAC \\
AFLP_M_CAA & GATGAGTCCTGAGTAACAA \\
AFLP_M_CAT & GATGAGTCCTGAGTAACAT \\
AFLP_M_CAG & GATGAGTCCTGAGTAACAG \\
AFLP_M_CAC & GATGAGTCCTGAGTAACAC \\
AFLP_M_CCA & GATGAGTCCTGAGTAACCA \\
AFLP_M_CCC & GATGAGTCCTGAGTAACCC \\
AFLP_M_CTCA & GATGAGTCCTGAGTAACTCA \\
AFLP_M_CGAA & GATGAGTCCTGAGTAACGAA \\
\end{tabular}

of 5 pmol of EcoRI adapter, $50 \mathrm{pmol}$ of Tru1I adapter, 1× T4 DNA ligase buffer and 1UT4 DNA ligase (MBI Fermentas, Germany) were added to the digested DNA. The solution was incubated at $20^{\circ} \mathrm{C}$ for $2 \mathrm{~h}, \mathrm{~T} 4$ ligase was inactivated by heating to $65^{\circ} \mathrm{C}$ for $10 \mathrm{~min}$ and the mixture was diluted 10-fold with TE buffer. Following ligation, a first amplification was carried out with primers containing one selective nucleotide (cytocine and adenine for Msel and EcoRI primers, respectively) (Table 7), dNTPs (0.125 mM, Takara Bio Inc., Japan), $1 \times$ PCR buffer (MBI Fermentas, Germany), $1.5 \mathrm{mM} \mathrm{MgCl}_{2}$ and $1 \mathrm{U}$ Taq polymerase (MBI Fermentas, Germany) were added in a total volume of $10 \mu \mathrm{l}$. PCR was performed for 20 cycles, which consisted of $30 \mathrm{~s}$ at $94^{\circ} \mathrm{C}, 1 \mathrm{~min}$ at $56^{\circ} \mathrm{C}$ and $1 \mathrm{~min}$ at $72^{\circ} \mathrm{C}$ in a Tpersonal thermocycler (Biometra, Göttingen, Germany). The PCR products were diluted 10 -fold with TE buffer. The second amplification was carried out with eight primer combinations using labelled EcorRIprimer (Cy5)E_ACA combined with one of the eight Msel primers listed in Table 7. The PCR mixture consisted of 2 $\mu \mathrm{L}$ of diluted preamplified DNA, $4.2 \mathrm{ng}$ of (Cy5)E_ACA primer, $11.4 \mathrm{ng}$ of Msel primer $0.25 \mathrm{mM}$, dNTPs (Takara Bio Inc., Japan), $1 \times$ R buffer (MBI Fermentas, Germany), $1.5 \mathrm{mM} \mathrm{MgCl}$ and $1 \mathrm{U} \mathrm{Taq}$ polymerase (MBI Fermentas, Germany) in a total volume of $10 \mu \mathrm{L}$. The thermocycler program consisted of two segments. The first segment comprised 12 cycles with the annealing temperature decreased from $65^{\circ} \mathrm{C}$ by $0.7^{\circ} \mathrm{C}$ in each cycle: $30 \mathrm{~s}$ at $94^{\circ} \mathrm{C}$, $30 \mathrm{~s}$ at $65^{\circ} \mathrm{C}$ to $57.3^{\circ} \mathrm{C}$ and $1 \mathrm{~min}$ at $72^{\circ} \mathrm{C}$. The second segment consisted of 23 cycles of $30 \mathrm{~s}$ at $94^{\circ} \mathrm{C}, 1 \mathrm{~min}$ at $56^{\circ} \mathrm{C}$ and $1 \mathrm{~min}$ at $72^{\circ} \mathrm{C}$. The PCR products were mixed with $10 \mu \mathrm{L}$ of loading buffer ( $98 \%$ formamide, $10 \mathrm{mM}$ EDTA and $0.025 \%$ bromophenolblue), denatured for 4 minutes at $90^{\circ} \mathrm{C}$ and $5 \mu \mathrm{L}$ of this mixture were loaded onto a $7 \%$ polyacrylamide gel ReproGel ${ }^{m}$ LongRead (Amersham Pharmacia Biotech, Uppsala, Sweden) in an ALFexpress II DNA analyser (Amersham Pharmacia Biotech, Uppsala, Sweden). Three microliters of Genemark
500 Fluorescent DNA ladder labeled with Cy5 (Northernbiothech, Weston, USA) were loaded on each gel and the electrophoresis was performed for $700 \mathrm{~min}$ at $1500 \mathrm{~V}, 25$ $\mathrm{W}, 60 \mathrm{~mA}$ and $55^{\circ} \mathrm{C}$. The chromatogram recorded by software ALFwin ${ }^{m}$ Sequence Analyser 2.00 (AmershamPharmacia Biotech, Uppsala, Sweden) was transformed to a pseudogel image in TIFF-format, visualized in Adobe R $^{\mathrm{R}}$ ImageReady ${ }^{\mathrm{m}}$ version 3.0 (Adobe Systems Inc., USA) and analyzed using GelComparll (Applied Maths, Belgium).

\section{Statistical analysis}

Bands were automatically recognised by GelCompar II using threshold values of $5 \%$ of profiling (relative to the maximum value within each lane). Band matching was performed and the results were exported as a binary matrix. It was used to study the phenetic relationship among AFLP patterns by means of cluster analysis (GelCompar II) and an ordination analysis, specifically principal coordinates, using the software NTSySpc 2.11T [39]. Jaccard's similarity coefficient and the unweighted pair group method with arithmetic mean (UPGMA) were used to perform the clustering analysis. This was tested with three statistical significance tests, also using GelCompar II: the Bootstrap analysis [40] for the assessment of the robustness of dendrogram topology, the standard deviation of the cluster nodes, and cophenetic correlation as an estimation of the faithfulness of cluster analysis [41]. Firstly, bootstraping analysis was carried out, and we tried to find robust groups at the same similarity level and finally we calculated the standard deviation for these groups. Dendrogram-derived similarities were compared with experimental similarities to get cophenetic correlation.

To study the genetic structure of Sesamum indicum L. species, the accessions were grouped in five sets according to the geographical distribution. Gene diversity indices such as total diversity $\left(\mathrm{H}_{\mathrm{T}}\right)$, average diversity within group $\left(\mathrm{H}_{\mathrm{ST}}\right)$, diversity among groups $\left(\mathrm{D}_{\mathrm{ST}}\right)$ and coefficient of population differentiation $\left(\mathrm{G}_{\mathrm{ST}}\right)[42]$ were calculated for each band and then averaged for the total set. Heterozygocity cannot be directly observed in AFLP data because AFLP markers are dominant. To calculate allele frequencies, the absence of a band was considered as homozygous state of a recessive allele $\left(q^{2}\right)$ and presence of a band as either dominant homozygote $\left(\mathrm{p}^{2}\right)$ or a heterozygous state (2 pq). Frequencies $\mathrm{p}$ and $\mathrm{q}$ are calculated accordingly. Also unbiased measures of genetic identity and genetic distance between groups were calculated [33]. All Nei's parameters, which use gene frequencies, were calculated using Popgene v. 1.32 software. To get another approach on the genetic structure with no assumed gene frequencies, analysis of molecular variance (AMOVA) [43] was carried out using Arlequin v. 2.000 software, to estimate variance components for the AFLP patterns and to parti- 
tion the total variance into 'within groups' and 'among groups'. Significance of variance components was tested after 1000 permutations. Pairwise group $\mathrm{F}_{\mathrm{ST}}$ (genetic distances) values matrix was obtained to explain the significance of the variance components, also using 1000 permutations.

\section{Authors' contributions}

HL participated in the design of the study, performed DNA extraction, AFLP and data analysis and participated in interpretation of results and manuscript preparation. PK participated in the design of the study, designed DNA extraction and participated in the discussion for preparing the manuscript and did the final revision.

\section{Acknowledgements}

This work was supported by the Programme Alban, European Union Programme of High Level Scholarships for Latin America, Identification Number E03DI330IVE, International PhD program for Agricultural Sciences in Göttingen University (IPAG) and Universidad Centroccidental Lisandro Alvarado. The authors thank Dr. Uli Hettwer for help with data processing.

\section{References}

I. Bedigian D, Harlan J: Evidence for cultivation on sesame in the ancient world. Economic Botony 1986, 40:137-154.

2. Ashri A: Sesame breeding. Plont Breeding Reviews 1998, 16:179-228.

3. FAO: FAOstot Datobases 2005 [http://faostat. facoorg/]

4. Brar G, Ahuja R: Sesame: its culture, genetics, breeding and biochemistry. In Annu Rev Plant Sci Edited by: Malik CP. New Dehli, Kalyani publishers; 1979:285-313.

5. Bedigian D: Evolution of sesame revisited: domestication, diversity and prospects. Genetic Resources and Crop Evolution 2003. 50:779-787.

6. Zeven A, Zhukovsky P. Dictionary of cultivated plants and their centres of diversity Wageningen, PUDOC; 1975.

7. Hawkes ): The diversity of crop plants Cambridge, Harvard Unirversity Press; 1983.

8. Bedigian D, Smyth C, Harlan J: Patterns of morphological variation in sesame. Econamic Botany 1986, 40:353-365.

9. Bisht L, Mahajan R, Loknathan T, Agrawal R: Diversity in Indian sesame collection and stratification of germplasm accessions in different diversity groups. Genetics Resources and Crop Evolution 1998, 45:325-335.

10. Isshiki S, Umezake T: Genetic variations of isozymes in cultivated sesame. Euphytica 1997, 93:375-377.

11. Diaz A, Layrisse A, Pugh T: Análisis de la diversidad genética en el ajonjoli mediante isoenzimas. Agron Trop (Maracay) 1999, 49(2):169-186.

12. Bhat V, Babrekar P, Lakhanpaul S: Study of genetic diversity in Indian and exotic sesame (Sesamum indicum L.) germplasm using random amplified polymorphic DNA (RAPD) markers. Euphytico 1999, 1 10:21-33.

13. Ercan $A$. Taskin M. Turgut $K$. Analyisis of genetic diversity in Turkish sesame (Sesamum indicum L.) populations using RAPD markers. Genetic Resources and Crop Evalution 2004, 5 I:599-607.

14. Kim D, Zur G, Danin-Poleg Y, Lee S, Shim K, Kang C, Kashi Y: Genetic relationships of sesame germplasm collection as revealed by inter-simple sequence repeats. Plant Breeding 2002, 121:259-262.

15. Uzun B, Lee D, Donini P, Cagrirgan M: Identification of a molec ular marker linked to the closed capsule mutant trait in sesame using AFLP. Plant Breeding 2003, 122:95-97.

16. Savelkoul P, Aarts H, DeHaas J. Dijkshoorn L, Duim B, Otsen M, Rademaker J. Schouls L, Lenstra J: Amplified-fragment length polymorphism analysis: the state of an art. Journal of Clinicol Microbiology 1999, 37:3083-3091.

17. Zeid M, Shon C, Link W: Genetic diversity in recent elite faba bean lines using AFLP markers. Theor Appl Genet 2003, 107:1304-1314.

18. Fanizza G, Chaabane R, Lamaj F, Ricciardi L, Resta P: AFLP analysis of genetic relationships among aromatic grapevine (Vitis vinifera). Thear Appl Genet 2003, 107:1043-1047

19. Zong X, Kaga A, Tomooka N, Wang X, Han O, Vaughan D: The genetic diversity of the Vigna angularis complex in Asia. Genome 2003, 46:647-658.

20. Ferriol M, Pico B, Nuez F: Genetic diversity of a germplasm collection of Cucurbita pepo using SRAP and AFLP markers. Theor Appl Genet 2003, 107:271-282

21. Bahulikar RA, Stanculescu D, Preston CA, Baldwin ITKatzir N: ISSR and AFLP analysis of the temporal and spatial population structure of the post-fire annual, Nicotiana attenuato, in SW Utah. BMC Ecology 2004, 4:12.

22. Ude G, Pillay M, Ogundiwin E, Tenkouano A: Genetic diversity in an African plantain core collection using AFLP and RAPD markers. Theor Appl Genet 2003, 107:248-255.

23. Uptmoor R, Wenzel W, Friedt W, Donaldson G, Ayisi K, Ordon F Comparative analysis on the genetic relatedness of Sorghum bicolor accessions from Southern Africa by RAPDs, AFLPs and SSRs. Theor Appl Genet 2003, 106: 1316-1325.

24. Segovia-Lerma A, Cantrell R, Conway J, Ray I: AFLP-based assessment of genetic diversity among nine alfalfa germplasm using bulk DNA templates. Genome 2003, 46:51-58.

25. Soleimani V, Baum B, Johnson D: AFLP and pedigree-based genetic diversity estimates in modern cultivars of durum wheat [Triticum turgidum L. subsp. Durum (Desf.) Husn]. Theor Appl Genet 2002, 104:350-357.

26. Steiger L, Nagai C, Moore H, Morden W, Ossood V, Ming R: AFLP analysis of genetic diversity within and among Coffea arabica cultivars. Theor Appl Genet 2002, 105:209-215.

27. Ovesná J. Poláková K, Leisová L: DNA analyses and their applications in plant breeding. Czech J Genet Plant Breed 2002, 38:29-40.

28. Karp A, Kresovich S, Bhat K, Ayad W, Hodgkin T: Molecular tools in plant genetic resources conserwation: $a$ guide to the technologie Rome. IPGRI Technical Bulletin No. 2. International Plant Genetic Resources Institute; 1997

29. Lynch M, Milligan B: Analysis of population genetic structure with RAPD markers. Molecular Ecology 1994, 3:9|-99.

30. Zhyvotovsky L: Estimating population structure in diploids with multilocus dominant DNA markers. Molecular Ecology 1999, 8:907-913.

31. Krauss S: Accurate gene diversity estimates from amplified fragment length polymorphism (AFLP) markers. Molecular Ecology 2000, 9:1241-1245.

32. Caicedo A, Gaitán E, Duque M, ToroChica O, Debouck D. Tohme J: AFLP fingerprinting of Phaseolus lunatus $L$, and related wild species from South America. Crop Science 1999, 39:1497-1507.

33. Nei M: Estimation of average heterozygosity and genetic distance from a small number of individuals. Genetics 1978 89:583-590

34. Weiss E Sesame Oilseed crops 2nd edition. London. Blackwell Science; 2000

35. Bedigian D, Harlan f: Nuba agriculture and ethnobotany, with particular reference to sesame and sorghum. Economic Botony 1983, 37:384-395.

36. Ramanatha $R$, Hodgkin $T$ : Genetic diversity and conservation and utilization of plant genetic resources. Plan Cell, Tissue and Organ Culture 2002, 68:1-19.

37. Voss P, Hogers R, Bleeter M, Reijans M, van de Lee T, Hornes M, Frijters A, Pot ]. Peleman J, Kuiper M, Zabeau M: AFLP: a new technique for DNA fingerprinting. Nudeic Acids Res 1995, 23:4407-44|4.

38. Reineke A, Karlovsky P: Simplified AFLP protocol: replacement of primer labeling by the incoporation of alpha-labeled nucleotides during PCR. BioTechniques 2000, 28:622-623.

39. Rohlf F: NTSYS-pcnumerical taxonamy and multivariate anolysis system, version 2. I IT New York, Exeter Software; 2004.

40. Efron B: Bootstrap methodst another look at the jackknife. Ann Stathst 1979, $7 \div 1-26$.

41. RohlfF, Solcal R: Comparing numerical taxonomic studies. Systematic Zool 1981, 30:459-490. 
42. Nei M: Molecular evolutionary genetics New York, Columbia University Press; 1987.

43. Excoffier L, Smouse P, Quaturo J: Analysis of molecular variance inferred from metric distance among DNA haplotypes; application to human mitochondrial DNA restriction data. Genetics 1992, 131:479-491.

Publish with BioMed Central and every scientist can read your work free of charge

-Biomed Central will be the most significant development for disseminating the results of biomedical research in our lifetime." Sir Paul Nurse, Cancer Research UK

Your research papers will be:

- available free of charge to the entire biomedical community

- peer reviewed and published immediately upon acceptance

- cited in PubMed and archived on PubMed Central

- yours - you keep the copyright 


\title{
Chapter 3. AFLP fingerprinting of sesame (Sesamum indicum L.) cultivars: identification, genetic relationship and comparison of AFLP informativeness parameters
}

Final and accepted version published in Genetic Resources and Crop Evolution, 2007. DOI $10.1007 / \mathrm{s} 10722-006-9128-\mathrm{y}$

Hernán Laurentin and Petr Karlovsky

\begin{abstract}
Amplified fragments length polymorphism (AFLP) was used to distinguish 20 cultivars of sesame (Sesamum indicum L.) and to elucidate the genetic relationship among these genotypes. The data were also used to estimate the usefulness of parameters currently used to assess the informativeness of molecular markers. A total of 339 markers were obtained using 8 primer combinations. Of the bands, $91 \%$ were polymorphic. Five primer combinations were able to distinguish all 20 cultivars used. None of the remaining three primer combinations could distinguish all accessions if used alone, but using all three combinations reduced the probability of a random match to $5 \times 10^{-5}$. Polymorphic information content (PIC), resolving power (Rp) and marker index (MI) of each primer combination failed to correlate significantly with the number of genotypes resolved. Jaccard's similarity coefficients ranged from 0.31 to 0.78 . Fifteen cultivars were grouped by four UPGMA-clusters supported by bootstrapping values larger than 0.70 . The grouping pattern was similar to the grouping generated by principal coordinate analysis. The results demonstrated that AFLP-based fingerprints can be used to identify unequivocally sesame genotypes, which is needed for cultivar identification and for the assessment of the genetic variability of breeding stocks. We recommend to use the number of cultivars identified by a primer combination instead of PIC, $\mathrm{Rp}$ and MI; and to calculate the maximal, instead of average probability of identical match by chance in the assessment of the informativeness of a marker for cultivar identification.
\end{abstract}

Key words: AFLP - DNA fingerprinting - genotype identification - genotyping - sesame 


\section{Introduction}

Sesame (Sesamum indicum L.) is an important crop in tropical and subtropical areas (Ashri 1998). Over six millions hectares were harvested worldwide in 2004, producing over three million tons of seeds (FAO 2005). India, Sudan, Myanmar and China are the most important sesame producers, with $68 \%$ of world production. The production in America is 170,000 tons per year; Mexico, Guatemala and Venezuela contribute $60 \%$ to the production on the continent with a little contribution to world production (only $6 \%$ ), but very important exportation trade $(22 \%)$. Venezuela is the $16^{\text {th }}$ biggest wold producer $(30,000$ tons per year), and the $7^{\text {th }}$ biggest exporter of sesame seed $(24,000$ tons per year). Its sesame is considered to be of high quality.

Sesame production in Venezuela is important in the Western Llanos, specifically around Turen town, in Portuguesa state. In the early years of Venezuelan sesame production, since 1940 until 1990, sesame was used as oil source for the national market, and some as oil for export. Presently it is used for export as processed grain. Because of its importance for export, sesame breeding attained a high priority in Venezuela leading to the development of over 30 cultivars during the last 60 years. Reliable identification of these cultivars is a requirement. DNA fingerprinting has been used for checking the identity and purity of cultivars in different crops and for assessing the genetic variability of breeding stocks (Fernandez et al. 2002; Archak et al. 2003; Rajora and Rahman 2003; Moretzsohn et al. 2004; Dangi et al. 2004; Buhariwalla at al. 2005). It has been particularly useful for the selection of germplasm in crossing schemes. Amplified fragment length polymorphism (AFLP) is a reliable genotyping method with a high degree of reproducibility and discriminatory power (Savelkoul et al. 1999). AFLP has proved to be a robust marker technique to distinguish plant genotypes (Milbourne et al. 1997; Zhang et al. 1999; Muminovic et al. 2004). A recently developed database format for AFLP data allows for storage and comparison of profiles of cultivars and accessions (Hong and Chuah 2003). The ability of markers to discriminate between genotypes 
is usually estimated by means of probability of identical match by chance (Pi) (Ramakrishna et al. 1994), marker index (MI) (Powell et al. 1996), resolving power (Rp) (Prevost and Wilkinson 1999), polymorphic information content (PIC) (Roldan-Ruiz et al. 2000) and recording both the number of fingerprints or haplotypes observed, and the number of genotypes with unique fingerprints (Rajora and Rahman 2003).

The aims of the present study were to evaluate the ability of AFLP markers for distinguishing 20 sesame cultivars, to determine the genetic relationship among these genotypes and to estimate the usefulness of parameters currently used to assess the informativeness of molecular markers for genotyping.

\section{Material and methods}

Plant materials

Twenty cultivars, coming from different sesame breeding programs and representative of the commercial cultivars used in Venezuela, were used in the present study. They are listed in Table 1 with information regarding their origin.

DNA extraction

Three grams of apical young leaves from 6 plants per accession were collected and used for DNA extraction. Leaves were ground in liquid nitrogen and the tissue powder was dispersed in CTAB buffer (2.3 g sorbitol, $1 \mathrm{~g}$ N-laurylsarcosine, $0.8 \mathrm{~g}$ CTAB, $4.7 \mathrm{~g}$ sodium chloride, and $1 \mathrm{~g}$ polyvinylpyrodidone in a total volume of $100 \mathrm{ml}$ of $20 \mathrm{mM}$ EDTA, $10 \mathrm{mM}$ Tris $(\mathrm{pH}$ set to 8.0 ) containing $0.4 \mathrm{mg}$ proteinase $\mathrm{K}$ and $20 \mu \mathrm{L}$ mercaptoethanol. The homogenates were incubated for 10 minutes at $42^{\circ} \mathrm{C}$ and 10 minutes at $65^{\circ} \mathrm{C}$, cooled to room temperature and extracted with $8 \mathrm{ml}$ of chloroform/isoamylalchohol (24:1). Phases were separated by centrifugation for 10 minutes at 
Table 1. Commercial cultivars used in the present study and their respective origin

\begin{tabular}{|c|c|}
\hline Cultivar & Origin \\
\hline Venezuela 51 & $\begin{array}{l}\text { Originated by individual selection from the offspring of } \\
\text { a Chinese accession (Langham and Rodriguez, 1946). }\end{array}$ \\
\hline Acarigua & $\begin{array}{l}\text { A high performance F2 plant obtained by the cross } \\
\text { between a cultivar from Nicaragua and a cultivar from } \\
\text { China, was crossed with the cultivar Venezuela 51, its } \\
\text { offspring was selected for three seasons, resulting in } \\
\text { "Acarigua" (Mazzani, 1952) }\end{array}$ \\
\hline Inamar & $\begin{array}{l}\text { Individual selection from the offspring from the same } \\
\text { Acarigua's parents (Mazzani, 1953). }\end{array}$ \\
\hline Maporal & $\begin{array}{l}\text { Selected from cultivar Arapatol, from Ethiopia } \\
\text { (Mazzani et al., 1973). }\end{array}$ \\
\hline Caripucha & Unknown \\
\hline Felicidad & Introduced from Mexico. Unknown origin \\
\hline Chino Amarillo & Introduced from Mexico. Unknown origin \\
\hline UCV-1 & $\begin{array}{l}\text { Elite line selected from first cycle of recurrent selection } \\
\text { toward high yield. The original population was } \\
\text { obtained by cross, one to one, among } 50 \text { exotic } \\
\text { accessions (Laurentin et al., 2000). }\end{array}$ \\
\hline $43 \times 32,19 \times 10$ & $\begin{array}{l}\text { Selected lines from second cycle of recurrent selection } \\
\text { toward high yield, under heavy whitefly infestation. } \\
\text { The original population was obtained by cross, one to } \\
\text { one, among } 50 \text { exotic accessions (Laurentin et al., } \\
2000 \text { ) }\end{array}$ \\
\hline $\mathrm{UCV}-3$ & Individual selection from Arawaca (unpublished data). \\
\hline Fonucla & $\begin{array}{l}\text { Selection from cultivar Arawaca (Montilla and Cedeño, } \\
\text { 1991). Arawaca was obtained by selection of the } \\
\text { mixture of } 496 \mathrm{~F} 1 \text { plants obtained from crosses among } \\
32 \text { cultivars without reciprocal. The origin of these } \\
\text { cultivars is unknown. }\end{array}$ \\
\hline UCLA1 & $\begin{array}{l}\text { Individual selection from a USA accession (Montilla } \\
\text { and Teran, 1996). Unknown origin }\end{array}$ \\
\hline $\begin{array}{l}\text { UCLA37-1, UCLA65, UCLA83, UCLA90, UCLA249, } \\
\text { UCLA295 }\end{array}$ & $\begin{array}{l}\text { Elite lines from Universidad Centrooccidental Lisandro } \\
\text { Alvarado Sesame Breeding Program. Unknown origin }\end{array}$ \\
\hline Glauca & Unknown origin. \\
\hline
\end{tabular}

12000 RCF (relative centrifugal force or g value). Polyethyleneglycol (PEG 6000, SERVA

Electrophoresis, Germany) stock solution (30\%) was added to the aqueous phase to a final 
concentration of $6 \%$, mixed, and after 30 minutes of incubation at room temperature the precipitated DNA was sedimented by centrifugation for 20 minutes at 12000 RCF. The pellets were washed twice with $70 \%$ ethanol and dissolved in $200 \mu \mathrm{L}$ TE buffer $(10 \mathrm{mM}$ Tris $\mathrm{HCl} \mathrm{pH} 8.0,0.1 \mathrm{mM}$ EDTA). $500 \mu \mathrm{L}$ of $5 \mathrm{M}$ ammonium acetate solution were added and samples were kept at $0^{\circ} \mathrm{C}$ for 30 minutes, centrifuged for 30 minutes at $4^{\circ} \mathrm{C}$ and $18000 \mathrm{RCF}$. $500 \mu \mathrm{L}$ of isopropanol were added to the supernatant and DNA was precipitated (10 min at room temperature). Samples were centrifuged at $18000 \mathrm{RCF}$ at room temperature for 10 minutes; pellets were washed twice with $70 \%$ ethanol, dried and dissolved in $200 \mu \mathrm{L}$ of TE buffer. DNA concentration was determined by electrophoresis in a $0.8 \%$ agarose gel with lambda DNA standard.

\section{AFLP analysis}

AFLP analysis was performed as originally proposed (Vos et al. 1995) with minor modifications (Reineke and Karlovsky 2000; Laurentin and Karlovsky 2006). In general, AFLP were carried out in the following way: $250 \mathrm{ng}$ of DNA were used for each reaction, which was replicated twice for each cultivar. DNA was digested with $10 \mathrm{U}$ EcoRI and $3 \mathrm{U}$ of Tru1I (both entzymes from MBI Fermentas, Germany). $10 \mu \mathrm{l}$ of a solution with final concentration of 5 pmol of EcoRI adapter, 50 pmol of Tru1I adapter, 1X T4 DNA ligase buffer and 1U T4 DNA ligase (MBI Fermentas, Germany) were added to the digested DNA. The solution was incubated at $20^{\circ} \mathrm{C}$ for 2 hours, and diluted 10 -fold with TE buffer. Following ligation, a first amplification was carried out with primers containing one selective nucleotide (cytocine and adenine for MseI and EcoRI primers, respectively) (Table 2), in a total volume of $10 \mu \mathrm{l}$. PCR was performed for 20 cycles, which consisted of 30 seconds at $94^{\circ} \mathrm{C}, 1$ minute at $56^{\circ} \mathrm{C}$ and 1 minute at $72^{\circ} \mathrm{C}$ in the thermocycler Tpersonal (Biometra, Göttingen, Germany). The PCR products were diluted 10-fold with TE 
Table 2. Primer sequences used in the first and second amplification

\begin{tabular}{ll}
\hline Primer name & Sequence $\mathbf{5}^{\prime}$-- $\mathbf{3}^{\prime}$ \\
\hline AFLP_E_A & GACTGCGTACCAATTCA \\
AFLP_E_ACA & (Cy5)GACTGCGTACCAATTCACA \\
AFLP_M_C & GATGAGTCCTGAGTAAC \\
AFLP_M_CAA & GATGAGTCCTGAGTAACAA \\
AFLP_M_CAT & GATGAGTCCTGAGTAACAT \\
AFLP_M_CAG & GATGAGTCCTGAGTAACAG \\
AFLP_M_CAC & GATGAGTCCTGAGTAACAC \\
AFLP_M_CCA & GATGAGTCCTGAGTAACCA \\
AFLP_M_CCC & GATGAGTCCTGAGTAACCC \\
AFLP_M_CTCA & GATGAGTCCTGAGTAACTCA \\
AFLP_M_CGAA & GATGAGTCCTGAGTAACGAA \\
\hline
\end{tabular}

buffer. The second amplification was carried out with eight primer combinations using labelled EcorRI-primer (Cy5)E_ACA combined with one of the eight MseI primers listed in Table 2. The thermocycler program consisted of two segments. The first segment comprised 12 cycles with the annealing temperature decreased from $65^{\circ} \mathrm{C}$ by $0.7^{\circ} \mathrm{C}$ in each cycle: $30 \mathrm{~s}$ at $94^{\circ} \mathrm{C}, 30 \mathrm{~s}$ at $65^{\circ} \mathrm{C}$ to $57.3^{\circ} \mathrm{C}$ and $1 \mathrm{~min}$ at $72^{\circ} \mathrm{C}$. The second segment consisted of 23 cycles of $30 \mathrm{~s}$ at $94^{\circ} \mathrm{C}, 1 \mathrm{~min}$ at $56^{\circ} \mathrm{C}$ and $1 \mathrm{~min}$ at $72{ }^{\circ} \mathrm{C}$. PCR products were mixed with $10 \mu \mathrm{L}$ of loading buffer (98\% formamide, 10mM EDTA and $0.025 \%$ bromophenolblue), denatured for 4 minutes at $90^{\circ} \mathrm{C}$ and $5 \mu \mathrm{L}$ of each reaction (twice per cultivar) were loaded onto a $7 \%$ polyacrylamide gel (ReproGel ${ }^{\mathrm{TM}}$ LongRead,Amersham Pharmacia Biotech, Uppsala, Sweden) and run in the ALFexpress II DNA analyser (Amersham Pharmacia Biotech, Uppsala, Sweden). Three microliters of Genemark 500 Fluorescent DNA ladder, labeled with Cy5 (Northernbiothech, Weston, USA), were loaded on each gel and the electrophoresis was performed for 700 minutes at $1500 \mathrm{~V}, 25 \mathrm{~W}, 60 \mathrm{~mA}$ and $55^{\circ} \mathrm{C}$. The electropherogram recorded by software ALFwin ${ }^{\mathrm{TM}}$ Sequence Analyser 2.00 (AmershamPharmacia Biotech, Uppsala, 
Sweden) was transformed to a pseudogel image in TIFF-format, visualized in Adobe ${ }^{\mathrm{R}}$ ImageReady $^{\mathrm{TM}}$ version 3.0 (Adobe Systems Inc., USA) and analysed using GelCompar II (Applied Maths, Belgium).

Statistical analysis

Bands were automatically recognised by GelCompar II using threshold values of $5 \%$ of profiling (relative to the maximum value within each lane). Band matching was performed and repeatable fragments between the two AFLP reactions for each cultivar were identified (in all the cases between 94 and $100 \%$ ). Repeatable fragments were exported as a binary matrix, which was used for all the analysis. Discriminatory power of AFLP markers was evaluated by means of three parameters. The Polymorphic Information Content (PIC) for each AFLP was calculated as previously proposed (Roldan-Ruiz et al. 2000): $P I C_{i}=2 f_{i}\left(1-f_{i}\right)$, where $P I C_{i}$ is the polymorphic information content of marker $i, f_{i}$ the frequency of the marker bands which were present and $1-f_{i}$ the frequency of marker bands which were absent. Dominant markers as AFLP have a maximum PIC of 0.5 when half of the accessions have the band and the other half does not have the band (De Riek et al. 2001). PIC was averaged over the bands for each primer. Marker index (MI) was calculated as proposed by Powell et al. (1996) and used by Milbourne et al. (1997): $M I$ is the product between diversity index (equivalent to $P I C)$ and effective multiplex ratio $(E M R)$, where $E M R$ is defined as the product of the fraction of polymorphic loci and the number of polymorphic loci. This parameter was calculated for each primer. Resolving power $(R p)$ of each primer was calculated according Prevost and Wilkinson (1999): $R p=\sum I b$ where $I b$ (band informativeness) takes the values of: $1-[2 x \mid 0.5$ $p\lfloor$, where $p$ is the proportion of the genotypes containing the band. In addition to these parameters, number of different fingerprints per primer and number of elite lines with unique fingerprints per primer were recorded. Pearson correlation coefficients were calculated between the three parameters and both number of different fingerprints per primer and number of cultivars with unique fingerprint per primer. To get the level of confidence in 
identifying the 20 cultivars, the probability of identical match by chance (Pi) was calculated as proposed by Wetton (1987) and Ramakrishna et al. (1994): $P i=X^{n}$, where $X$ is a similarity index between 2 genotypes and $n$ is the average number of bands in the two genotypes compared. Pi expresses the probability that a band present in one genotype is also present in the other. $X$ was calculated as $2 N_{A B} /\left(N_{A}+N_{B}\right)$, where $N_{A B}$ is the number of bands present in both genotypes, $N_{A}$ the total number of bands in genotype $A$, and $N_{B}$ the total number of bands in genotype $B$. This index represents the probability that the bands present in one cultivar are also present in the other. This probability was calculated for each possible comparison between pairs of cultivars and for each primer and the highest probability was recorded. We believe that for genotype identification purposes it is desirable to know the highest probability of identical match by chance rather than the average value for each primer combination, as proposed by Ramakrishna et al. (1994).

Jaccard's similarity coefficient and unweighted pair group method with arithmetic mean (UPGMA) were used to perform the clustering analysis, which was tested with two statistical significance tests. They were the bootstraping analysis for the assessment of the robustness of the dendrogram topology, and the cophenetic correlation as an estimation of the faithfulness of the cluster analysis. Firstly, the bootstraping analysis was carried out using WinBoot software. Dendrogram-derived similarities were compared with experimental similarities to get cophenetic correlation. Principal coordinates analysis (PCA) was also carried out to display the location of the 20 cultivars in three-dimensions. All numerical taxonomic analyses were conducted using NTSYS-PC software, version 2.11T (Exeter Software, New York). 


\section{Results}

Table 3 displays the number of bands (NB), number of polymorphic bands (NPB), number of exclusive bands (NEB), number of haplotypes (NH), number of genotypes with exclusive haplotypes (NGEH), polimorphic information content (PIC), resolving power (Rp) and marker index (MI) obtained per AFLP primer combination. The total number of bands was 339; ninety nine percent of them being polymorphic. Number of bands per primer combination ranged from 22 (E_ACA + M_CGAA) to 70 (E_ACA + M_CAT), and polymorphism ranged from $71 \%\left(\mathrm{E} \_\mathrm{ACA}+\mathrm{M} \_\mathrm{CCA}\right)$ to $100 \%\left(\mathrm{E} \_\mathrm{ACA}+\mathrm{M} \_\mathrm{CGAA}\right.$ and E_ACA + M_CAG). Fifty unique bands were obtained for 13 genotypes, where Maporal, UCLA83 and UCLA37-1 had most with 18, 7 and 6 respectively. Five primer combinations were able to discriminate the 20 cultivars. Combination E_ACA + M_CAG recorded the highest values for PIC, Rp, and MI. With PIC, Rp or MI, no significant correlation was found between either the number of fingerprints or elite lines with exclusive fingerprints. Number of bands per genotype ranged between 106 for 19x10 and 197 for UCV-1, with an average of 160 bands per genotype.

Table 4 displays minimum, maximum and average probability of identical match by chance per primer. Using the 8 primer combinations, the maximum probability of identical match by chance was 1:20000 between cultivars Fonucla and UCLA65. For three primer combinations, some genotypes generated identical AFLP patterns, leading to Pi value of $100 \%$. Even then, the average probability of identical match by chance in patterns generated by these three primers were either low, medium or high as compared with the other primers. This shows that the average probability is not suitable as a measure for the assessment of the capability of primer pairs to distinguish among genotypes.

Jaccard's similarity coefficients ranged from 0.31 between Chino Amarillo and Maporal to 0.78 between Fonucla and UCLA65, with an average of 0.52 (Table 5). The UPGMA-based 
Table 3. Number of bands (NB), number of polymorphic bands (NPB), number of exclusive bands (NEB), number of haplotypes (NH), number of genotypes with exclusive haplotype (NGEH), polymorphic information content (PIC), resolving power (Rp) and marker index (MI) obtained per AFLP primer combination

\begin{tabular}{lcccccccc}
\hline $\begin{array}{l}\text { Primer } \\
\text { E_ACA } \\
\text { combined } \\
\text { with: }\end{array}$ & NB & NPB & NEB & NH & NGEH & PIC & Rp & MI \\
\hline M_CTCA & 27 & 26 & 3 & 20 & 20 & $0.27 \pm 0.16$ & 10.30 & 6.88 \\
M_CAA & 41 & 36 & 3 & 18 & 17 & $0.29 \pm 0.18$ & 18.20 & 9.10 \\
M_CCA & 42 & 30 & 6 & 20 & 20 & $0.22 \pm 0.19$ & 13.10 & 4.62 \\
M_CGAA & 22 & 22 & 6 & 20 & 20 & $0.30 \pm 0.17$ & 10.10 & 6.65 \\
M_CAT & 70 & 68 & 15 & 19 & 18 & $0.29 \pm 0.16$ & 29.30 & 18.89 \\
M_CAG & 50 & 50 & 3 & 20 & 20 & $0.39 \pm 0.13$ & 30.50 & 19.39 \\
M_CCC & 33 & 30 & 4 & 19 & 18 & $0.22 \pm 0.14$ & 19.40 & 6.12 \\
M_CAC & 54 & 48 & 10 & 20 & 20 & $0.26 \pm 0.18$ & 20.60 & 11.09 \\
Average & 42.40 & 38.90 & 6.25 & 19.38 & 18.88 & $0.28 \pm 0.16$ & $18.94 \pm 7.34$ & $10.34 \pm 5.40$ \\
\hline
\end{tabular}

phenogram (Figure 1) and biplot from principal coordinates analysis (Figure 2) showed a similar pattern: cultivars Maporal, Chino Amarillo, 19x10, Felicidad, Inamar, and UCLA37-1 were different, and they appeared separated from the others for the two analyses. The other cultivars were grouped in two clusters by dendrogram. Both analyses failed to group together all the cultivars that are related by pedigree: Acarigua and Inamar coming from Venezuela 51; UCV-1, 19x10, 43x32 coming from the same basic population; Fonucla and UCV-3 selected from the same cultivar. The cophenetic correlation coefficient was 90\%. Bootstrapping values were $>70 \%$ in cluster grouping 15 cultivars at 0.58 similarity value. The principal coordinate analysis (PCO) showed that the first three axes accounted for $95 \%$ of total variation. 
Table 4. Minimum, maximum and average of probability of identical match by chance for each primer combination

Probability of identical match by chance

\begin{tabular}{|c|c|c|c|}
\hline $\begin{array}{l}\text { Primer E_ACA } \\
\text { combined with: }\end{array}$ & Minimum & Average & Maximum between: \\
\hline M_CTCA & $2.39 \times 10^{-17}$ & 0.102 & $\begin{array}{l}0.3568, \text { UCLA249 } \\
\text { and UCLA } 83\end{array}$ \\
\hline M_CAA & $4.11 \times 10^{-16}$ & 0.079 & $\begin{array}{l}\text { 1.000, UCLA } 295, \\
\text { UCLA } 37-1 \text { and } 19 \times 10\end{array}$ \\
\hline M_CCA & $4.36 \times 10^{-8}$ & 0.126 & $\begin{array}{l}0.8521, \text { UCLA } 83 \text { and } \\
\text { UCLA65 }\end{array}$ \\
\hline M_CGAA & 0.000 & 0.039 & $\begin{array}{l}0.7500, \text { Acarigua and } \\
\text { Inamar }\end{array}$ \\
\hline M_CAT & $2.42 \times 10^{-35}$ & 0.031 & $\begin{array}{l}1.000, \text { Inamar and } \\
19 \times 10\end{array}$ \\
\hline M_CAG & 0.000 & 0.014 & $\begin{array}{l}0.5398, \text { Caripucha and } \\
\text { Glauca }\end{array}$ \\
\hline M_CCC & $6.11 \times 10^{-11}$ & 0.134 & $\begin{array}{l}\text { 1.000, UCLA } 295 \text { and } \\
\text { UCLA37-1 }\end{array}$ \\
\hline M_CAC & $8.77 \times 10^{-19}$ & 0.040 & $\begin{array}{l}0.7023, \text { UCLA } 249 \\
\text { and UCLA295 }\end{array}$ \\
\hline TOTAL & $3.11 \times 10^{-78}$ & $2.70 \times 10^{-7}$ & $\begin{array}{l}5.19 \times 10^{-5}, \text { Fonucla } \\
\text { and UCLA65 }\end{array}$ \\
\hline
\end{tabular}


Table 5. Minimum, maximum and mean of Jaccard's similarity coefficients of 20 sesame cultivars based on 339 AFLP markers

\begin{tabular}{|c|c|c|c|}
\hline \multirow[t]{2}{*}{ Cultivar } & \multicolumn{3}{|c|}{ Simmilarity coefficient } \\
\hline & Minimum & Maximum & Mean \pm SD \\
\hline Chino Amarillo & 0.309 & 0.476 & $0.385 \pm 0.042$ \\
\hline Felicidad & 0.376 & 0.587 & $0.463 \pm 0.059$ \\
\hline Venezuela 51 & 0.389 & 0.747 & $0.551 \pm 0.109$ \\
\hline Acarigua & 0.394 & 0.744 & $0.560 \pm 0.098$ \\
\hline UCV-1 & 0.359 & 0.747 & $0.555 \pm 0.107$ \\
\hline Maporal & 0.309 & 0.490 & $0.405 \pm 0.040$ \\
\hline Caripucha & 0.376 & 0.705 & $0.571 \pm 0.097$ \\
\hline Inamar & 0.370 & 0.646 & $0.491 \pm 0.063$ \\
\hline Glauca & 0.434 & 0.659 & $0.555 \pm 0.056$ \\
\hline $43 \times 32$ & 0.338 & 0.681 & $0.560 \pm 0.101$ \\
\hline $19 \times 10$ & 0.337 & 0.500 & $0.434 \pm 0.042$ \\
\hline UCLA249 & 0.379 & 0.685 & $0.563 \pm 0.093$ \\
\hline UCLA83 & 0.361 & 0.684 & $0.540 \pm 0.100$ \\
\hline UCLA1 & 0.397 & 0.674 & $0.542 \pm 0.076$ \\
\hline UCLA90 & 0.356 & 0.674 & $0.560 \pm 0.085$ \\
\hline UCLA295 & 0.384 & 0.672 & $0.525 \pm 0.083$ \\
\hline UCLA37-1 & 0.398 & 0.646 & $0.500 \pm 0.073$ \\
\hline Fonucla & 0.377 & 0.781 & $0.558 \pm 0.101$ \\
\hline UCLA65 & 0.352 & 0.781 & $0.582 \pm 0.100$ \\
\hline $\mathrm{UCV}-3$ & 0.341 & 0.613 & $0.509 \pm 0.068$ \\
\hline
\end{tabular}




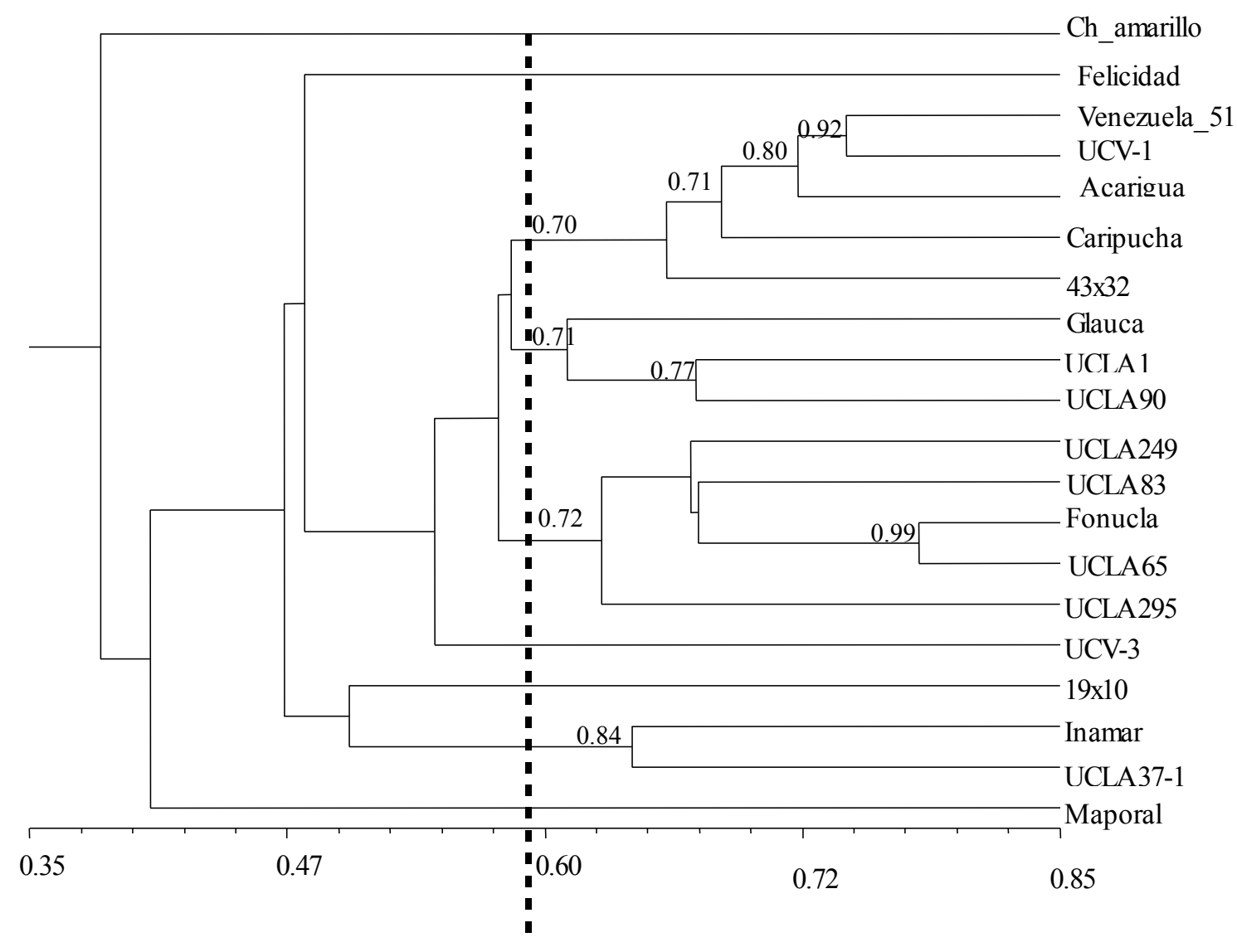

Jaccard's similarity coefficient

Figure 1. Phenogram of 20 sesame cultivars based on Jaccard's similarity coefficients using 339 AFLP markers. Bootstrapping values are indicated for clusters with values equal or higher than 0.70 


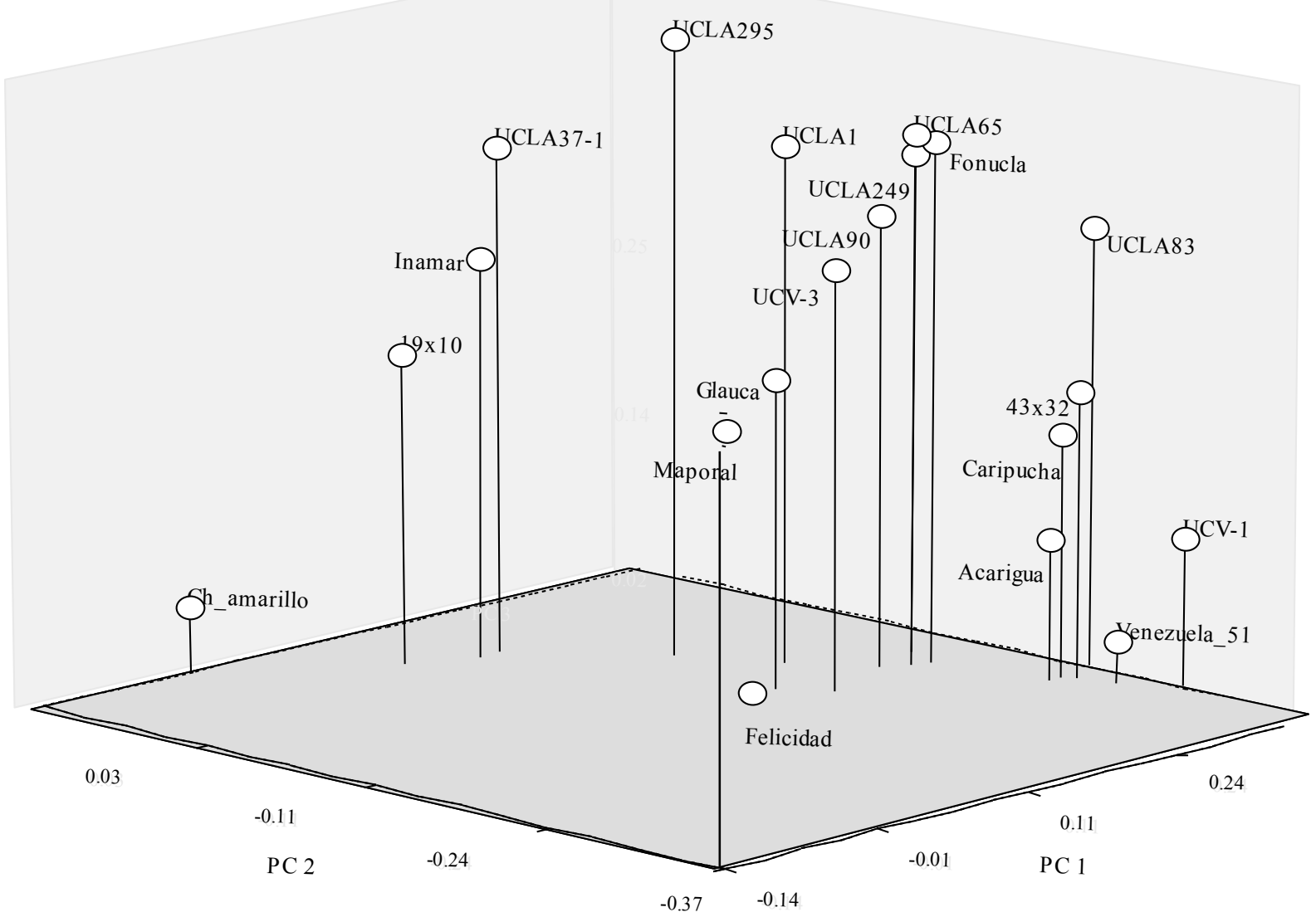

Figure 2. Three-dimensional graph from the principal coordinate analysis of 339 AFLP markers of 20 sesame cultivars

\section{Discussion}

AFLPs from 8 primer combinations have been a successful tool for identifying commercial cultivars with a low probability of getting identical match by chance. E_ACA+M_CAG is considered a valuable primer combination, because it is the most informative for all the indexes calculated: polymorphic information content, marker index, resolving power, number 
of haplotypes, number of cultivars resolved, average probability of identical match by chance, and it presented the second lowest value for the maximum probability of identical match by chance when all the possible comparisons were carried out. Polymorphic information content (PIC) and marker index (MI) have been used to measure informativeness of AFLP primer combinations in other self-pollinated crops such as soybean (Glycine max L. Merr.) (PIC=0.32 and $\mathrm{MI}=6.14$, Powell et al. 1996), wheat (Triticum aestivum L.) ( $\mathrm{PIC}=0.32$ and $\mathrm{MI}=3.41$, Bohn et al. 1999; PIC=0.31, Stodart et al. 2005), cornsalad (Valerianella locusta ) ( $\mathrm{PIC}=0.25$ and $\mathrm{MI}=4.47$, Muminovic et al. 2004) and triticale (xTriticosecale Wittm.) $(\mathrm{PIC}=0.25$ and $\mathrm{MI}=8.60$, Tams et al. 2005). Why these parameters related with the informativeness of molecular markers for identifying genotypes is not totally clear. Most of the studies have used these indexes for comparing AFLPs with other molecular markers. Discrimination of as many cultivars as possible would be the most important feature of one primer combination, when the purpose of the evaluation is to identify unequivocally a specific genotype. Prevost and Wilkinson (1999) and Fernandez et al. (2002) found a strong and linear relationship between the ability of a primer to distinguish genotypes and resolving power (Rp), but not with marker index (MI). The data reported by Rajora and Rahman (2003) indicate significant correlation $(P<0.05)$ between PIC and number of genotypes observed, but not with number of cultivars with unique genotype. Lack of correlation between PIC, MI, Rp and both number of haplotypes and number of cultivars resolved in our study, or lack of consistency in the correlation in other studies, make it clear that these indexes do not ever evaluate the informativeness of a primer combination. It would be more suitable to record how many genotypes are discriminated by primer, than to calculate parameters such as PIC, $\mathrm{Rp}$ and MI, when fingerprints are carried out for identifying genotypes.

Probability of identical match by chance is an important calculation when the purpose of fingerprinting is to identify genotypes for checking identity and purity of a cultivar. Our results suggest that averages of this probability for each primer do not seem suitable for this 
purpose. Primer combinations with low (E_ACA + M_CAT) and intermediate (E_ACA+M_CAA) average probability of identical match by chance, resulted with probability of $100 \%$ of identical match by chance between at least one pair of comparisons. This result indicates the importance for calculating of maximal probability of identical match by chance, and also suggests the use of several primer combinations for identifying genotypes. Maximal probability of $100 \%$ for individual primer combinations became maximal probability of 0.000052 when 8 primer combinations were used. AFLP fingerprint showed an average of 6 unique bands per primer combination; this may be very useful for genotyping cultivars, because these unique bands can be converted into STS (sequence tagged site) markers. This in turn may be useful for detecting mixes between cultivars (Fernadez et al. 2002).

The UPGMA-based phenogram and principal coordinate analysis displayed similar patterns. Cultivars UCV-1, 19x10 and 43×32, derived from the same basic population, did not group together. This basic population resulted from crosses among 50 accessions to produce a highly variable population. Three best lines of the recurrent selection program mentioned above, which cover a broad genetic diversity as compared with the remaining 17 cultivars, originate from this highly variable population. Cultivars Fonucla and UCV-3, selected from the same cultivar (Arawaca), differed considerably from each another. Arawaca was obtained by a bulk population method, which is characterized by selecting a mixture of genotypes with similar phenotypic traits; therefore there is a theoretical explanation for this result. Inamar and Acarigua come from the same single cross between Venezuela 51 and an $F_{2}$ plant. This $F_{2}$ plant must have had a high level of heterozygocity to obtain such dissimilar cultivars. Genetically dissimilar cultivars coming from the same single cross have been reported in other crops such as barley (Hordeum vulgare L.) (Fernandez et al. 2002) and cashew (Anacardium occidentale L.) (Archak et al. 2003). This observation is so interesting in sesame breeding, because it is revealing that only two parents may be enough for generating a 
base population with broad genetic variability.

Nine cultivars used in this study (Fonucla, UCLA1, UCLA249, UCLA295, UCLA37-1, UCLA65, UCLA83, UCLA90 and UCV-3) were characterized using morphological traits (Laurentin et al., 2004) and RAPD (Salazar et al., 2006). When only these cultivars were subjected to principal coordinate analysis with our AFLP data, the three studies were similar only in grouping closely UCLA90 and UCLA1. But when we compare AFLP and RAPD studies with each other, even though Mantel test showed non-significant correlation between similarity matrices $(\mathrm{P}<0.05)$, two clusters grouped the same cultivars: UCLA1, UCLA90 in one cluster, and UCLA65, UCLA295, Fonucla in other one; furthermore both analysis failed to assign UCV-3 and UCLA37-1 to some cluster. Why this differs from the morphological characterization can be explained because molecular characterization covers the entire genome variability (Ovesná et al. 2002) excluding the environmental influence (Rao 2004), whereas morphological characterization, mainly of quantitative traits in multi-environment experiments as those studied by Laurentin et al. (2004), are subjected to strong environmental influence (Karp et al. 1997, Rao 2004). According to our study, and in agreement with the previous study using RAPD (Salazar et al., 2006), UCLA37-1 appear to be the most suitable parents of an eventual new "white seed" population when crossed with some of the other white seed cultivars studied (elite lines from Universidad Centrooccidental Lisandro Alvarado sesame breeding program, Table 1), under the assumption that the more is the genetic distance between parents the more is the possibility to identify potential and suitable new cultivars from a segregant population.

Five cultivars used in the present study $(19 \times 10,43 \times 32$, Fonucla, UCV-3 and UCLA37-1) were characterized according presence or absence of secondary metabolites in roots, stems, leaves, fruits and seeds (Laurentin et al. 2003). The three-dimensional graph from the principal coordinate analysis, even though Mantel test showed non-significant correlation between similarity matrix (AFLP) and correlation matrix (secondary metabolites) $(\mathrm{P}<0.05)$, 
displayed a similar grouping to that of these cultivars using AFLP. This close relationship between AFLP and secondary metabolites could be useful in future breeding programs, even more so when these secondary metabolites were related with resistance against whitefly.

The results of the present study have demonstrated that AFLP-based fingerprints are a useful tool to identify sesame genotypes unequivocally. This information could be used for cultivar identification and protection of breeder's rights. Also, AFLP-fingerprints have been used successfully in our study for assessing genetic variability of breeding stocks and for the determination of the genetic relationship among cultivars.

\section{Acknowledgements}

This work was supported by the Programme Alban, European Union Programme of High Level Scholarships for Latin America, Identification Number E03D13301VE, International $\mathrm{PhD}$ program for Agricultural Sciences in Göttingen University (IPAG) and Universidad Centroccidental Lisandro Alvarado. 


\section{References}

Archak S, Gaikwad B, Gautam D, Rao E, Swamy K, Karihaloo J (2003) DNA fingerprinting of Indian cashew (Anacardium occidentale L.) varieties using RAPD and ISSR techniques. Euphytica 230:397-404

Ashri A (1998) Sesame breeding. Plant Breeding Reviews 16:179-228

Bohn M, Utz H, Melchinger A (1999) Genetic similarities among winter wheat cultivars determined on the basis of RFLPs, AFLPs and SSRs and their use for predicting progeny variance. Crop Sci 39:228-237

Buhariwalla HK, Jayashree, B, Eshwar K, Crouch JH (2005) Development of ESTs from chickpea roots and their use in diversity analysis of the Cicer genus. BMC Plant Biol 5:16.

Dangi RS, Lagu MD, Choudhary LB, Ranjekar PK, Gupta VS (2004) Assessment of genetic diversity in Trigonella foenum-graecum and Trigonella caerulea using ISSR and RAPD markers. BMC Plant Biol 4:13

De Riek J, Calsyn E, Everaert I, Van Bockstaele E, De Loose M (2001) AFLP based alternatives for the assessment of distinctness, uniformity and stability of sugar beet varieties. Theor Appl Genet 103:1254-1265

FAO (2005) FAOstat Databases. http://faostat.fao.org/

Fernandez M, Figueiras A, Benito C (2002) The use of ISSR and RAPD markers for detecting DNA polymorphism, genotype identification and genetic diversity among barley cultivars with known origin. Theor Appl Genet 104:845-851

Hong Y, Chuah A (2003) A format for databasing and comparison of AFLP fingerprint profiles. BMC Bioinformatics 4:7

Karp A, Kresovich S, Bhat K, Ayad W, Hodgkin T (1997) Molecular tools in plant genetic resources conservation: a guide to the technology. IPGRI Technical Bulletin No. 2. International Plant Genetic Resources Institute. Rome. Italy

Langham D, Rodriguez M (1946) Dos nuevas variedades de ajonjolí Venezuela 51 y Venezuela 52. Circular N ${ }^{\circ}$ 15. Departamento de Genetica. Dirección de Agricultura. Maracay. Venezuela

Laurentin H., Layrisse A, Quijada P (2000) Evaluación de dos ciclos de selección recurrente para altos rendimientos de semilla en una población de ajonjolí. Agronomía Tropical (Maracay) 50:521-535

Laurentin H, Pereira C, Sanabria M (2003) Phytochemical characterization of six sesame (Sesamum indicum L.) genotypes and their relationships with resistance against whitefly (Bemisia tabaci Gennadius). Agronomy Journal 95(6):1577-1582

Laurentin H, Montilla D, Garcia V (2004) Relación entre el rendimiento de ocho genotipos de ajonjolí (Sesamum indicum L.) y sus componentes. Comparación de metodologías. Bioagro $16: 153-162$ 
Laurentin H, Karlovsky P (2006) Genetic relationship and diversity in a sesame (Sesamum indicum L.) germplasm collection using amplified fragment length polymorphism. BMC Genetics 7:10

Mazzani B (1952) Una nueva variedad de ajonjolí producica en el Instituto Nacional de Agricultura. Agronomía Tropical (Maracay) 1:269-277

Mazzani, B (1953) Inamar: nueva variedad de ajonjolí producidad en el Instituto Nacional de Agricultura. Agronomía Tropical (Maracay) 3:211-213

Mazzani, B (1999) Investigación y tecnología del cultivo del ajonjolí en Venezuela. Ediciones del Consejo Nacional de Investigaciones Cientificas y Tecnológicas. Caracas. Venezuela. 103 pp. http://ajonjoli.sian.info.ve/mazzani.pdf

Mazzani B, Nava C, Martinez A, Layrisse A (1973) Maporal, una nueva variedad de ajonjoli para los Llanos Occidentales. Agronomia Tropical 23:501-508

Milbourne D, Meyer R, Bradshaw J, Baird E, Bonar N, Provan J, Powell W, Waught R (1997) Comparison of PCR-based marker systems for the analysis of genetic relationships in cultivated potato. Mol Breed 3:127-136

Moretzsohn M de C, Hopkins MS, Mitchell SE, Kresovich S, Valls JF, Ferreira ME (2004) Genetic diversity of peanut (Arachis hypogaea L.) and its wild relatives based on the analysis of hypervariable regions of the genome. BMC Plant Biology 4:11

Montilla D, Cedeño T (1991) Fonucla: una nueva variedad de ajonjolí (Sesamum indicum L.). Bioagro 3:52-54

Montilla D, Teran H (1996) UCLA1, una nueva variedad de ajonjolí (Sesamum indicum L.). Bioagro 8:26-29

Muminovic, J, Melchinger A, Lübberstedt $\mathrm{T}$ (2004) Genetic diversity in cornsalad (Valerianella locusta) and related species as determined by AFLP markers. Plant Breeding 123:460-466

Ovesná J, Poláková K, Leisová L (2002) DNA analyses and their applications in plant breeding. Czech J Genet Plant Breed 38:29-40

Powell W, Margenta M, Andre C, Hanfrey M, Vogel J, Tingey S and Rafalsky A (1996) The utility of RFLP, RAPD, AFLP and SSR (microsatellite) markers for germplasm analysis. Mol Breed 2:225-238

Prevost A, Wilkinson M (1999) A new system of comparing PCR primers applied to ISSR fingerprinting of potato cultivars. Theor Appl Genet 98:107-112

Rajora O, Rahman M (2003) Microsatellite DNA and RAPD fingerprinting, identification and genetic relationships of hybrid poplar (Populus x canadensis) cultivars. Theor Appl Genet 106:470-477

Ramakrishna, W, Lagu M, Gupta V, Ranjekar P (1994) DNA fingerprinting in rice using oligonucleotide probes specific for simple repetitive DNA sequences. Theor Appl Genet 
$88: 402-406$

Rao N (2004) Plant genetic resources: advancing conservation and use through biotechnology. African Journal of Biotechnology 3:136-145

Reineke A, Karlovsky P (2000) Simplified AFLP protocol: replacement of primer labeling by the incoporation of $\alpha$-labeled nucleotides during PCR. BioTechniques 28:622-623

Roldán-Ruiz I, Dendauw J, VanBockstaele E, Depicker A and De Loose M (2000) AFLP markers reveal high polymorphic rates in ryegrasses (Lolium spp.) Molecular Breeding 6:125134

Salazar B, Laurentin H, Dávila M, Castillo M (2006) Reliability of the RAPD technique for germplasm analysis of sesame (Sesamum indicum L.) from Venezuela. Interciencia 31:456460

Savelkoul P, Aarts H, DeHaas J, Dijkshoorn L, Duim B, Otsen M, Rademaker J, Schouls L, Lenstra J (1999) Amplified-fragment length polymorphism analysis: the state of an art. Journal of Clinical Microbiology 37:3083-3091

Stodart B, Mackay M, Raman H (2005) AFLP and SSR analysis of genetic diversity among landraces of bread wheat (Triticum aestivum L. em. Thell.) from different geographic regions. Australian Journal of Agricultural Research 56:691-697

Tams S, Melchinger A, Bauer E (2005) Genetic similarity among European winter triticale elite germplasm assessed with AFLP and comparisons with SSR and pedigree data. Plant Breeding 124:154-160

Voss P, Hogers R, Bleeter M, Reijans M, van de Lee T, Hornes M, Frijters A, Pot J, Peleman J, Kuiper M, Zabeau M (1995) AFLP: a new technique for DNA fingerprinting. Nucleic Acids Res 23:4407-4414

Wetton J, Carter R, Parkin D, Walters D (1987) Demographic study of a wild house sparrow population by DNA fingerprinting. Nature 327:147-149

Zhang, LH, Ozias-Akins P, Kochert G, Kresovich S, Dean R, Hanna W (1999) Differentiation of bermudagrass (Cynodon spp.) genotypes by AFLP analysis. Theor Appl Genetics 98:895902 


\title{
Chapter 4. Analysis of association between seed metabolic profiles and genetic diversity in sesame (Sesamum indicum L.)
}

Hernán Laurentin, Astrid Ratzinger and Petr Karlovsky

\begin{abstract}
Germplasm collections are routinely characterized to obtain a comprehensive overview of the genetic diversity and/or to provide information about the value of the collection according to important agronomic and/or nutritional traits. The aim of the present study was to evaluate genetic diversity and metabolic profiles in seed on a set of 10 sesame accessions, and to discern the relationship between the two approaches. Matrices of Jaccard's similarity coefficient and Rogers' distance were calculated for AFLP data. Euclidean distance, correlation coefficient and simple matching coefficient were calculated for metabolic profiles. Comparison between matrices were achieved by means of Pearson's correlation and Mantel test, scatter plots and visual comparison of biplots obtained by principal component or coordinate analysis. Pearsons's correlation did not indicate any relationship between the two data set $(\mathrm{P}<0.05)$, but scatter plots and biplots displayed consistencies independently of the similarity level. Indirect selection of some metabolites in seed by farmers, and differences in the sampling of the genome for the two methodologies may explain the results. The aim of recording metabolic profiles to get an overview of the genetic diversity in sesame requires metabolic profiles from all the organs (root, stem, leaf, fruit, seed). This approach would avoid bias toward sampling of part of the genome too related with phenotypic selection. Whether the aim of future study is to know metabolic diversity at seed level, any other study does not seem to have predictable value, seed metabolic profiles by themselves would be required.
\end{abstract}

\section{Introduction}

Understanding the complexity of a plant species requires different approaches at different levels. Genome analysis seeks to record and catalog the inherited make-up of an organism, which is 
insensitive to environmental influences and can be used at any developmental stage of the organism (Ovesná et al., 2002; Rao, 2004). Approaches based on functional genomics (transcriptomics and proteomics) reveal gene expression underlying the phenotype. They depend on the the environmental conditions and developmental stage of the organism and may be associated with traits of commercial value. Metabolomics represents the chemical phenotype itself, but it also provides insight into the functional basis of higher-level characters such as color, resistance to pathogens and pests, and susceptibility to UV light.

An inherent feature of biological complexity is the diversity of characters within a species. Most of the studies of biological diversity have so far focused on morphological characters or molecular markers. These two sorts of data represent the two extremes on the path of gene expression from the genome to complex phenotype. Deeper understanding of biological diversity, however, requires the integration of data pertinent to different levels of gene expression. The level of metabolites is dealt with by metabolomics, the final goal of which is to identify and quantify all metabolites in a sample (Dunn and Ellis, 2005; Hall, 2006). This goal is too ambitious for most practical purposes. Instead of full-scale metabolomics, metabolite analysis with a limited scope concerning coverage and/or identification have been established. In line with the terminology established in genome and transcriptome analysis, metabolic fingerprinting designates procedures generating static profiles of signals (HPLC peaks, TLC spots, mass spectra) representing anonymous metabolites, which are characteristic for a given sample and can be used, for example, to confirm its origin or uncover surrogates. Metabolic profiling, in analogy to transcription profiling, generates profiles of metabolites, either anonymous or identified, and is mostly used for quantitative comparisons among varieties, physiological states or treated/untreated samples. Profiling of metabolite classes defined by their chemical nature (e.g., glucosinolates or oxylipins) is used to describe quantitatively the representation of these substances in the sample. Alternative definitions of metabolic profiling and metabolic fingerprinting (Fiehn, 2002; Fiehn and Weckwerth, 2003) are likely to lead to 
confusion whenever metabolic analysis, genome fingerprinting and transcription profiling are treated jointly.

Sesame (Sesamum indicum L.) is one of the most ancient crop (Bedigian and Harlan, 1986). It is grown in tropical and subtropical areas. Its seed, which is highly nutritive (50\% oil and $25 \%$ protein), is used for direct consumption an as a source of oil of excellent quality. Studies of secondary metabolites in sesame have been focussed on lignans and lignan glycosides in seeds and oil such as episesaminone, sesamin, sesamol, sesamolin, sesaminol, (Marchand et al., 1997, Yoshida and Takagi, 1997, Shyu and Hwang, 2002, Dachtler et al., 2003, Shirato-Yasumoto et al., 2003). The main motivation for studying sesame lignans is their antioxidative properties, which are believed to convey health-promoting properties to sesame products (Kang et al., 1998; Kang et al., 1999; Nakai et al., 2003; Jeng and Hou, 2005). Sesame lignans are believed to play a role in the resistance of sesame against insect pests and microbial pathogens. (Devine and Denholm, 1998; Devine et al., 1999; Brooker et al., 2000; Victor et al., 2001; Harmatha and Nawrot, 2002, Nascimento et al., 2003). The metabolism of sesame lignans after ingestion is understood to a limited extent (Peñalvo et al., 2005).

The application of metabolic profiling to diversity studies in Sesamum indicum have not been reported so far. Integrating metabolite profiling with genome profiling techniques will help identifying valuable genotypes for use in breeding for nutritional or health-promoting values and toward pest management. The aim of the present study was to evaluate genetic and metabolic diversity on a set of 10 sesame accessions and to statistically discern the relationship between metabolic and genomic data. 


\section{Material and methods}

Plant material

Seeds originating from 10 sesame accessions from Centro Nacional de Investigaciones Agropecuarias (CENIAP) Germplasm Bank (Venezuela) were grown in the greenhouse. Eight of these accessions were selected based on a previous genetic diversity study (Laurentin and Karlovsky, 2006), as representing most of the diversity identified. Two additional genotypes were added to the study, an experimental line and a commercial cultivar (Table 1).

\section{AFLP analysis}

DNA was extracted from leaves, and AFLP analysis was performed as previously reported (Laurentin and Karlovsky, 2006). AFLP reactions were performed twice for each accession and DNA fragments were separated on ALFexpress II DNA analyser (Amersham Pharmacia Biotech, Uppsala, Sweden). Automatic band recognition and matching was achieved using GelCompar II software (Applied Math, Belgium). The threshold value of 5\% relative to the maximum value within each lane was applied and only fragments identified in both replicas (between 94 and $100 \%$ of all bands recorded) were used for band matching. The results of band matching were encoded as a binary matrix, which was used for all further analysis.

\section{Metabolic profiling}

Seeds originating from five plants per accessions were bulked and $1 \mathrm{~g}$ was frozen with liquid nitrogen, ground in a mortar and subjected to extraction with a mixture of $80 \%$ ethanol (HPLC grade, Roth, Germany) and 20\% water for $16 \mathrm{~h}$ with stirring (100 rpm) under exclusion of oxygen. The liquid phase was filtered through $0.45 \mu \mathrm{m}$ filters and kept at $-20^{\circ} \mathrm{C}$ until HPLC analysis.

For HPLC analysis, $10 \mu \mathrm{l}$ aliquots of extracts were loaded onto a polar-modified RP-18 phase 
Table 1. Accessions from CENIAP Germplasm Bank (Venezuela) and their respective origin country and diversity centre

\begin{tabular}{|c|c|c|c|}
\hline Accessions & Country of Origin & Working code & Diversity Centre \\
\hline $93-2223$ & India & India 1 & India \\
\hline 89-007 & India & India 5 & India \\
\hline $95-464$ & India & India 7 & India \\
\hline $92-2918$ & India & India 8 & India \\
\hline 92-2922 & Turkey & Turkey & Western Asia \\
\hline 93-2022 & Syria & Syria & Western Asia \\
\hline $92-310$ & Sudan & Sudan 2 & Africa \\
\hline $92-2872$ & Sudan & Sudan 3 & Africa \\
\hline & & \multicolumn{2}{|c|}{ Origin } \\
\hline Experimental line $43 \times 32$ & Selected in Venezuela & \multicolumn{2}{|c|}{$\begin{array}{l}\text { Selected lines from second cycle of } \\
\text { recurrent selection toward high yield, } \\
\text { under heavy whitefly infestation. The } \\
\text { original population was obtained by cross, } \\
\text { one to one, among } 50 \text { exotic accessions } \\
\text { (Laurentin et al., 2000) }\end{array}$} \\
\hline $\begin{array}{l}\text { Commercial cultivar } \\
\text { Inamar }\end{array}$ & Selected in Venezuela & \multicolumn{2}{|c|}{$\begin{array}{l}\text { Individual selection from the offspring } \\
\text { from the same Acarigua's parents } \\
\text { (Mazzani, 1953). }\end{array}$} \\
\hline
\end{tabular}

column (C18-Pyramid, Macherey-Nagel, Düren, Germany, $4 \mu, 2 \mathrm{x} 100 \mathrm{~mm}$ ) and separated at $40^{\circ} \mathrm{C}$ with a gradient of $10 \%-98 \%$ methanol, at a flow rate of $0.2 \mathrm{ml} \mathrm{m^{-1 }}$. The eluent was subjected to electrospray ionisation (ESI). Ions were analyzed both in positive and negative full scan mode between 50 and $1000 \mathrm{~m} / \mathrm{z}$ on an triple quadrupole mass spectrometer $(1200 \mathrm{LC}$, Varian, Germany). Accession Sudan3, randomly selected among the 10 accessions, was loaded three times to assess the reproducibility of the results.

Data processing and analysis

Raw data from metabolic study were processed by CODA algorithm (background reduction and spike elimination, Winding et al., 1996). Extracted ion chromatograms which satisfied a certain mass chromatogram quality index (MCQ 0.85, according to technical manual of $\mathrm{ACD} / \mathrm{MS}$ Manager v. 8.0, Advanced Chemistry Development, Toronto, Canada) were generated and 
compared. Based on these chromatograms, peak tables were generated. Ten peaks with the largest areas for each accession were identified. For each of these peaks, matching peaks in all accessions were identified, building a set of peaks which was used for further analysis. Isotopes peaks for the same compound, recognised by the difference of one unit in the molecular weight and the same retention time, were combined to generate one value per mass per accession.

Peak areas were standardized twice, firstly within every accession by dividing the area by the total sum of areas of all peaks for each accession to compensate for loading differences, and secondly within every $\mathrm{m} / \mathrm{z}$ value by dividing all peak areas by the maximal area with this $\mathrm{m} / \mathrm{z}$ value to weigh major peaks in each extracted ion chromatogram equally. The resultant matrix was used to calculate Euclidean distances between pairs of accessions as a measure of dissimilarity and correlation coefficients as a measure of similarity. In order to assess the effect of differences in signal intensities within extracted ion chromatograms, the matrix of doublynormalized intensities was transformed in a binary matrix replacing by 1 all the values greater than 0 . Using the binary matrix, simple matching coefficient was calculated for each pair of accession as a similarity measure. Correlation coefficient between Euclidean distance based matrix and simple matching coefficient based matrix was calculated by means Mantel test (500 permutations). To visualize the relationship among accessions according to metabolite content, principal component analysis was performed for correlation matrix, but not for Euclidean distance because eigenvectors and eigenvalues cannot be calculated from a dissimilarity matrix. Therefore the dissimilarity matrix was transformed to scalar product form, which allows to calculate eingenvalues and eigenvectors and visualise the relationship among accessions based on Euclidean distances using principal coordinate analysis. This ordination method was used for simple matching coefficient matrix as well. Calculations of similarity and dissimilarity coefficients, principal component and coordinate analysis were performed using software NTSySpc 2.11T.

A binary matrix from AFLP data was obtained as reported by Laurentin and Karlovsky (2006). 
Jaccard coefficient similarity matrix and Rogers' distance dissimilarity matrix were calculated. The relationship among accessions was visualised by means of principal coordinate analysis. Comparison of ordination obtained by AFLP and metabolite content was based on Pearson correlation and Mantel test between the matrices using 1000 permutations. Furthermore, the two approaches were also compared by scatter plots to understand correlation value. Plot space was split in three sections (high similarity, intermediate similarity and low similarity) both in $\mathrm{X}$ axis and Y axis. Visual comparison between graphic obtained from principal coordinate analysis using AFLP data and graphic obtained from principal component/coordinate analysis using metabolic data was performed as well.

\section{Results}

A total of 381 AFLP markers, ranging from 100 to 550 base-pairs, were recorded using 8 primer combinations on the 10 sesame accessions. Ninety-five percent of the markers were polymorphic. Eighty-eight bands (23\%) were unique, ranging from 5 (Turkey) to 21 (India 7) per accession (Table 2).

Metabolic analysis displayed good reproducibility because all comparisons performed (similarity and dissimilarity measures, principal component analysis) showed little variation among three Sudan3 loaded as compared to the other 9 accessions. Data of Sudan3 represented by the average of the three loading were used further.

Eighty-eight metabolic signals were identified in seed extracts from 10 accessions, 47 in negative mode and 41 in positive mode. More than $50 \%$ of these peaks were eluted with a retention time between 15 and $27 \mathrm{~min}$. Thirty-four signals were common for all accessions, 16 in positive mode and 18 in negative mode. Eight signals were accession-specific or absent in only one accession 
Table 2. Total number of bands, number of polymorphic bands, percentage of polymorphic bands and number of unique bands obtained per AFLP primer combination

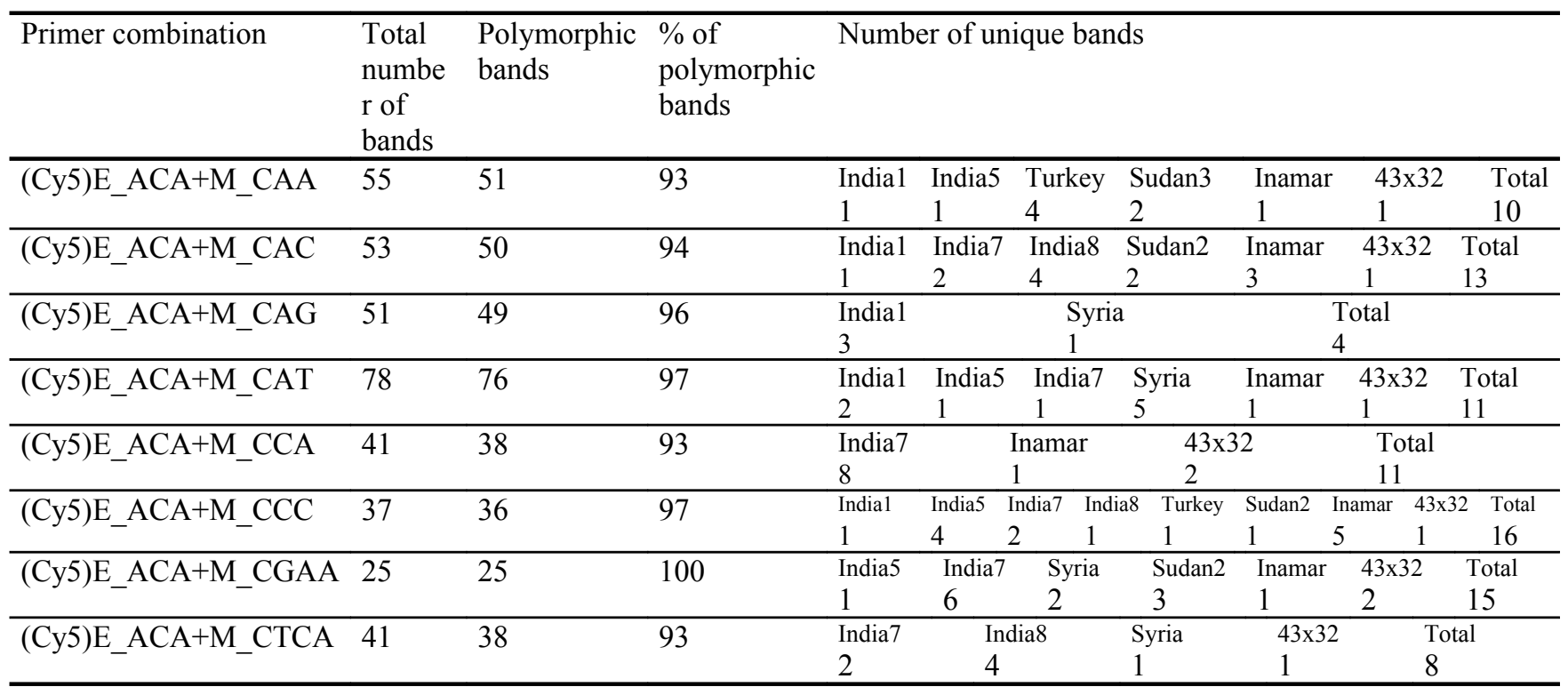

(Table 3). No relationship was found between the number of unique AFLP markers and number of specific masses (or masses lacking in only one accession) within accessions.

Correlation coefficient between Euclidean-distance-based matrix and simple-matchingcoefficient-based matrix resulted in $-0.56(\mathrm{P}<0.01)$. Correlation between matrices obtained from AFLP data and metabolic profiles were no significant. Comparisons to Jaccard's coefficient matrix resulted in $-0.09(\mathrm{P}<0.33)$ for simple matching coefficient matrix, $0.20(\mathrm{P}<0.77)$ for Euclidean distance matrix and $-0.24(\mathrm{P}<0.18)$ for correlation matrix. Similarly, comparisons to Rogers' distance matrix resulted in $0.12(\mathrm{P}<0.75),-0.17(\mathrm{P}<0.20)$ and $0.22(\mathrm{P}<087)$ respectively. Scatter plots displayed some important consistences for certain pairs of comparisons (Figure 1) based on two criteria: how close is a compared-pair to an ideal correlation line (1 comparing similarity matrices or -1 comparing similarity to dissimilarity matrices) and whether a compared-pair falls in the same arbitrary category (i.e. high similarity, intermediate similarity, low similarity) for both axes. For all comparisons the pair Syria-Sudan3 revealed a high 
Table 3. Signals detected in sesame extracts by HPLC-MS

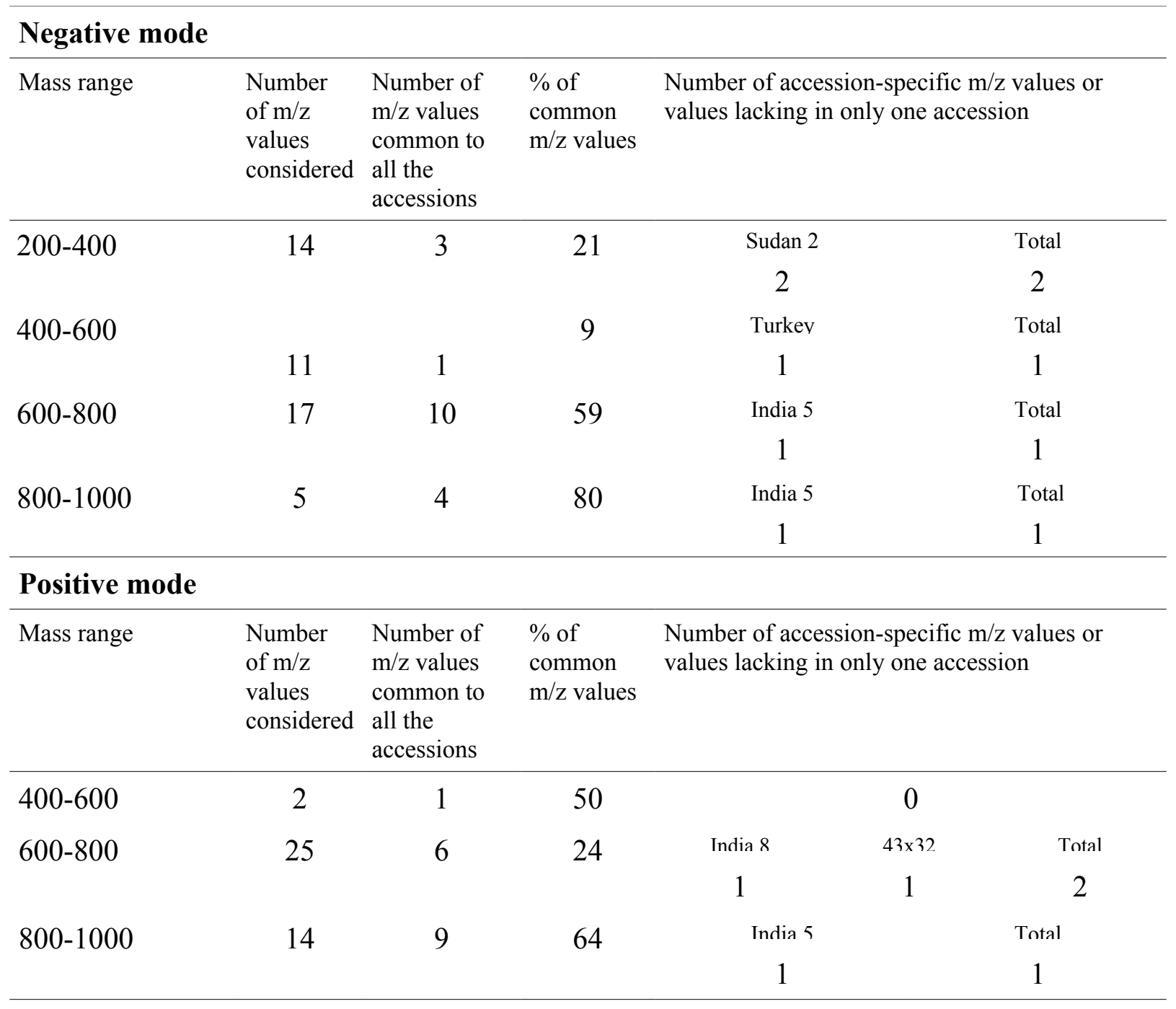

similarity in both axes, Sudan2-43x32 and India5-Sudan2 a low similarity, and India8-43x32 and India1-Turkey an intermediate similarity.

Biplots of principal coordinate analysis based on AFLP data, calculated both from Jaccard's coefficient (which covered $64 \%$ of variation) and Rogers' distance (which covered 54\% of variation), displayed similar pattern (Figure 2). Accessions Sudan2 and India7 by one side, and commercial cultivars Inamar and $43 \times 32$ by the other, are grouped as the most distinctive. Biplots of principal component/coordinate analysis based on correlation coefficient (which covered 62\% of variation), Euclidean distance (which covered $62 \%$ of variation as well) and simple matching 

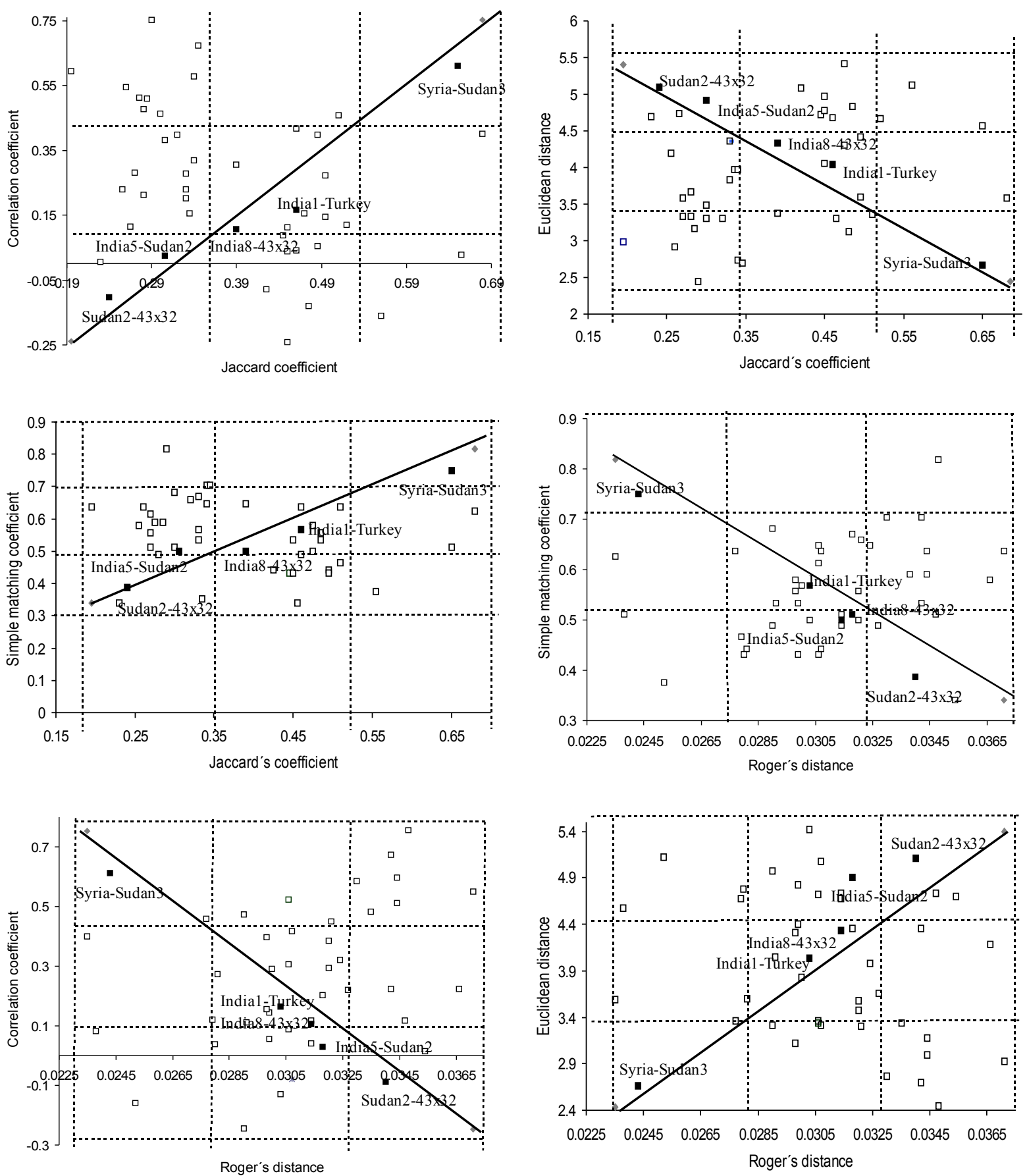

Figure 1. Scatter plots comparing ordination performed by AFLP (Jaccard's coefficient and Roger's distance) to ordination performed by metabolic profiles (correlation coefficient, Euclidean distance and simple matching coefficient). Each pairwise comparison is represented by white square and black squares. Black squares correspond to the five most consistent pairwise comparisons. The black line represents an ideal correlation. 

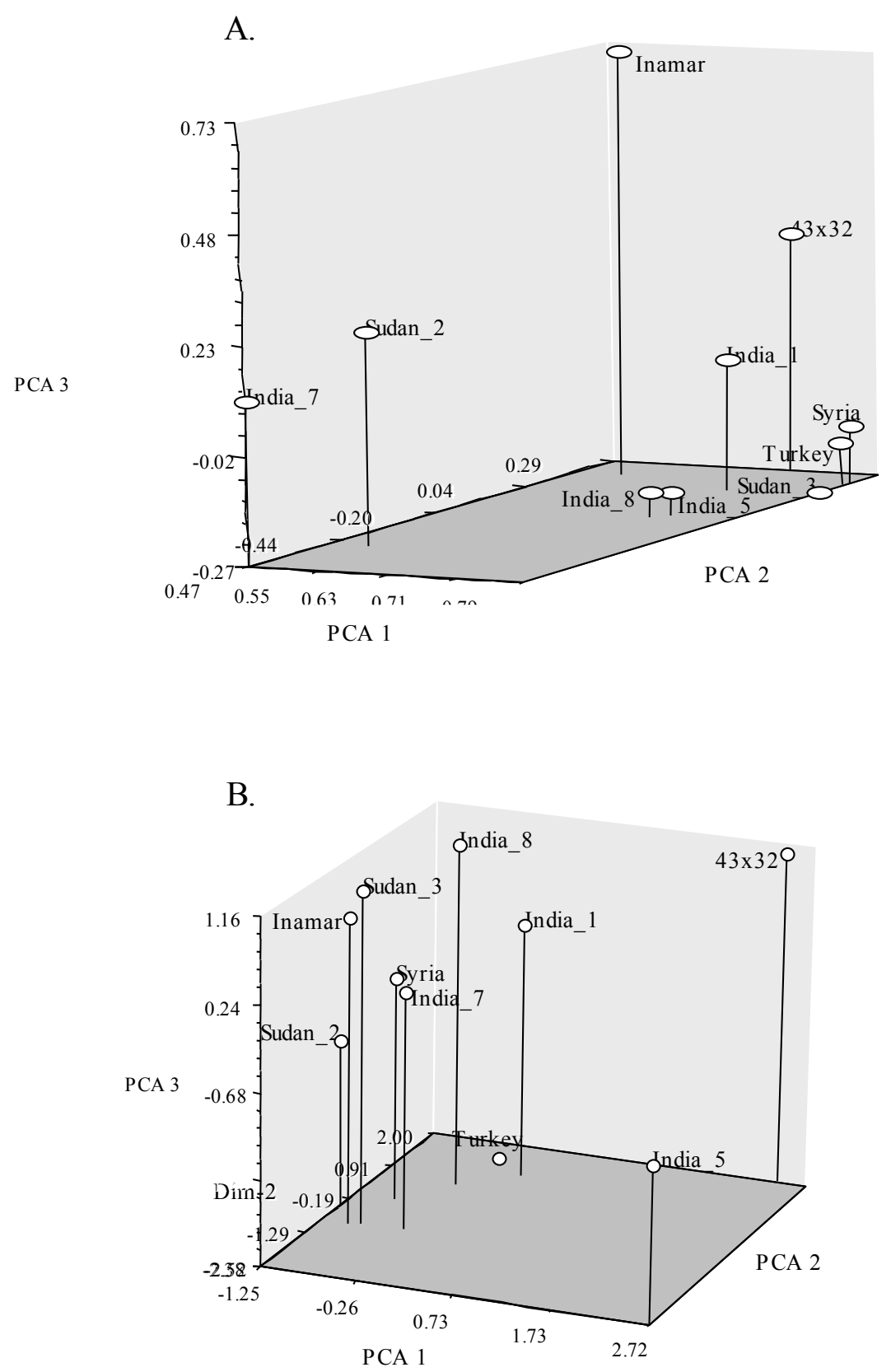

Figure 2. Biplot of principal coordinate analysis. A. Based on AFLP data using Jaccard's coefficient. B. Based on seed metabolic profiles using correlation coefficient 
coefficient (which covered $77 \%$ of variation) had a similar pattern (Figure 2), where accessions India5 and $43 \times 32$ formed one group and the other accessions formed another group. Visual comparison of biplots obtained with AFLP and metabolic profiles agreed in classifying cultivar $43 \times 32$ as one of the most distinctive, therefore the Sudan $2-43 \times 32$ was one of the most dissimilar pairs. Both biplots grouped Syria-Sudan3 as the most similar pair and India1-Syria, India1Sudan3, India1-Turkey and I8-43x32 as pairs with intermediate similarity. The most important contradiction between both biplots was the placement of India5, India7 and Inamar. AFLP classified India7 and Inamar as two most distinctive accessions whereas metabolic profiles grouped them together with other 6 accessions. Similarly, India5 is classified according metabolic profiles as one of the most distinctive, but AFLP grouped it together with 5 other accessions.

\section{Discussion}

Seed metabolic profiles analysis failed to indicate any relationship to the geographical origin of the accessions studied, similarly as reported before for AFLP (Laurentin and Karlovsky, 2006). The diversity analysis results based on AFLP and seed metabolic profiles were quite different. A similar study carried out by Wolde-meskel et al. (2004) on rhizobial strains did not find relatedness between metabolic and genomic (AFLP) data; but Seymour et al. (2004) found strong similarities between genotypic variation and metabolite diversity in two endophytic fungi.

Considering that the number of characters reflects the sampling depth, AFLP-based analysis could be considered more reliable than seed metabolic profiles (363 polymorphic bands for AFLP and 88 signals for seed metabolic profiles). As compared to AFLP, metabolic profiles contain additional information because they consists of continuous variables. This information is lost after the transformation of metabolic data to a binary matrix. However, the results provided 
by metabolic profiles recorded as sets of continuous variables or after transformation to binary data were nearly identical. In this case the difference in the sampling is much higher: 363 characters for AFLP and 54 for seed metabolic profiles.

The two methods sample different genetic information. AFLP detects recognition sites for restriction enzymes and flanking nucleotides complementary to the selective nucleotides of the primers (Voss et al., 1995; Savelkoul et al., 1999). This sampling is insensitive to the gene expression. Seed metabolic profiles sample metabolic activities in the seed, corresponding to the expression of a small fraction of genes in the genome. Representative sampling for both methodologies would lead to similar results only if the diversification in sesame on both levels is governed by the same evolutionary forces. Because the majority of plant genomes consists of non-coding sequences, changes in AFLP patterns are expected to result mainly from mutations randomly fixed by genetic drift. Concerning metabolic profiles, it is reasonable to assume that most changes underly selection, both positive (resistance to pests and pathogens, protection from light, improved dissemination of seeds etc.) and negative (for example metabolic costs, bitter taste, attraction for insect pests). The disparity between diversity patterns as revealed by AFLP and metabolic profiling are therefore expected to provide insights into processes which contributed to the makup of current sesame accessions.

A second source of inconsistencies of diversity patterns revealed by different methods between a pair of accessions is non-representative sampling. If at least one of the sampling is not representative, inconsistencies will appear in some pairwise comparisons. The difference between the relatedness of the accessions on metabolic and genomic level will be overestimated by calculating a correlation coefficient for the whole data set, because the result concerning one accession affects many pairwise comparisons (data are interdependent). For example, when two accessions are grouped differentially, 17 pair-wise comparisons will be affected. Obviously similarity/dissimilarity matrices will be different and biplots of principal component/coordinates analysis as well. For this reason, scatter plots are useful tool to identify these inconsistencies, 
knowing for the correlation data set which pair-accession similarity/dissimilarity values are correlated and which not and also being aware about the interdependence of the data. Therefore the consistencies found become important, because they indicate in which comparisons the sampling was representative for the pair of accessions. In this case, for instance, pair $43 \times 32-$ Sudan 2 resulted in one of the most dissimilar pairs for both analysis, indicating that seed metabolic profiles are a good sample of the genome for this comparison. The same comment is valid for pairs Syria-Sudan3, India1-Syria, India1-Sudan3, India1-Turkey and I8-43x32. According to these results, consistencies are not dependent on the level of similarity (consistencies were found for high, intermediate and low similarity), rather than it depends on the pair of accessions compared.

Another aspect to consider as responsible of the lack of consistency between analyses is the selection influence on seed metabolic profiles. Sesame growers have been manipulating the crop due to migration and trade for centuries. The oldest remnants of sesame, found in the Harappa valley in the Indian subcontinent (Bedigian and Harlan, 1986) date the origin of these activities to at least $5500 \mathrm{BP}$. Needs and preferences of local people led to direct selection of some sesame seeds traits such as colour, size, taste, etc., and indirectly metabolic content of the seeds. If two close related genotypes follow different ways of selection of some oligogenic traits they will keep, after a limited number of generations, the close relationship but they will differ in the traits under selection. In the current work Turkey-Syria pair is an example of this. Also possible is that two non-related genotypes, under selection pressure for the same phenotype (and therefore for the metabolites related to the phenotype), after many generation result in genetically non-related genotypes but with similar phenotype, in the current work for instance India7-Syria. In the case of consistency between both analyses, the explanation is that differentiation processes at metabolic level due to selection of seed traits, between accessions in each pair, has been proportional to the extent of genetic differentiation. This fact suggests that identification of similarity/dissimilarity relationship between pairs based on AFLP and seed metabolic profiles 
depend on the genotypes under comparison, due to differences in evolutionary history of each genotype. Therefore the assumption that genetic distance between two genotypes is directly proportional to the probability of identifying very different levels in some important agronomic or quality trait is not necessarily true, and is not supported by this work. Genetic analysis based on molecular markers cannot be used as prediction of similarity or dissimilarity in the content of seed metabolites.

Because the production of secondary metabolites in different plant organs is likely to affect the selection by farmers and breeders in different ways, recording metabolic profiles from all organs (root, stem, leaf, fruit, seed) is needed to provide a complete picture. For example, the production of metabolites protecting sesame against leaf pathogens might be either irrelevant or even undesirable (taste) in seeds. Furthermore, functional studies are necessary to reveal how the production of secondary metabolites have been affected by the selection for resistance and other phenotypic traits. We intend to address both the metabolite content in different plant organs and their affect on pests and pathogens in our future work.

\section{Acknowledgments}

This work was supported by the Programme Alban, European Union Programme of High Level Scholarships for Latin America, Identification Number E03D13301VE, International PhD program for Agricultural Sciences in Göttingen University (IPAG) and Universidad Centroccidental Lisandro Alvarado. 


\section{Literature cited}

Bedigian, D. and J. Harlan. 1986. Evidence for cultivation on sesame in the ancient world. Economic Botany 40:137-154

Brooker, N., J. Long and S. Stephan. 2000. Field assessment of plant derivative compound for managing fungal soybean diseases. Biochemical Society Transactions 28:917-920

Dachtler, M., F. van de Put, F. Stijn, C. Beindorff and J. Fritsche. 2003. On-line LC-NMR-MS characterization of sesame oil extracts and assessment of their antioxidant activity. Eur. J. Lipid Sci. Technol. 105:488-496

Devine, G., and I. Denholm. 1998. An unconventional use of piperonyl butoxide for managing the cotton whitefly, Bemisia tabaci (Hemiptera:Aleyrodidae). Bulletin of Entomological Research 88:601-610

Devine, G., I. Ishaaya, A. Horowitz and I. Denholm. 1999. The response of pyriproxyfenresistant and susceptible Bemisia tabaci Genn. (Homoptera:Aleyrodidae) to pyriproxyfen and fenoxycarb alone and in combination with piperonyl butoxide. Pestic. Sci. 55:405-411

Dunn, W. and D. Ellis. 2005. Metabolomics: current analytical platforms and methodologies. Trends in Analytical Chemistry 24:285-294

Fiehn, O. 2002. Metabolomics - the link between genotypes and phenotypes. Plant Molecular Biology 48:155-171

Fiehn, O. and W. Weckwerth. 2003. Deciphering metabolic networks. Eur. J. Biochem. 270:579-588

Hall, R.D. 2006. Plant metabolomics: from holistic hope, to hype, to hot topic. New Phytologist. 169:453-468

Harmatha, J. and J. Nawrot. 2002. Insect feeding deterrent activity of lignans and related phenylpropanoids with a methylenedioxyphenyl (pyperonyl) structure moiety. Entomologia Experimentalis et Applicata 104:51-60

Jeng, K. and R. Hou. 2005. Sesamin and sesamolin: nature's therapeutic lignans. Current Enzyme Inhibition 1:11-20

Kang, M., M. Naito, N. Tsujihara and T. Osawa. 1998. Sesamolin inhibits lipid peroxidation in rat liver and kidney. J. Nutr. 128:1018-1022

Kang, M., Y. Kawai, M. Naito and T. Osawa. 1999. Dietary deffated sesame flour decreases susceptibility to oxidative stress in hypercholesterolemic rabbits. J. Nutr. 129:1885-1890

Laurentin, H., Layrisse A. and Quijada P. 2000. Evaluación de dos ciclos de selección recurrente para altos rendimientos de semilla en una población de ajonjolí. Agronomía Tropical (Maracay) 50:521-535.

Laurentin, H., and P. Karlovsky. 2006. Genetic relationship and diversity in a sesame (Sesamum indicum L.) germplasm collection using amplified fragment length polymorphism (AFLP). 
BMC Genetics 7:10

Marchand, P., M. Kato and N. Lewis. 1997. (+) -Episesaminone, a Sesamum indicum furofuran lignan. Isolation and hemisynthesis. J. Nat. Prod. 60:1189-1192

Mazzani, B. 1953. Inamar: nueva variedad de ajonjolí producida en el Instituto Nacional de Agricultura. Agronomía Tropical (Maracay) 3:211-213.

Nakai, M., M. Harada, K. Nakahara, K. Akimoto, H. Shibata, W. Miki and Y. Kiso. 2003. Novel antioxidative metabolites in rat liver with ingested sesamin. J. Agric. Food Chem. 51:1666-1670

Nascimento, I., A. Murata, S. Bortoli and L. Lopes. 2004. Insecticidad activity of chemical constituents from Aristolochia pubescens against Anticarsia gemmatalis larvae. Pest Manag Sci $60: 413-416$

Ovesná, J., K. Poláková and L. Leisová. 2002. DNA analyses and their applications in plant breeding. Czech J Genet Plant Breed. 38(1):29-40

Peñalvo, J., S. Heinonen, A. Aura and H. Adlerreutz. 2005. Dietary sesamin in converted to enterolactone in humans. J. Nutr. 135:1056-1062

Rao, N. 2004. Plant genetic resources: advancing conservation and use through biotechnology. African Journal of Biotechnology 3(2):136-145

Savelkoul, P, H. Aarts, J. DeHaas, L. Dijkshoorn, B. Duim, M. Otsen, J. Rademaker, L. Schouls and J. Lenstra. 1999. Amplified-fragment length polymorphism analysis: the state of an art. Journal of Clinical Microbiology 37:3083-3091

Seymour, F., J. Cresswell, P. Jack, H. Lappin-Scott, H. Haag and N. Talbot. 2004. The influence of genotypic variation on metabolite diversity in populations of two endophytic fungal species. Fungal Genetics and Biology 41:721-734

Shirato-Yasumoto, S., M. Komeichi, Y. Okuyama and A. Horigane. 2003. A simplified HPLC quantification of sesamin and sesamolin in sesame seed. SABRAO Journal of Breeding and Genetics 35:27-34

Shyu, Y. and L. Hwang. 2002. Antioxidative activity of the crude extract of lignan glycosides from unroasted Burma black sesame meal. Food Research International 35:357-365

Victor, S., F. Crisóstomo, F. Bueno, F. Pagnocca, J. Fernandes, A. Correa, O. Bueno, J. Hebling, M. Bacci Jr., P. Vieira and F. daSilva. 2001. Toxicity of synthetic piperonyl compounds to leafcutting ants and their symbiotic fungus. Pest Manag. Sci. 57:603-608

Vos, P, R. Hogers, M. Bleeter, M. Reijans, T. van de Lee, M. Hornes, A. Frijters, J. Pot, J. Peleman, M. Kuiper, M. Zabeau. 1995. AFLP: a new technique for DNA fingerprinting. Nucleic Acids Res. 23:4407-4414

Winding, W., Phalp, J. M., Payne, A. W. A.1996. Noise and Background Reduction Method for Component Detection in Liquid Chromatography/Mass Spectrometry. Anal. Chem. 68: $3602-3606$ 
Wolde-meskel, E., Z. Terefework, K. Lindstrom and A. Frostegard. 2004. Metabolic and genomic diversity of rhizobia isolated from field standing native and exotic woody legumes in southern Ethiopia. Syst. Appl. Microbiol. 27:603-611

Yoshida, H and S. Takagi. 1997. Effects of seed roasting temperature and time on the quality characteristics of sesame (Sesamum indicum) oil. J. Sci. Food Agric. 75:19-26 


\section{Chapter 5. Standardising bioassays for testing novel compounds against Macrophomina phaseolina (Tassi) Goidanich}

Hernán Laurentin and Petr Karlovsky

\section{Abstract}

Background

Macrophomina phaseolina (Tassi) Goidanich is an important plant pathogenic fungus that causes damage by plugging or rotting of vascular tissue in roots and lower stems in more than 300 crop species. Novel compounds from higher plants, bacteria, algae, etc. have been tested for controlling the fungus, but current experiment conditions require large amounts of extracts. The present study determined the best conditions to achieve a rapid and highthroughput bioassay adequate for evaluating the effect of small amount of novel compounds, from a large amount of sources, on the growth of Macrophomina phaseolina.

Results

Obtaining of abundant microsclerotia (up to 35000 per 9 cm-diameter petri dish) was achieved growing the fungus on modified PDA ( $4 \%$ agar) with two pieces of filter paper ( $1 \mathrm{x} 1$ $\mathrm{cm}$ placed on the surface of the agar) at 25 or $35^{\circ} \mathrm{C}$ depending on the isolate. The best conditions to test novel compounds on fungus growth from microsclerotia were determined. Dilution series of compounds to be tested are placed into 96-well flat-bottom microplate and dried. Twenty microsclerotia in $40 \mu \mathrm{L}$ of PDB are added, and microplate is incubated at $35^{\circ} \mathrm{C}$. Fungal growth was monitored by measuring turbidity at $550 \mathrm{~nm}$ using a spectrophotometer. Effectiveness of the method was demonstrated using Benomyl.

\section{Conclusion}

The proposed bioassay has the advantage of being suitable to test small amount of compounds, reducing required laboratory space and therefore being suitable for testing a great amount of sources with several replications. This is especially advantageous for testing natural compounds from plant genetic resources collections, because of the large amount of 
sources available.

\section{Background}

Macrophomina phaseolina (Tassi) Goidanich is an important plant pathogenic fungus, causal agent of charcoal rot of more than 300 crop species. It is a soil borne fungus that causes damage by plugging or rotting of vascular tissue in roots and lower stems (Wyllie, 1989). This fungus attacks susceptible hosts under stress conditions such as high temperature and drought (Papavizas, 1960; Edmunds, 1964; Dhingra and Sinclair, 1978; Odvody and Dunkle, 1979). Microslerotia act as primary source of inoculum and persist up to three years in the soil (Dhingra and Sinclair, 1978) and nine years on stored seed (Gomes et al., 2002). Microsclerotia germination is affected by oxygen and carbon dioxide concentration (Wyllie et al., 1984), temperature, and water tension (Viana and de Souza, 2002). Charcoal rot is controlled, as the other diseases, by means of cultural practices, development of resistant varieties, and application of synthetic or natural pesticides. To obtain natural pesticides as well as to develop efficiently resistant cultivars, it is necessary to identify sources of biologically active compounds with antifungal properties. Natural compounds are a huge source of chemical diversity (Verpoorte, 1998) which could be used as active compounds in plant disease control. Traditional bioassays methods have been successful to identify biologically active compounds against M. phaseolina from algae (Mahakhant et al., 1998), bacteria (Bhatia et al., 2003; Gohel et al., 2004), fungi (Gallardo et al., 2006) and plants (Saxena and Mathela, 1996; Dwivedi and Singh, 1998; Ghosh, 2006). These traditional methods need large amounts of natural extracts and, therefore, they are not suitable for managing several treatments with several replications, conditions which are necessary for an efficient and effective screening of natural products against $M$. phaseolina. The aim of the present study was to develop a rapid and little-format bioassay adequate for evaluating the effect of small amount of novel compounds, from a large amount of sources, on the growth of 
Macrophomina phaseolina.

\section{Results}

Fungus growth in Petri dishes

No differences in growth were observed between the media with or without pieces of filter paper, therefore the data within each medium were combined for growth analysis. After $60 \mathrm{~h}$ of incubation, fungus covered the complete area of modified PDA ( $4 \%$ agar) petri dishes incubated at $35^{\circ} \mathrm{C}$ for both isolates. Analysis of variance revealed significant differences $(\mathrm{P}<0.05)$ in growth among media and between incubation temperatures, but not for isolates and interactions; therefore Figure 1 displays only the variables which presented significant effect on fungus growth. Comparison within the same medium varying incubation temperature showed faster fungus growth at $35^{\circ} \mathrm{C}$ than at $25^{\circ} \mathrm{C}$.

\section{Microsclerotia production}

Microsclerotia production showed a significant interaction $(\mathrm{P}<0.01)$ for Isolate $\mathrm{x}$ Incubation temperature x Medium. Table 1 displays effect of these factors on number of microsclerotia produced. For both isolates the largest microsclerotia production was reached on modified PDA (4 \% agar) and two pieces of filter paper, but at different incubation temperatures. SNA medium, with and without pieces of filter paper, was not suitable for producing large amount of microsclerotia. Venezuelan isolate microsclerotia production was enhanced by the placing of 2 pieces of filter paper on modified PDA ( $4 \%$ of agar) incubated at $25^{\circ} \mathrm{C}$, on PDA at both temperatures, and on SNA at $35^{\circ} \mathrm{C}$; whereas for DSMZ isolate this occurred for modified PDA (4 \% agar) at both incubation temperatures, and PDA at $35^{\circ} \mathrm{C}$. 


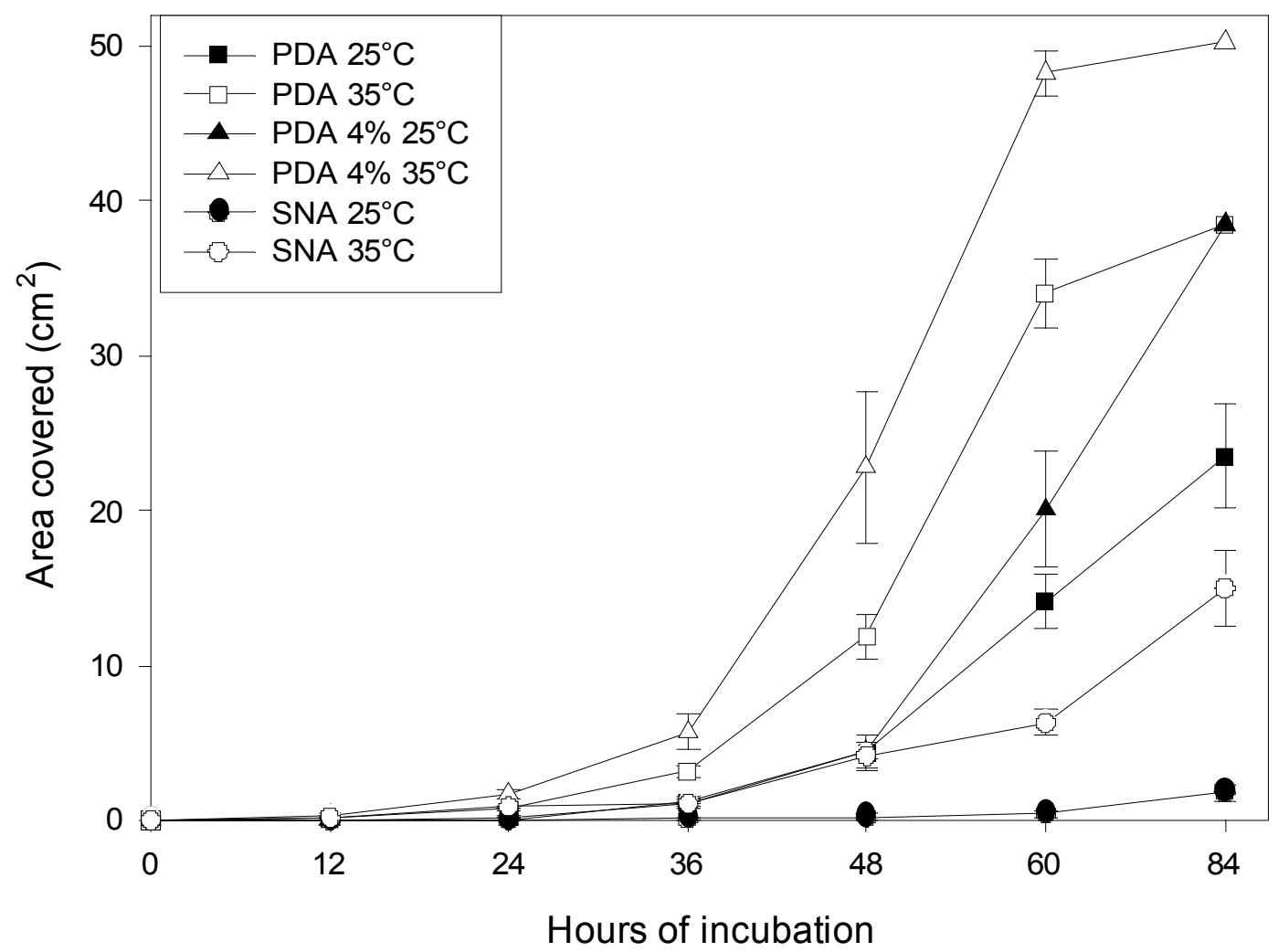

Figure 1. Growth (mean \pm S.E.) of M. phaseolina on 32 petri dishes averaged on 2 isolates and 2 independent experiments, varying temperature of incubation and culture medium.

Table 1. Number of microsclerotia per petri dish (20 $\mathrm{ml}$ of medium) for two isolates of $M$. phaseolina in six culture media (PDA4+FP is modified PDA ( $4 \%$ of agar) and two pieces of filter paper, PDA4 is modified PDA (4 \% of agar), PDA+FP is normal PDA and two pieces of filter paper, PDA is normal PDA, SNA+FP is low-nutrient agar medium and two pieces of filter paper, and SNA is low-nutrient agar medium) and two temperatures of incubation

\begin{tabular}{|c|c|c|c|c|c|c|c|c|c|c|c|c|}
\hline & \multicolumn{6}{|c|}{$25^{\circ} \mathrm{C}$} & \multicolumn{6}{|c|}{$35^{\circ} \mathrm{C}$} \\
\hline & PDA4+FP & PDA4 & $\mathrm{PDA}+\mathrm{FP}$ & PDA & $\begin{array}{l}\text { SNA+F } \\
\text { P }\end{array}$ & SNA & PDA4+FP & PDA4 & $\mathrm{PDA}+\mathrm{FP}$ & PDA & $\mathrm{SNA}+\mathrm{FP}$ & SNA \\
\hline $\begin{array}{l}\text { Isolate } \\
\text { DSMZ }\end{array}$ & $10975 \mathrm{c}^{1} \mathrm{~B}^{2}$ & $6975 \mathrm{~dB}$ & $4750 \mathrm{efB}$ & $11400 \mathrm{cB}$ & $725 \mathrm{hB}$ & $1800 \mathrm{hA}$ & $16750 \mathrm{aA}$ & $14475 \mathrm{bA}$ & $6075 \mathrm{deB}$ & $2000 . \mathrm{hB}$ & $3775 \mathrm{fgB}$ & $2050 \mathrm{ghA}$ \\
\hline $\begin{array}{l}\text { Isolate } \\
\text { VZLA }\end{array}$ & 33775 aA & $20125 \mathrm{cA}$ & $31150 \mathrm{aA}$ & $25575 \mathrm{bA}$ & $4050 \mathrm{fA}$ & $3150 \mathrm{fA}$ & $17450 \mathrm{cdA}$ & $15463 \mathrm{dA}$ & $24600 \mathrm{bA}$ & $15850 \mathrm{dA}$ & $8250 \mathrm{eA}$ & $1850 \mathrm{fA}$ \\
\hline
\end{tabular}

${ }^{1}$ Treatments within each isolate followed by the same lower case letter are not significant different $(\mathrm{P}<0.01)$ according to Tukey test

2 Treatments within each culture medium followed by the same capital letter are not significant different $(\mathrm{P}<0.01)$ according to Tukey test

Measuring fungus growth in 96-wells microplates 
Measuring fungus growth in 96-wells microplates

Progress of the growth was observable during the complete experiment. MTT assay was carried out at $120 \mathrm{~h}$ of incubation. Correlation of values of optical density in the well without addition of MTT at 120 hours, and with addition of MTT at this time after formazan was dissolved, was highly significant $(\mathrm{P}<0.01)$. Linear regression resulted also highly significant, giving the equation $O D$ using $M T T=1.68+0.72 \times O D$ without $M T T \quad\left(\mathrm{R}^{2}=0.08\right.$, fitting the constant) or $O D$ using $M T T=3.09 \times O D$ without $M T T\left(\mathrm{R}^{2}=0.88\right.$, forcing the regression line through the origin).

Fungus growth in 96-well microplates

Fungus growth from microsclerotia displayed a highly significant interaction $(\mathrm{P}<0.01)$ among Isolate $\mathrm{x}$ Temperature $\mathrm{x}$ Time, and Microsclerotia concentration x Isolate. The greatest growth was reached at $35^{\circ} \mathrm{C}$ for both isolates (Figure 2). The most suitable concentration for both isolates was 20 microsclerotia per well in a total volume of $40 \mu \mathrm{L}$ (500 microsclerotia per ml) (Figure 3). After $120 \mathrm{~h}$ of incubation growth of both isolates was slower in PDB+sorbitol from 0.55 molal than in only PDB or PDB+sorbitol 0.06 or 0.14 molal (Figure 4). Any of the tested sorbitol concentration stimulated fungus growth.

Fungus growth in presence of Benomyl

Toxicity of Benomyl was recorded at $2.5 \mu \mathrm{g} \mathrm{ml}^{-1}$ for DSMZ isolate and at $10 \mu \mathrm{g} \mathrm{ml}^{-1}$ for Venezuelan isolate. Different growth rates at the same concentration caused a significant interaction $(\mathrm{P}<0.01)$ for Isolate $\mathrm{x}$ Concentration of Benomyl $\mathrm{x}$ Time of incubation (Figure 5). Growth was completely inhibited for both isolates from $25 \mu \mathrm{g} \mathrm{ml}^{-1}$. DSMZ isolate did not showed growth inhibition at $1 \mu \mathrm{g} \mathrm{m} \mathrm{m}^{-1}$. Venezuelan isolate showed stimulatory effect on growth rather than inhibition at $1,2.5$ and $5 \mu \mathrm{g} \mathrm{ml}^{-1}$. 


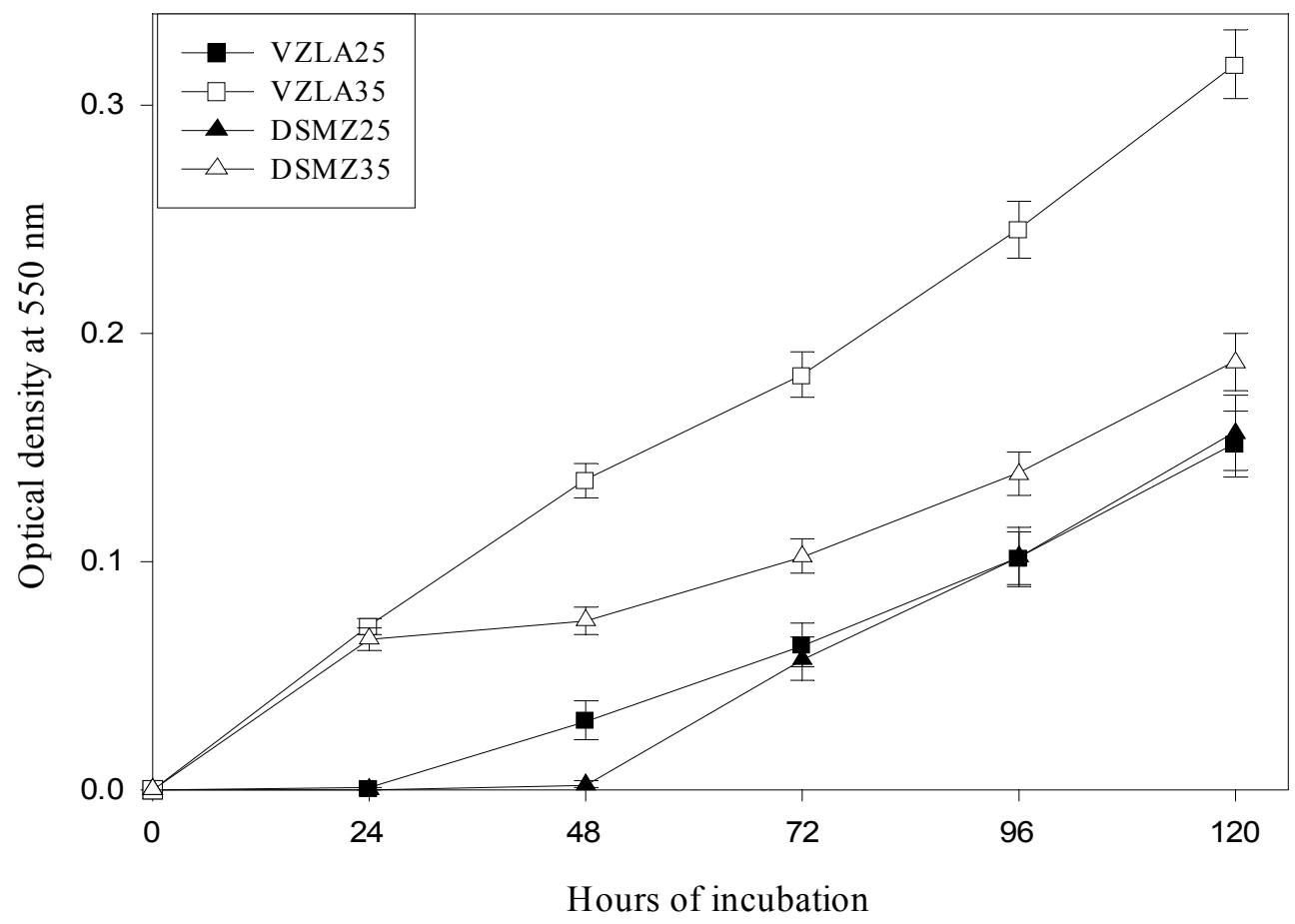

Figure 2. Growth (mean \pm S.E.) of M. phaseolina in 96-well microplates from microsclerotia, averaged on 3 microsclerotia concentration and 2 independent experiments, varying temperature of incubation and isolate

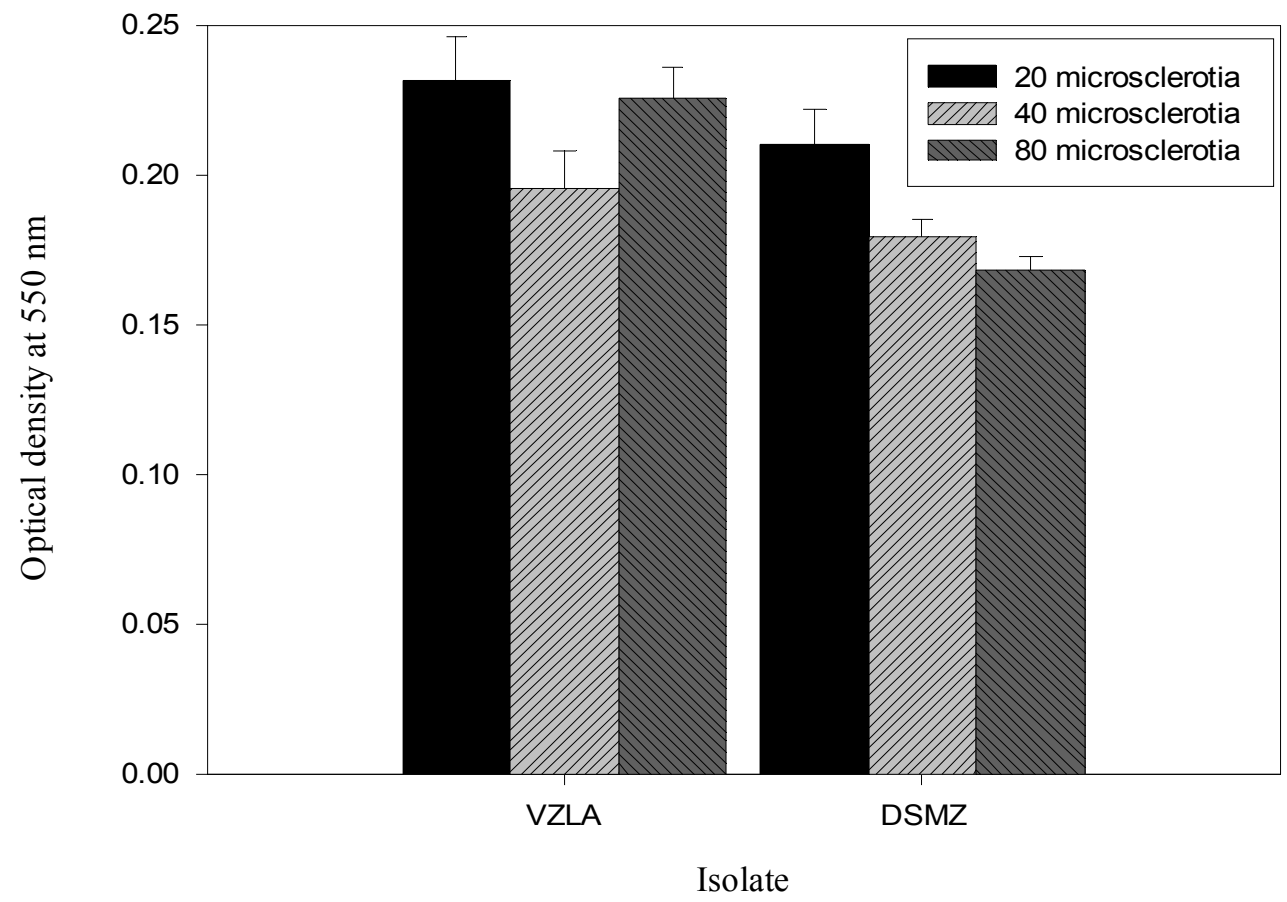

Figure 3. Effect of microsclerotia concentration on fungus growth in 96-well microplate in two isolates 


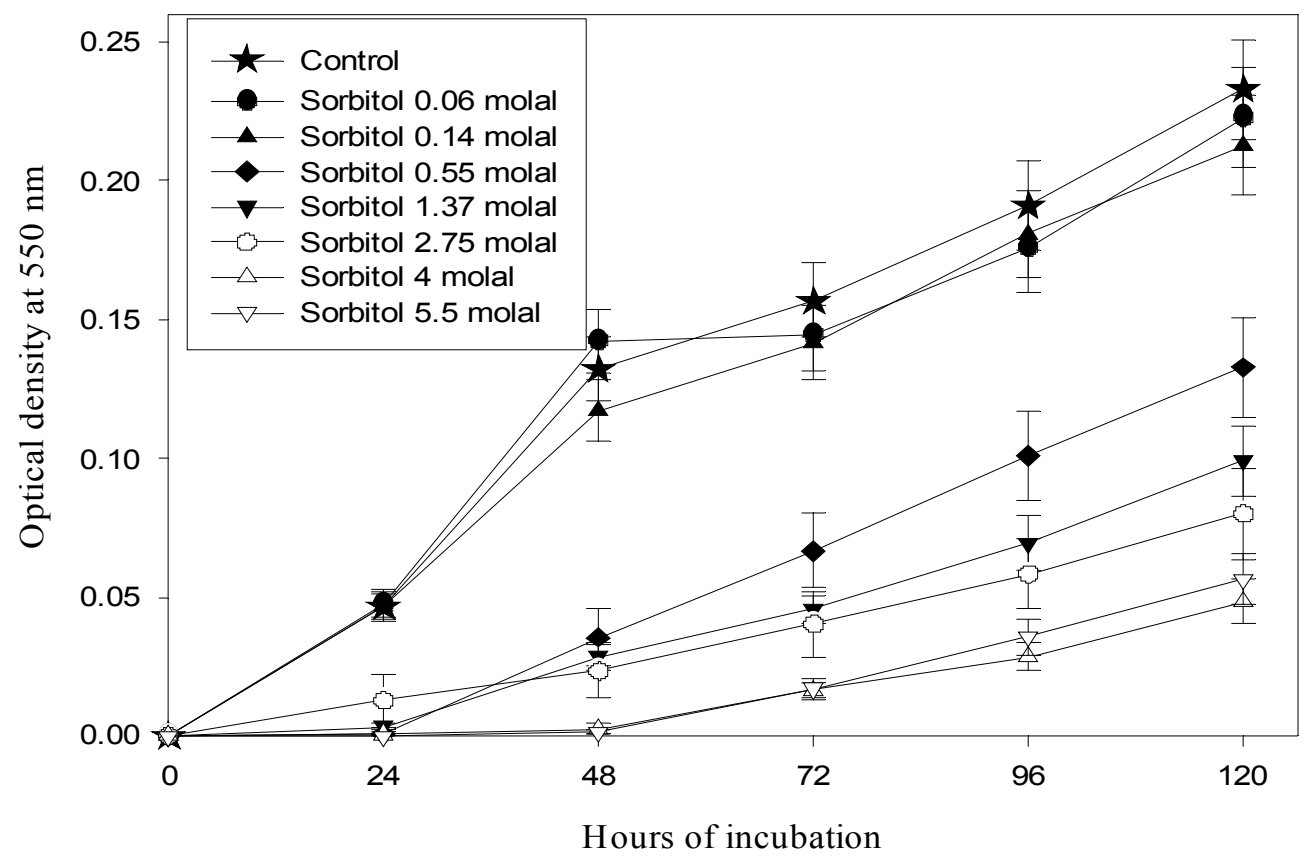

Figure 4. Growth (mean \pm S.E.) of $M$. phaseolina in 96-well microplates from microsclerotia, using PDB + different concentration of sorbitol as medium

\section{Discussion}

The best conditions for growing $M$. phaseolina have not been reported, and it has been cultured by tradition on PDA; however PDA (4\% agar w/v) resulted in faster growth than PDA both $25^{\circ} \mathrm{C}$ and $35^{\circ} \mathrm{C}$. The fungus grew faster at $35^{\circ} \mathrm{C}$ than at $25^{\circ} \mathrm{C}$ for all the media evaluated. Ahmed and Ahmed (1969) reported faster growth at $32^{\circ} \mathrm{C}$ than at room temperature $\left(25-32^{\circ} \mathrm{C}\right)$; these results in vitro support the general idea about increase of the disease caused by M. phaseolina on the field at high temperatures.

Optimal incubation temperature for microsclerotia production depended on the isolate, but addition of pieces of filter paper on modified PDA enhanced production both on the two isolates and the two temperatures of incubation tested. Addition of pieces of filter paper is a 

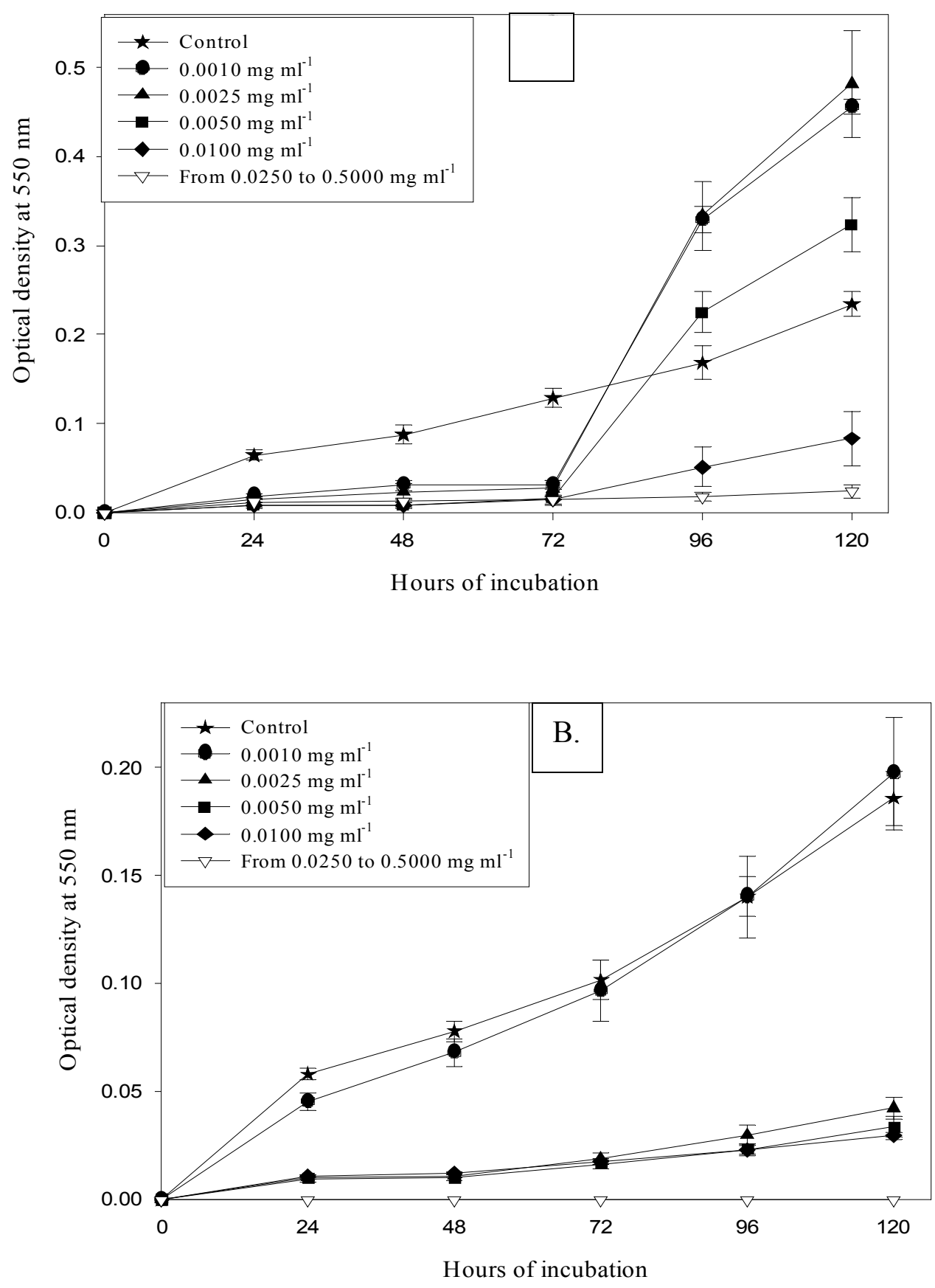

Figure 5. Growth (mean \pm S.E.) of two isolates of $M$. phaseolina at different concentration of Benomyl. A. Isolated from Venezuelan soil sample. B. From DSMZ (German Collection of Microorganisms and Cell Cultures)

common procedure to enhance conidia production on genus Fusarium (Nirenberg, 1990). Modified PDA has already been reported as suitable medium for microsclerotia production 
for 4 Venezuelan isolates, resulting up to 12000 microsclerotia per petri dish after 15 days of growth (Simosa and Delgado, 1991); amount of microsclerotia obtained in the present work under similar growth conditions was similar.

Rather than evaluating microsclerotia germination (Souza 2002, Pratt 2006), we monitored fungal growth initiated by germinated microsclerotia. Highly significant correlation between the two methods to monitor fungus growth indicates that they are measuring it with the same accuracy. Measure of optical density as result of MTT addition gives a final report of cell concentration, but its use interrupt the experiment and it is not possible to get several readings from the same well. On the contrary, changes in turbidity of the wells caused by fungus growth can be monitored at any time, without affecting the experiment, therefore it is possible to know how is the growth dynamics of the fungus in a simple well.

Temperature has been considered as critical aspect of microsclerotia germination of $M$. phaseolina. Our results are similar to those reported by Viana and de Souza (2002), who observed a percentage of microsclerotia germination larger at incubation temperatures of 27 , 30,33 and $36^{\circ} \mathrm{C}$ than at $24^{\circ} \mathrm{C}$. Use of solutions is easier than use of soils for evaluating effect of water tension on micro-organism, but the component matric potential is not taken into account. Adebayo and Harris (1971) reported that osmotic potential simulate adequately total water potential in the soil when fungal growth is evaluated. Inhibitory effects on fungus growth rather than stimulatory effect was found increasing osmotic potential, however, range of osmotic potential tested was not accurately measured. Cervantes-Garcia et al. (2003) found growth inhibition of the fungus because of three osmotic potential sources $(\mathrm{NaCl}, \mathrm{KCl}$ and sucrose) as well. Shokes et al. (1977) found a maximal mycelial growth at $30^{\circ} \mathrm{C}$ and -17 bars, observing reduced growth above and below this water potential. They also observed some growth after $50 \mathrm{~h}$ at -38 bars. Olaya and Abawi (1996) reported not significant differences in microsclerotia germination after 2 days of incubation between $-320(3.2$ bars $)$ and $-4760 \mathrm{~J} \mathrm{~kg}^{-}$ ${ }^{1}$ (47.6 bars). All this results, including the ours, indicate that it is not neither necessary nor 
adequate to add some solute to the growth medium for increasing osmotic potential and microsclerotia germination.

M. phaseolina growth in presence of Benomyl demonstrated feasibility of the bioassay format proposed to test antifungal compounds. Effect of very small amounts of the fungicide on fungus growth was identified. The 96-well microplate format bioassay was able to differentiate growth behaviour through the time between the two isolates. The manner of monitoring the growth allows inferring about possible detoxification of Venezuelan isolate after 72 hours, therefore it becomes able to use the fungicide in low concentration as nutrient. A bioassay for testing effect of novel compounds on growth of Macrophomina phaseolina was established using two isolates. Obtaining of microsclerotia should be achieved in modified PDA (4 \% agar) because of a faster fungus growth and higher amount of microsclerotia obtained. To test novel compounds, they are dissolved in ethanol $80 \%$ and placed in 96-well microplate, waiting until total evaporation of the solvent. After that, 20 microsclerotia suspended in $40 \mu \mathrm{L}$ of PDB are placed in each well and microplate is incubated at $35^{\circ} \mathrm{C}$. Fungus growth is monitored at any time measuring changes in the turbidity in the wells using a spectrophotometer at $550 \mathrm{~nm}$. Required volumes of the compounds to test are very small, for instance, whether the extraction of the compound was achieved with $1 \mathrm{~g}$ of fresh weight in $5 \mathrm{ml}$ of solvent $(200 \mathrm{mg}$ in $1 \mathrm{ml})$, adding in the well $200 \mu \mathrm{L}$ is equivalent to add $40 \mathrm{mg}$. Effect of high concentration as $1 \mathrm{~g}$ of fresh weight in $1 \mathrm{ml}$ of solution is performed whether $40 \mu \mathrm{L}$ of microsclerotia suspension is added, as proposed.

The format of the proposed bioassay has the advantage of being suitable to test small amount of compounds, reducing required laboratory space and therefore being suitable for testing a great amount of sources with several replications. This is especially advantageous for testing natural compounds from plant genetic resources collections. 


\section{Conclusions}

Large amount of microsclerotia is produced on petri dishes containing PDA 4\% agar plus two pieces of filter paper at $35^{\circ} \mathrm{C}$. Changes in optical density in wells of microplates through the time, as consequence of mycelia formation from microsclerotia in PDB medium, is a good indicator of fungus growth. Effect of small amount of novel compounds on fungus growth can be tested.

\section{Material and methods}

Fungus isolates

Isolate 62743 from DSMZ (German Collection of Microorganisms and Cell Cultures) and another one isolated from a 14-days diseased sesame plantlet grown on a soil sample from Portuguesa state, Venezuela (soil cultivated for at least 15 years with rotation maize-sesame) were used in this study. Both were maintained on petri dishes containing $20 \mathrm{ml}$ of potato dextrose agar medium (PDA) ( $2.4 \% \mathrm{w} / \mathrm{v}$ powder of potato dextrose broth from Duchefa Biochemie, The Netherlands, and $1.5 \% \mathrm{w} / \mathrm{v}$ agar from AppliChem, Germany) at $25^{\circ} \mathrm{C}$ and subcultured each 15 days.

Fungus growth and microsclerotia production

Twelve treatments consisting in three media with and without two pieces of sterile filter paper $(1 \times 1 \mathrm{~cm})$ in the center of the petri dish incubated at $25^{\circ} \mathrm{C}$ and $35^{\circ} \mathrm{C}$ were tested to determine the most favourable conditions for fungus growth and to produce microsclerotia. Media used were PDA, modified PDA (4\% agar w/v) and synthetic low-nutrient agar medium (SNA) (based on w/v $0.1 \% \mathrm{KH}_{2} \mathrm{PO} 4,0.1 \% \mathrm{KNO}_{3}, 0.05 \% \mathrm{MgSO}_{4} \cdot 7 \mathrm{H}_{2} \mathrm{O}, 0.05 \% \mathrm{KCl}, 0.02 \%$ glucose, $0.02 \%$ sucrose, and $2 \%$ agar). Each treatment was replicated four times for each isolate. Inoculation in each petri dish was carried out transferring one 5-mm agar plug from the 
leading edge of a 5-day-old colony in PDA onto the center of a new petri dish. Growth was recorded every 12 hours measuring the area covered by the fungus. After 15 days the content of each petri dish was blended in a mixer for 3 minutes helped by $30 \mathrm{ml}$ of sterile water. The resulting suspension was passed through a $200-\mu \mathrm{m}$ sieve to eliminate aggregates of microsclerotia and microsclerotia larger than $200 \mu \mathrm{m}$. To count microsclerotia per volume unit, the suspension was centrifuged at $12000 \mathrm{G}$ for $10 \mathrm{~min}$, the water was discarded, and microsclerotia and medium were resuspended in $10 \mathrm{ml}$ sterile water. Eight $50-\mu \mathrm{L}$ aliquots from the content of each petri dish were taken, to count microsclerotia on filter paper under microscope; number of microsclerotia per petri dish was calculated.

Fungus growth from different microsclerotia concentration in 96-well microplates Microsclerotia were obtained as above explained, but they were resuspended in potato dextrose broth (PDB) (Duchefa Biochemie, The Netherlands) instead water. Content of a petri dish without fungus followed the same procedure as control. Dilutions were carried out to get three microsclerotia concentrations (i.e. 80,40 and 20 in 40 microliters). Forty microliters of suspension containing the microsclerotia, replicated six times for each concentration, were pippeted into wells of a 96-well flat bottom microplate. To avoid evaporation, wells in the margins of the microplate were filled with $300 \mu \mathrm{L}$ of sterile water, lid was placed and incubation was achieved in a closed plastic box with $1 \mathrm{~cm}$ of sheet of sterile water, which acted as moist chamber. Incubations temperatures tested were $25^{\circ} \mathrm{C}$ and $35^{\circ} \mathrm{C}$ for both isolates. Growth of the fungus in the wells was monitored every 12 hours taking readings of optical density at $550 \mathrm{~nm}$ for 5 days with a microplate spectrophotometer $\mu$ Quant Universal $\left(\right.$ BioTek $^{\mathrm{R}}$ Instruments, Inc. USA) and visualized by the software KC4 v.3.4 (BioTek ${ }^{\mathrm{R}}$ Instruments, Inc. USA). Changes in optical density were consequence of changes in turbidity of the wells caused by mycelia formation. All values were corrected for optical density at time zero. At day 5, $10 \mu \mathrm{L}$ of MTT (3-(4,5-dimethylthiazol-2-yl)-2,5-diphenyltetrazolium 
bromide) $\left(5 \mathrm{mg} \mathrm{ml}^{-1}\right)$ were added in each well and microplates incubated at $35^{\circ} \mathrm{C}$ for 4 hours in shaking. Water-insoluble formazan formed by mitochondrial action, was dissolved adding $50 \mu \mathrm{L}$ of DMSO and incubation of the microplates took place at $35^{\circ} \mathrm{C}$ for 10 minutes. Optical density in each well was determined at $550 \mathrm{~nm}$.

Effect of osmotic potential on fungus growth

To evaluate effect of osmotic potential on fungus growth from microsclerotia in 96-well microplates, it proceeded as above explained but sorbitol was added to PDB in concentrations of $0.06,0.14,0.55,1.37,2.75,4.0$ and 5.5 molal. Each concentration was replicated 6 times and control was microsclerotia in PDB without sorbitol. This experiment was carried out for both isolates. Optical density at $550 \mathrm{~nm}$ was monitored each 12 hours for 7 days.

Fungus growth in presence of antifungal compounds

To determine the effect of antifungal compounds on M. phaseolina in 96-well microplates using little amount of the compound, $50 \mathrm{mg}$ Benomyl $60 \mathrm{WC}$ (Hoechst, Germany) were dissolved in $100 \mathrm{ml}$ ethanol $80 \%$ to get a solution of $500 \mu \mathrm{g} \mathrm{ml}^{-1}$. From this solution, others concentrations were prepared: $250 \mu \mathrm{g} \mathrm{ml}^{-1}, 100 \mu \mathrm{g} \mathrm{ml}^{-1}, 50 \mu \mathrm{g} \mathrm{ml}^{-1}, 25 \mu \mathrm{g} \mathrm{ml}^{-1}, 10 \mu \mathrm{g} \mathrm{ml}^{-1}, 5$ $\mu \mathrm{g} \mathrm{ml}^{-1}, 2.5 \mu \mathrm{g} \mathrm{ml}^{-1}$ and $1 \mu \mathrm{g} \mathrm{ml}^{-1}$. Forty microlitres of each concentration were placed into a six wells of a 96-well microplate. Control consisted in $40 \mu \mathrm{L}$ of ethanol $80 \%$ in six wells as well. After total evaporation (about 4 hours), 20 microsclerotia were placed in the microplate as already explained. Four microplates were prepared in the same way, 2 incubated at $25^{\circ} \mathrm{C}(1$ for each of both isolates) and the other two at $35^{\circ} \mathrm{C}$ ( 1 for each of both isolates). Fungus growth was recorded for 7 days by measuring optical density in each well every $12 \mathrm{~h}$ at 550 $\mathrm{nm}$.

\section{Statistical analysis}

All the experiment were replicated twice in different dates. Because of similar error variance, based on Bartlet's test, between pairs of experiments (i.e. fungus growth in Petri dishes, 
microsclerotia production, fungus growth from different microsclerotia concentration, effect of osmotic potential on fungus growth, and fungus growth in presence of antifungal compounds), the data were combined for each type of experiments. They were analyzed as factorial design. Comparisons among treatments was achieved by Tukey test $(\mathrm{P}<0.01)$. To compare both estimations of fungus growth (with and without use of MTT) correlation and regression analysis were achieved between last reading at day 5 without adding MTT and readings after adding MTT. Statistical calculations were carried out using Statistix 8 (Analytical Software, USA).

Authors' constribution

HL participated in the design of the study, performed the experiments and data analysis, and participated in interpretation of results and manuscript preparation. PK participated in the design of the study, interpretation of results, and discussion for preparing the manuscript.

\section{Acknowledgments}

This work was supported by the Programme Alban (European Union Programme of High Level Scholarships for Latin America, Identification Number E03D13301VE), International $\mathrm{PhD}$ program for Agricultural Sciences in Göttingen University (IPAG), and Universidad Centroccidental Lisandro Alvarado. 


\section{Literature cited}

Adebayo, A. and R. Harris. 1971. Fungal growth responses to osmotic as compared to matric water potential. Soil Sci. Soc. Am. Proc. 35:465-469

Ahmed, N. and Q. Ahmed. 1969. Physiologic specialisation in Macrophomina phaseoli (Maubl.) Ashby., causing stem rot of jute, Corchorus species. Mycopathologia 39:129-138

Bathia, S., S. Bhatia, R. Dubey and D. Maheshwari. 2003. Antagonistic effect of fluorescent pseudomonas against Macrophomina phaseolina that causes charcoal rot of groundnut. Indian J. Exp. Biol. 41:1442-1446

Cervantes-García, D., J. Padilla-Ramírez, J. Simpson and N. Mayek-Pérez. 2003. Osmotic potential effects on in vitro growth, morphology and pathogenicity of Macrophomina phaseolina. J. Phytopathology 151:456-462

Dhingra, O. and J.Sinclair. 1978. Biology and pathology of Macrophomina phaseolina. Impresa Universitaria. Universidade Federal de Viçosa. Minas Gerais, Brasil.

Dwivedi, S. and K. Singh. 1998. Fungitoxicity of some higher plant products against Macrophomina phaseolina (Tassi) Goid. Flavour and Fragance Journal 13:397-399

Edmuns, L.K. 1964. Combined relation of plant maturity, temperature and soil moisture to charcoal stalk rot development in grain sorghun. Phytopathology 54:514-517

Gallardo, G., M. Butler, M. Gallo, M Rodriguez, M. Eberlin and G. Cabrera. 2006. Antimicrobial metabolites produced by an intertidal Acremonium furcatum. Phytochemistry 67:2403-2410

Ghosh, M. 2006. Antifungal properties of haem peroxidase from Acorus calamus. Annals of Botany 98:1145-1153

Gohel, V., T. Chaudary, P. Vyas and H. Chhatpar. 2004. Isolation and identification of marine chitinolytic bacteria and their potential in antifungal biocontrol. Indian J. Exp. Biol. 42:715720

Gomes, M., M. Wetzel and A. Rodrigues. 2002. Ocorrência e sobrevivência de fungos em germoplasma-semente de gergelim (Sesamum indicum L.). Boletim de Pesquisa e Desenvolvimento (ISSN 1676-1340). Empresa Brasileira de Pesquisa Agropecuaria. Brasilia

Mahakhant, A., P. Padugnwong, V. Arunpairojana and P. Atthasampunna. 1998. Control of the plant pathogenic fungus Macrophomina phaseolina in mung bean by a microalgal extract. Phycological Research 46:3-7

Nirenberg, H. 1990. Recent advances in the taxonomy of Fusarium. Stud. Mycol. 32:91-101

Odvody, G.N. and Dunkle L.D. 1979. Charcoal stalk rot of sorghum: effect of environment on host-parasite relations. Phytopathology 69:250-254

Olaya, G. and G. Abawi. 1996. Effect of water potential on mycelial growth and on production and germination of sclerotia of Macrophomina phaseolina. Plant Dis. 80:1347- 
Papavizas, G. 1960. Some factors affecting survival of sclerotia of Macrophomina phaseolina in soil. Soil Biol. Biochem. 9: 337-341

Pratt, R. 2006. A direct observation technique for evaluating sclerotium germination by Macrophomina phaseolina and effects of biocontrol materials on survival of sclerotia in soil. Mycopathologia 162:121-131

Saxena, J. and C. Mathela. 1996. Antifungal activity of new compounds from Nepeta leucophylla and Nepeta clarkei. Applied and Environmental Microbiology 62:702-704

Shokes, F., S. Lyda and W. Jordan. 1977. Effect of water potential on the growth and survival of Macrophomina phaseolina. Phytopathology 67:239-241

Simosa, N. And M. Delgado. 1991. Virulence of four isolates of Macrophomina phaseolina on four sesame (Sesamum indicum) cultivars. Fitopatología Venezolana 4: 20-23

Veerporte, R. 1998. Exploration of nature's chemodiversity: the role of secondary metabolites as leads in drug development. Drug Discovery Today 3:232-238

Viana, F. and N. de Souza. 2002. Efeito da interação temperatura-tensão de água sobre a germinação de microescleródios de Macrophomina phaseolina. Fitopatologia Brasileira 27:268-272

Wyllie, T., S. Gangopadhyay, W. Teague and R. Blanchar. 1984. Germination and production of Macrophomina phaseolina microsclerotia as affected by oxygen and carbon dioxide concentration. Plant and Soil 81:195-201

Wyllie, T. 1989. Charcoal rot. In: Compendium of soybean diseases. $3^{\text {rd }}$. ed. J.B. Sinclair and P.A. Backman eds. Pages 30-33. American Phytopathological Society, St. Paul, MN 


\title{
Chapter 6. Effect of plant extracts from a sesame (Sesamum indicum L.) germplasm collection on growth of the soil-borne fungi affecting Venezuelan sesame production
}

Hernán Laurentin and Petr Karlovsky

\begin{abstract}
Obtaining of natural fungicide as well as an efficient development of resistant cultivars require identification of plants containing compounds with antifungal properties. The aim of the present study was to explore the diversity of a sesame germplasm collection based on effect of extracts of root, stem, leaf and seed on growth of the soil-borne fungi Macrophomina phaseolina and Fusarium oxysporum f. sp. sesami. Ethanolic extracts from 51 sesame accessions of different geographical origin were dried into 96-wells microplates and reproductive structures of the fungi in adequate culture media were placed in the wells. Changes in the optical density at $550 \mathrm{~nm}$ in the wells content as consequence of the growth of the fungi was measured. Effect of extracts on the two fungi species was highly variable, depending on the accession which served as source. Strong inhibitory effect for root, stem and leaf extracts on growth of $M$. phaseolina, and for root, stem and seed extracts on growth of $F$. oxysporum was identified. Grouping of accessions according biological activity on both fungi showed a trend to separate Indian accessions from African accessions. Diethylether fraction from ethanolic extracts from the accessions with most inhibitory and stimulatory effect on fungi growth for all the organs, showed a stronger inhibitory effect than crude extract. Equivalent weight to $15 \mathrm{mg}$ of fresh weight for all the organs were able to inhibit the growth of both fungi. Intra-species screening sesame, resulted in identification of accessions possessing promising compounds with potential in control of fungal diseases.
\end{abstract}




\section{Introduction}

Sesame shares historical and economic value because it is one of the most ancient crops (Bedigian and Harlan, 1986), and important for tropical and subtropical areas (Ashri 1998). Sesame yield is negatively affected by biotic stress such as insect pest (Aponte et al., 1997; Laurentin and Pereira, 2001), phytoplasma (Al-Sakeiti et al., 2005), virus (Sreenivasulu et al., 1994), bacterias (Nyanapah et al., 1995; Shivas et al., 1996) and fungi (Pathirana, 1992; Ojiambo et al., 2000; El-Bramawy and Wahid, 2006). Venezuelan sesame production has been affected mainly by shoot webber (Antigastra catalaunalis Duponchel) (Aponte et al., 1997), whitefly (Bemisia tabaci Gennadius) (Laurentin and Pereira, 2001) and soil-borne fungi such as Macrophomina phaseolina, Fusarium oxysporum f.sp. sesami (Pineda and Avila, 1988) and Phytophthora parasitica (Malaguti, 1953; Mazzani, 1999). Sesame is used as rotation crop after corn (Zea mays L.) during the dry season in the western llanos of Portuguesa State, Venezuela. This crop obtains its water needs from moisture retained by clay soils during past raining season. Environmental conditions of sesame production in Venezuela favour root rot disease caused by M. phaseolina because of the pathogen increases its severity when it is under high temperature and low wet in the soil (Papavizas, 1960; Dhingra and Sinclair, 1978). Infection of $F$. oxysporum is currently associated to M. phaseolina (Dhingra and Sinclair, 1978; Pineda and Avila, 1988). Effect of root rot caused by M. phaseolina on sesame yield has been considered the most important among the fungal diseases because of the large incidence frequency (Pineda et al., 1985). Economic losses in Venezuela have been estimated in about 30\% (Pineda, 1987). Differential response of sesame cultivars to isolates of M. phaseolina (Pineda et al., 1985; Simoza and Delgado, 1991; Rajput et al., 1998; Avila, 2003) or F. oxysporum (El-Shazly et al., 1999) has been frequently found .

Diseases caused by soil-borne fungi are controlled by means of cultural practices, biological control, development of resistant varieties, and application of synthetic or natural fungicides. To obtain natural fungicide as well as to develop efficiently resistant cultivars, it is necessary 
to identify sources of biologically active compounds with antifungal properties.

The aim of the present study was to explore the diversity of a sesame germplasm collection based on effect of extracts of root, stem, leaf and seed on growth of the soil-borne fungi Macrophomina phaseolina, and Fusarium oxysporum f.sp. sesami.

\section{Material and methods}

Plant material

Seeds originating from 31 sesame accessions from Centro Nacional de Investigaciones Agropecuarias (CENIAP) Germplasm Bank (Venezuela) (Table 1) and 20 commercial cultivars or elite lines from Venezuelan sesame breeding programs (Table 2) were grown in the greenhouse. From about 80 fourteen-days-old plantlets, roots and stems were bulked separately, and $3 \mathrm{~g}$ of each one were frozen in liquid nitrogen, ground in a mortar and subjected to extraction with a mixture of $80 \%$ ethanol (HPLC grade, Roth, Germany) and $20 \%$ water for 16 hours with stirring $(100 \mathrm{rpm})$ under exclusion of oxygen. The same procedure of extraction was followed for $3 \mathrm{~g}$ of leaves and $3 \mathrm{~g}$ of seeds from 3 plants per each accession. The liquid phase was filtered through $0.45 \mu \mathrm{m}$ filters and kept at $-20^{\circ} \mathrm{C}$ until bioassays.

\section{Fungus isolates}

Isolate 62743 of Macrophomina phaseolina was obtained from DSMZ (German Collection of Microorganisms and Cell Cultures). Isolate 141118 of Fusarium oxysporum f.sp. sesami was obtained from CABI Genetic Resource Collection (CABI Biosciences, Egham, UK). Fungi were maintained on petri dishes containing $20 \mathrm{ml}$ of potato dextrose agar medium (PDA) $(2.4 \% \mathrm{w} / \mathrm{v}$ powder of potato dextrose broth from Duchefa Biochemie, The Netherlands, and $1.5 \% \mathrm{w} / \mathrm{v}$ agar from AppliChem, Germany) at $25^{\circ} \mathrm{C}$ and subcultured each 15 days. 
Table 1. Accessions from Centro Nacional de Investigaciones Agropecuarias (CENIAP) Germplasm Bank (Venezuela) used as source of root, stem, leaf and seed ethanolic extracts

\begin{tabular}{|c|c|c|c|}
\hline Accessions & Country of Origin & Working code & Diversity Centre \\
\hline $93-2223$ & India & India 1 & India \\
\hline $95-465$ & India & India 2 & India \\
\hline $95-469$ & India & India 3 & India \\
\hline $95-447$ & India & India 4 & India \\
\hline 89-007 & India & India 5 & India \\
\hline $93-2224$ & India & India 6 & India \\
\hline $95-464$ & India & India 7 & India \\
\hline $92-2918$ & India & India 8 & India \\
\hline $92-3091$ & Korea & Korea 1 & China-Japan-Korea \\
\hline $92-3093$ & Korea & Korea 2 & China-Japan-Korea \\
\hline $92-2922$ & Turkey & Turkey & Western Asia \\
\hline $92-3125$ & Greece & Greece & Western Asia \\
\hline $93-2022$ & Syria & Syria & Western Asia \\
\hline $93-2113$ & Sudan & Sudan 1 & Africa \\
\hline $92-310$ & Sudan & Sudan 2 & Africa \\
\hline $93-2010$ & Ethiopia & Ethiopia & Africa \\
\hline $95-272$ & Unknown & Africa 1 & Africa \\
\hline $92-2872$ & Sudan & Sudan 3 & Africa \\
\hline $93-2105$ & Sudan & Sudan 4 & Africa \\
\hline $95-234$ & Unknown & Africa 2 & Africa \\
\hline $95-223$ & Unknown & Africa 3 & Africa \\
\hline $92-2856$ & Japan & Japan 1 & China-Japan-Korea \\
\hline $92-3030$ & Japan & Japan 2 & China-Japan-Korea \\
\hline $92-3031$ & Japan & Japan 3 & China-Japan-Korea \\
\hline $92-3108$ & China & China 1 & China-Japan-Korea \\
\hline $95-383$ & China & China 2 & China-Japan-Korea \\
\hline $92-2930$ & Tadjikistan & Tadjikistan 1 & Central Asia \\
\hline $92-2947$ & Uzbekistan & Uzbekistan & Central Asia \\
\hline $92-2952$ & Turkmenistan & Turkmenistan 1 & Central Asia \\
\hline $92-2950$ & Tadjikistan & Tadjikistan 2 & Central Asia \\
\hline $92-2917$ & Tadjikistan & Tadjikistan 3 & Central Asia \\
\hline
\end{tabular}


Table 2. Commercial cultivars and experimental lines used as source of root, stem, leaf and seed ethanolic extracts

\begin{tabular}{cc}
\hline $\begin{array}{c}\text { Commercial cultivars or experimental } \\
\text { lines }\end{array}$ & Origin \\
\hline
\end{tabular}

Chino Amarillo

Felicidad

Venezuela 51

Acarigua

$\mathrm{UCV}-1$

Maporal

Caripucha

Inamar

Glauca

$43 \times 32,19 \times 10$

UCLA1

Fonucla

UCV-3
Introduced from Mexico. Unknown origin

Introduced from Mexico. Unknown origin

Originated by individual selection from the offspring of a Chinese accession (Langham and Rodriguez, 1946).

A high performance F2 plant obtained by the cross between a cultivar from Nicaragua and a cultivar from China, was crossed with the cultivar Venezuela 51, its offspring was selected for three seasons, resulting in "Acarigua" (Mazzani, 1952)

Elite line selected from first cycle of recurrent selection toward high yield. The original population was obtained by cross, one to one, among 50 exotic accessions (Laurentin et al., 2000).

Selected from cultivar Arapatol, from Ethiopia (Mazzani et al., 1973).

Unknown

Individual selection from the offspring from the same Acarigua's parents (Mazzani, 1953).

Unknown origin.

Selected lines from second cycle of recurrent selection toward high yield, under heavy whitefly infestation. The original population was obtained by cross, one to one, among 50 exotic accessions (Laurentin et al., 2000)

Individual selection from a USA accession (Montilla and Teran, 1996). Unknown origin

Selection from cultivar Arawaca (Montilla and Cedeño, 1991). Arawaca was obtained by selection of the mixture of $496 \mathrm{~F} 1$ plants obtained from crosses among 32 cultivars without reciprocal. The origin of these cultivars is unknown.

Individual selection from Arawaca (unpublished data).

UCLA37-1, UCLA65, UCLA83, UCLA90, Elite lines from Universidad Centrooccidental Lisandro UCLA249, UCLA295 Alvarado Sesame Breeding Program. Unknown origin 


\section{Bioassays}

Effect of plant extracts from 51 sesame accessions on growth of each fungus species was evaluated in 96-well flat bottom microplates. Microsclerotia for M. phaseolina, or conidia for F. oxysporum were used as initial propagule. They were obtained and prepared as reported by Laurentin and Karlovsky (Chapter 5), and Nirenberg (1990) respectively. Two-hundred microlitres of the treatments (root, stem, leaf and seed ethanolic extracts) equivalent to $40 \mathrm{mg}$ of fresh weight were placed separately in wells of a 96-well microplate, and $200 \mu \mathrm{L}$ of ethanol $80 \%$ in the wells which acted as control. All the treatments, including the control, had 4 replications. After air drying in a clean bench, $40 \mu \mathrm{L}$ of PDB (potato dextrose broth, Duchefa Biochemie, The Netherlands) containing 20 microsclerotia (from M. phaseolina) or 1500 conidia (from $F$. oxysporum) were added in each well. Final concentration of extracts tested was $1 \mathrm{~g}$ of fresh weight per $\mathrm{ml}$. To avoid evaporation in the microplate, wells in the margins were filled in with $300 \mu \mathrm{L}$ of sterile water and microplate covered with a lid. Incubation was carried out at $34^{\circ} \mathrm{C}$ (M. phaseolina) or $25^{\circ} \mathrm{C}(F$. oxysporum $)$ in dark in a plastic box with $1 \mathrm{~cm}$ of sheet of sterile water. Fungi growth was monitored every 12 hours taking readings of optical density at $550 \mathrm{~nm}$ for 5 days with a microplate spectrophotometer $\mu$ Quant Universal $\left(\right.$ BioTek $^{\mathrm{R}}$ Instruments, Inc. USA) and visualized by the software KC4 v.3.4 (BioTek ${ }^{\mathrm{R}}$ Instruments, Inc. USA). Changes in optical density were consequence of changes in turbidity of the wells caused by mycelia formation. All values were corrected for optical density at time zero. All the experiments were replicated twice, using independent ethanolic extracts. The data were combined over the two experiments. Differences in optical density at $24,48,72,96$ and 120 hours as consequences of fungus growth in presence of plant extracts were determined by analysis of variance in a factorial design. Differences in optical density of wells in which plant extracts were added as compared to the control were determined by orthogonal contrast $(\mathrm{P}<0.05)$ at 120 hours for M. phaseolina and 96 hours for $F$. oxysporum $\mathrm{f}$. sp. sesami to identify plant extracts with stimulatory effect(higher optical density than 
control) or inhibitory effect (lower optical density than control) on fungus growth. Analysis of variance and orthogonal contrasts were calculated using Statistix 8 (Analytical Software, USA).

\section{Principal component analysis}

Ordination of the 51 accessions based on the effect of plant extracts on fungi growth was achieved by means of a principal component analysis, using average values of optical density over the 2 experiments ( 4 replications per experiment) for each extract within each accession at 24, 48, 72 and 96 hours of incubation. Mantel test (500 permutations) was performed between the obtained matrix (for the 31 accessions from the germplasm bank ) and the matrix of geographical distance of the origin among the same accessions. Also Mantel test was performed between the obtained matrix and previous matrices obtained for the same genotypes based on AFLP (Laurentin and Karlovsky, 2006; Laurentin and Karlovsky, 2007). These analyses were done with NTSYSpc v. 2.11T (Applied Biostatistics, NY, USA).

\section{Fractionation ethanolic extracts}

The ethanolic extract with most inhibitory effect and the one with most stimulatory effect on the growth of each fungus species were partitioned into two fractions based on polarity. Two $\mathrm{ml}$ of ethanolic extracts were mixed with $2 \mathrm{ml}$ of sterile water to increase its density. Four $\mathrm{ml}$ of diethylether were added to the mixture ethanol:water, the suspension was shacked and two discernible phases appeared after few minutes. Superior phase (diethylether phase) was pippeted into a test tube, dried, and resuspended in $2 \mathrm{ml}$ of a mixture of $80 \%$ ethanol (HPLC grade, Roth, Germany) and $20 \%$ water. The two resulting fractions (i.e. diethylether fraction and remained ethanolic fraction), and the original ethanolic extract, were bioassayed for each fungus species as above explained, keeping the equivalent concentration of $1 \mathrm{~g}$ of fresh weight per $\mathrm{ml}(200 \mu \mathrm{L}$ for diethylether fraction and $400 \mu \mathrm{L}$ for the remained ethanolic extract 
after diethylether extraction). The extract with the most inhibitory effect for each plant organ on the growth of each fungus species, was diluted with ethanol $80 \%$ at $50,25,12.5,6.25$, 3.13, 1.56 and $0.5 \%(\mathrm{v} / \mathrm{v})$ and they were bioassayed as already explained, to test final concentrations equivalent to $1000 \mathrm{mg}$ up to $5.20 \mathrm{mg}$ of fresh weight. To compare the antifungal power of dilutions of ether extract to effect of commercial fungicides, one treatment was added to microplates, consisting in $0.02 \mathrm{mg} \mathrm{ml}^{-1}$ of Benomyl. This treatment was applied as the other treatments: $200 \mu \mathrm{L}$ of the suspension of Benomyl in ethanol $80 \%$ were placed in wells of the microplate. After total drying, $40 \mu \mathrm{L}$ of medium containing either microsclerotia or conidia were added, to get a final concentration of $0.1 \mathrm{mg} \mathrm{ml}^{-1}$ of Benomyl. Tukey test $(\mathrm{P}<0.05)$ at $120 \mathrm{~h}($ M. phaseolina $)$ or 96 hours $(F$. oxysporum f. sp. sesami) was used to compare optical density of the treatments (control, dilutions and Benomyl) by means of Statistix 8 (Analytical Software, USA).

\section{Results}

Effect of ethanolic extract of sesame root, stem, leaf, and seed on growth of the two fungi species was highly variable, depending on the accession which served as source (Table 3). Stimulatory effect was more common than inhibitory effect. Growth of M. phaseolina was inhibited by 18 extracts ( 8 from root, 3 from stem and 7 from leaf) and stimulated by 80 extracts ( 8 from root, 17 from stem, 19 from leaf and 36 from seed) (Figure 1). Growth of $F$. oxysporum f. sp. sesami was inhibited by 39 extracts (13 from root, 2 from stem and 24 from seed) and stimulated by 92 extracts ( 3 from root, 35 from stem, 48 from leaf and 6 from seed) (Figure 2). Any accession provided inhibitory effect for all the organs tested, however root and leaf extracts from accession Greece inhibited growth of $M$. phaseolina, whereas growth of F. oxysporum f. sp. sesami was inhibited by root and seed extracts from accessions India 1, Korea 1, Greece, Sudan 3, UCLA1, UCLA65, and stem and seed extract from accession Inamar. Three of the accessions which provided root extract with inhibition effect 
Table 3. Sesame accessions with plant extracts affecting changes in optical density as consequence of mycelia growth

\begin{tabular}{|c|c|c|c|}
\hline Fungus & Organ & $\begin{array}{l}\text { Lower optical density than } \\
\text { control }(\mathrm{P}<0.05)\end{array}$ & $\begin{array}{l}\text { Higher optical density than control } \\
(\mathrm{P}<0.05)\end{array}$ \\
\hline \multirow[t]{4}{*}{$\begin{array}{l}\text { M. } \\
\text { phaseolina }\end{array}$} & Root & $\begin{array}{l}\text { India 7, Korea 1, Greece, Sudan 4, } \\
\text { Africa 2, Japan 1, UCV-1, } \\
\text { Caripucha }\end{array}$ & $\begin{array}{l}\text { Korea 2, Syria, Sudan 2, Sudan 3, } \\
\text { Tadjikistan 1, Uzbekistan, Turkmenistan 1, } \\
\text { UCLA249 }\end{array}$ \\
\hline & Stem & Africa1, Africa3, UCLA1 & $\begin{array}{l}\text { India 8, Korea 1, Korea 2, Turkey, Greece, } \\
\text { Syria, Sudan 1, Sudan 2, Ethiopia, China 2, } \\
\text { Tadjikistan 1, Uzbekistan, Turkmenistan 1, } \\
\text { Tadjikistan 2, UCV-1, UCLA83, UCV-3 }\end{array}$ \\
\hline & Leaf & $\begin{array}{l}\text { India 3, India 4, India 8, Greece, } \\
\text { Turkey, Glauca, UCLA65 }\end{array}$ & $\begin{array}{l}\text { Africa 1, Sudan 4, Africa 2, Africa 3, Japan } \\
\text { 2, Japan 3, Tadjikistan 1, Turkmenistan 1, } \\
\text { Tadjikistan 2, Tadjikistan 3, Chino } \\
\text { Amarillo, Felicidad, Venezuela 51, } \\
\text { Acarigua, UCV-1, 43x32, UCLA249, } \\
\text { UCLA90, UCLA37-1 }\end{array}$ \\
\hline & Seed & None & $\begin{array}{l}\text { India 1, India 2, India 3, India 5, India 6, } \\
\text { India 7, Korea 2, Turkey, Syria, Sudan 1, } \\
\text { Sudan 2, Africa 1, Africa 2, Africa 3, Japan } \\
\text { 1, China 2, Uzbekistan, Turkmenistan 1, } \\
\text { Tadjikistan 2, Tadjikistan 3, Chino } \\
\text { Amarillo, Venezuela 51, Acarigua, UCV-1, } \\
\text { Maporal, Caripucha, Inamar, 19x10, } \\
\text { UCLA249, UCLA83, UCLA1, UCLA90, } \\
\text { UCLA295, Fonucla, UCLA65, UCV-3 }\end{array}$ \\
\hline \multirow[t]{4}{*}{$\begin{array}{l}\text { F. oxysporum } \\
\text { f.sp. sesami }\end{array}$} & Root & $\begin{array}{l}\text { India 1, India 6, India 7, Korea 1, } \\
\text { Greece, Sudan 3, Japan 1, China 2, } \\
\text { Venezuela 51, UCLA1, Fonucla, } \\
\text { UCLA65, UCV-3 }\end{array}$ & Africa 2, Africa 3, Tadjikistan 1 \\
\hline & Stem & Inamar, Glauca & $\begin{array}{l}\text { All the Indian, Korean, African and } \\
\text { Western Asia accessions, China 1, China 2, } \\
\text { Tadjikistan 1, Uzbekistan, Turkmenistan 1, } \\
\text { Turkmenistan 2, Tadjikistan 2, Venezuela } \\
\text { 51, UCV-1, Maporal, UCLA83, UCLA295, } \\
\text { UCLA37-1, UCV-3 }\end{array}$ \\
\hline & Leaf & None & $\begin{array}{l}\text { All except India 1, India 4, Greece and } \\
\text { UCLA-1 }\end{array}$ \\
\hline & Seed & $\begin{array}{l}\text { India 1, India 3, India 4, India 5, } \\
\text { India 8, Korea 1, Korea 2, Greece, } \\
\text { Syria, Africa 1, Sudan 3, Sudan 4, } \\
\text { Africa 3, Japan 3, Tadjikistan 1, } \\
\text { Uzbekistan, Felicidad, Acarigua, } \\
\text { Inamar, UCLA249, UCLA1, } \\
\text { UCLA90, UCLA37-1, UCLA65 }\end{array}$ & $\begin{array}{l}\text { Japan 1, Japan 2, Tadjikistan 3, Venezuela } \\
\text { 51, Caripucha, Fonucla }\end{array}$ \\
\hline
\end{tabular}



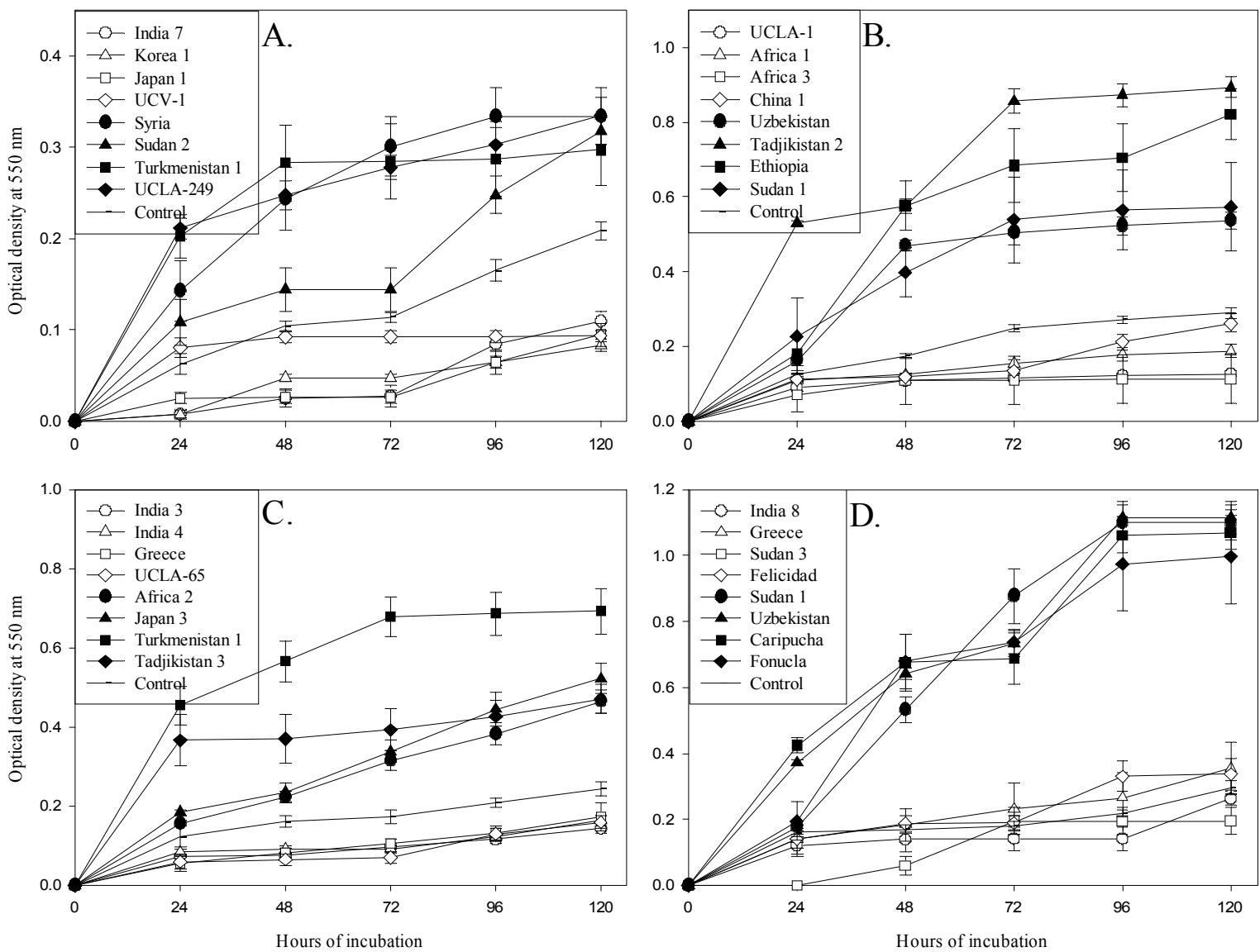

Figure 1. Changes in optical density (mean \pm standard error) as consequence of mycelia growth of M. phaseolina in presence of root (A.), stem (B.), leaf (C.) and seed (D.) extracts from sesame accessions. The four accessions with most inhibitory effect and the four with most stimulatory effect on fungus growth are presented.

on growth of M. phaseolina, provided also stem extracts with stimulatory effect, similar situation was observed for 9 accessions which provided root extracts with inhibitory effect on growth of F. oxysporum f. sp. sesami. Root extracts from accessions Korea 1, India 7, Greece and Japan 1 showed inhibitory effect on growth of both fungi. Extracts of seed had in average the highest stimulatory and the lowest inhibitory effect on growth of M. phaseolina, whereas this occurred for leaf extracts on growth of $F$. oxysporum f. sp. sesami, however inhibition until $48 \mathrm{~h}$ was observed for all the leaf extracts tested, following a fast growth as compared to growth in presence of extracts from other organs. Based on results from the orthogonal contrast, any relationship between geographical origin of accessions and inhibitory or 

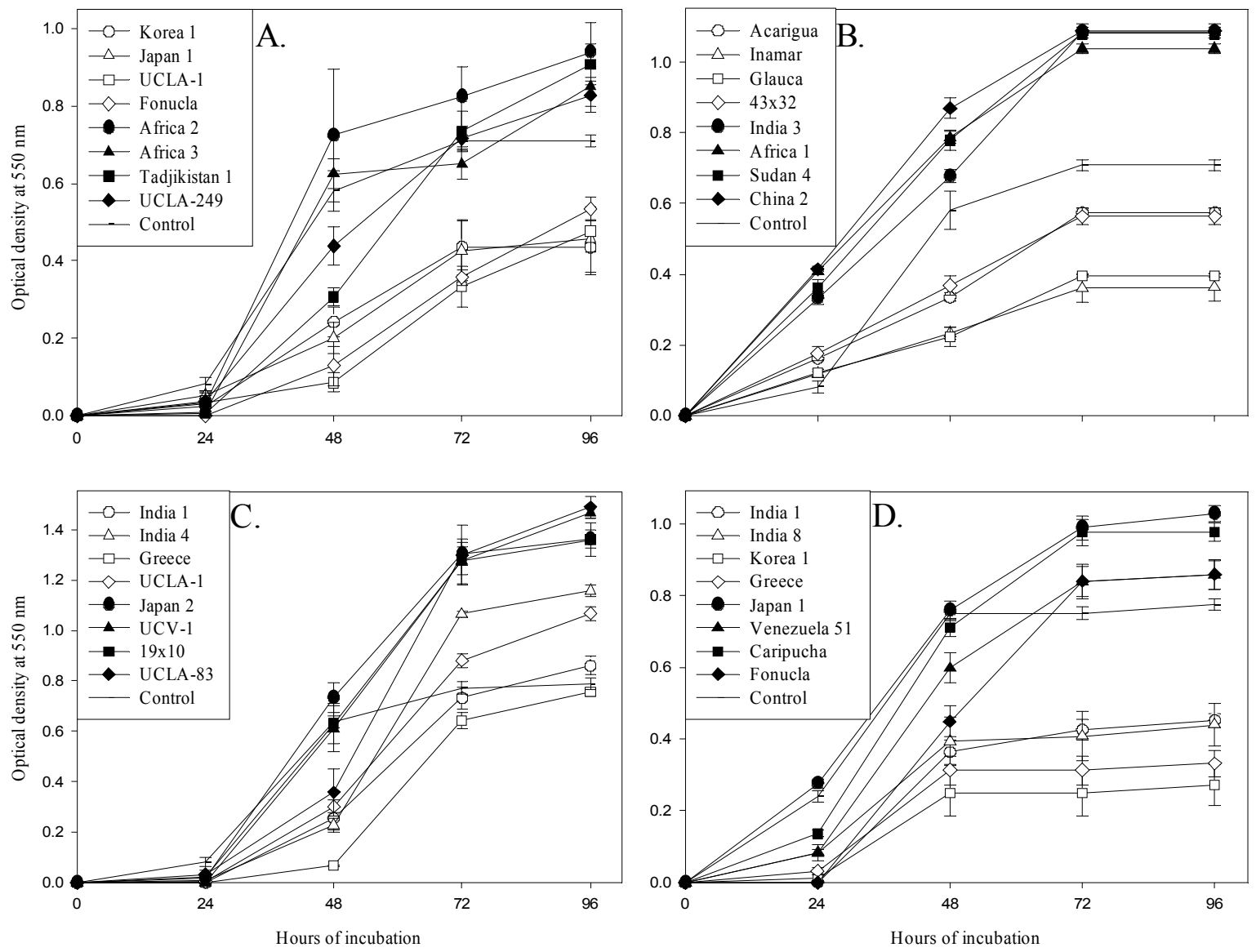

Figure 2. Changes in optical density (mean \pm standard error) as consequence of mycelia growth of $F$. oxysporum f.sp. sesami in presence of root (A.), stem (B.), leaf (C.) and seed (D.) extracts from sesame accessions. The four with most inhibitory effect and the four with most stimulatory effect on fungus growth are presented.

stimulatory effect of plant extracts on fungi growth was detected. The only trend was the presence of accessions from Central Asia in all the cases of stimulatory effect on growth of M. phaseolina and $F$. oxysporum $\mathrm{f}$. sp. sesami and the absence of these accessions in all the case of inhibition on fungi growth, except in effect of seed extracts on $M$. phaseolina. However, even when any of the correlation coefficient calculated by Mantel test resulted significant $(\mathrm{P}<0.05)$, principal component analysis was able to identify a trend between geographical origin of the accessions and biological activity of the plant extracts, grouping separately accessions from India, Africa and Central Asia (Figure 3). The variables most important to define the distribution of the accessions in the two-dimension space were the 
effect of leaf (first axis) and stem (second axis) on growth of both fungi (Table 4).

Diethylether extraction from ethanolic extract resulted to have a strong inhibitory effect on growth of both fungi (Figure 4 and 5) in almost all the cases. Optical density in presence of diethylether extracts resulted significant lower than the original ethanolic extract $(\mathrm{P}<0.01)$. This difference was not detected neither for diethylether extracts from stem of the accession whose ethanolic extract displayed more inhibitory effect on growth of $M$. phaseolina (UCLA1), nor for diethylether extracts from stem and seed of the accessions whose ethanolic extracts showed more inhibitory effect on growth of $F$. oxysporum (Inamar and Korea1 respectively). Remained ethanolic extract after extraction with diethylether resulted in higher optical density than ethanolic extracts $(\mathrm{P}<0.01)$ in five cases for M. phaseolina, and in only 2 cases for $F$. oxysporum, but it was never lower than the ethanolic extract. Tukey test of dilutions of the most inhibitory extracts resulted in conformation of four groups (Figures 6 and 7): control (with the highest optical density), dilutions of $0.50 \%$ and $1.56 \%$, dilutions of $3.13 \%$ up to $100 \%$ and Benomyl (with the lowest optical density). This grouping was different only for leaf extracts against $M$. phaseolina (three groups: control, dilutions $0.50 \%$ up to $3.13 \%$, and dilutions from $6.25 \%$ up to $100 \%$ in the same group of Benomyl) and stem extracts against $F$. oxysporum f. sp. sesami (three groups: control and dilutions of $0.50 \%$ and $1.56 \%$ in the same group, dilutions from $3.12 \%$ up to $100 \%$ in other group, and Benomyl conforming another group). 


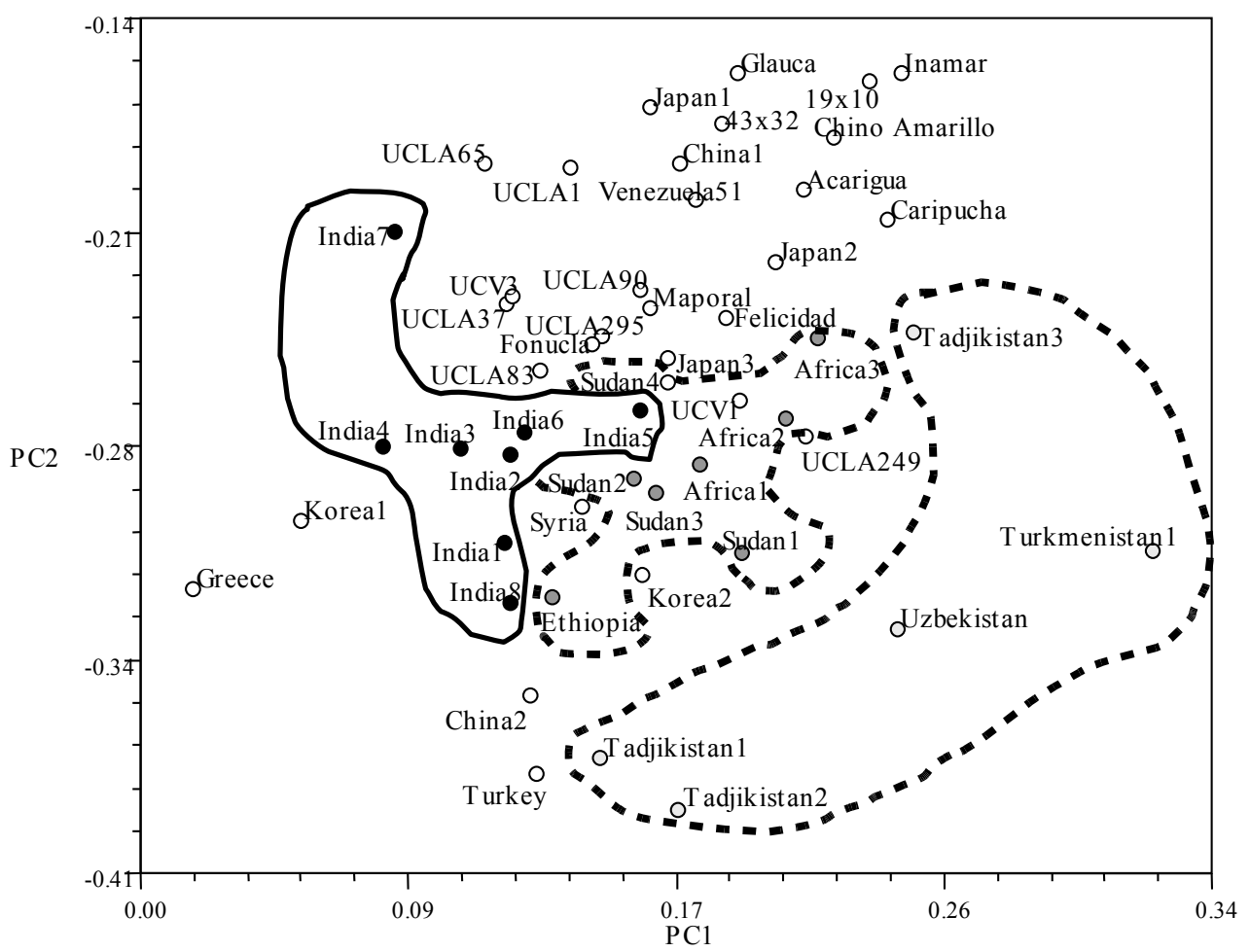

Figure 3. Biplot of principal component analysis based on effect of plant extracts of 51 sesame accessions on growth of Macrophomina phaseolina and Fusarium oxysporum f.sp. sesami

\section{Discussion}

Approximately 250,000-500,000 plant species exist, but only a few of these have been investigated for antimicrobial activity (De Lucca et al., 2005). Most of the studies searching antifungal compounds from plants focus on the inter-specific variability rather than intraspecific variability (e.g. Gata-Goncalves et al., 2003; Ghosh, 2006; Treyvaud Amiguet et al., 2006). The present study shows the importance of large screening within a species when antifungal activity from plants are being searched. Large within-species genetic variation has been originated by evolutionary forces, which can lead to differentiation at metabolite level 
Table 4. Eigenvectors of the first two axes of principal component analysis

PC1 PC2

Effect on $F$. oxysporum f.sp.sesami

\begin{tabular}{|c|c|c|}
\hline Leaf extract at $24 \mathrm{~h}$ & 0.5436 & 0.1611 \\
\hline Leaf extract at $48 \mathrm{~h}$ & 0.5778 & 0.1844 \\
\hline Leaf extract at $72 \mathrm{~h}$ & 0.2260 & 0.3286 \\
\hline Leaf extract at $96 \mathrm{~h}$ & 0.2015 & 0.3962 \\
\hline Root extract at $24 \mathrm{~h}$ & 0.2267 & 0.4385 \\
\hline Root extract at $48 \mathrm{~h}$ & 0.5349 & 0.0845 \\
\hline Root extract at $72 \mathrm{~h}$ & 0.4073 & -0.1417 \\
\hline Root extract at $96 \mathrm{~h}$ & 0.3978 & -0.2635 \\
\hline Seed extract at $24 \mathrm{~h}$ & 0.1540 & 0.3513 \\
\hline Seed extract at $48 \mathrm{~h}$ & 0.2389 & 0.0834 \\
\hline Seed extract at $72 \mathrm{~h}$ & 0.4132 & 0.3410 \\
\hline Seed extract at $96 \mathrm{~h}$ & 0.4421 & 0.3728 \\
\hline Stem extract at $24 \mathrm{~h}$ & -0.1589 & -0.6741 \\
\hline Stem extract at $48 \mathrm{~h}$ & -0.1748 & -0.6669 \\
\hline Stem extract at $72 \mathrm{~h}$ & -0.4467 & -0.6053 \\
\hline Stem extract at $96 \mathrm{~h}$ & -0.4689 & -0.5973 \\
\hline \multicolumn{3}{|l|}{ Effect on $M$. phaseolina } \\
\hline Leaf extract at $24 \mathrm{~h}$ & 0.8123 & -0.1899 \\
\hline Leaf extract at $48 \mathrm{~h}$ & 0.7982 & -0.2001 \\
\hline Leaf extract at $72 \mathrm{~h}$ & 0.7579 & -0.2093 \\
\hline Leaf extract at $96 \mathrm{~h}$ & 0.6918 & -0.0601 \\
\hline Root extract at $24 \mathrm{~h}$ & 0.5781 & -0.5418 \\
\hline Root extract at $48 \mathrm{~h}$ & 0.5703 & -0.5727 \\
\hline Root extract at $72 \mathrm{~h}$ & 0.5636 & -0.5397 \\
\hline Root extract at $96 \mathrm{~h}$ & 0.4063 & -0.609 \\
\hline Seed extract at $24 \mathrm{~h}$ & 0.481 & 0.0189 \\
\hline Seed extract at $48 \mathrm{~h}$ & 0.3339 & 0.0144 \\
\hline Seed extract at $72 \mathrm{~h}$ & 0.1934 & -0.1196 \\
\hline Seed extract at $96 \mathrm{~h}$ & 0.4145 & -0.0588 \\
\hline Stem extract at $24 \mathrm{~h}$ & -0.3649 & -0.3903 \\
\hline Stem extract at $48 \mathrm{~h}$ & -0.3032 & -0.7732 \\
\hline Stem extract at $72 \mathrm{~h}$ & -0.1115 & -0.8614 \\
\hline Stem extract at $96 \mathrm{~h}$ & -0.1628 & -0.8226 \\
\hline
\end{tabular}



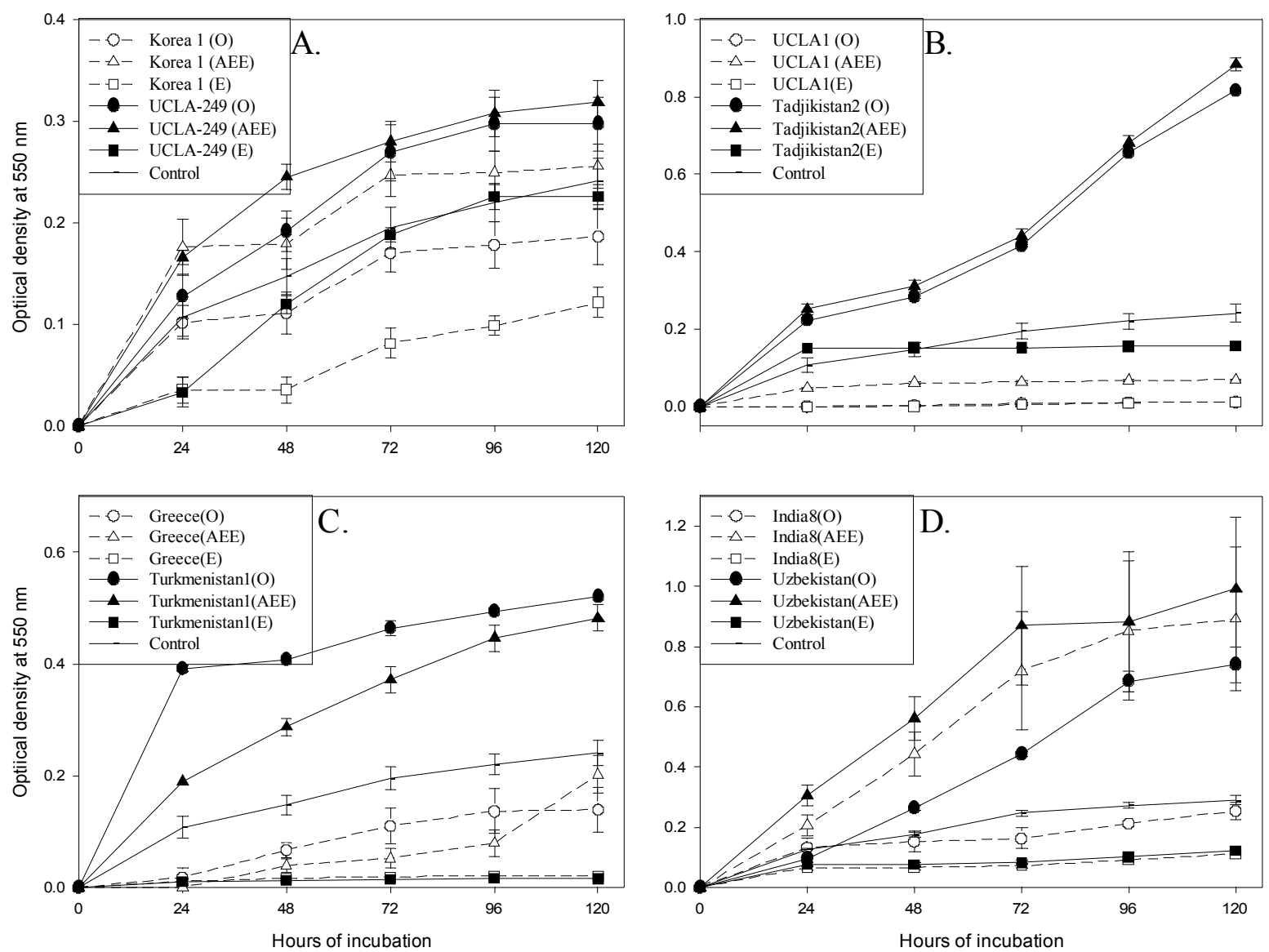

Figure 4. Changes in optical density as consequence of mycelia growth of M. phaseolina in presence of fractions of root (A), stem (B), leaf (C) and seed (D) ethanolic extracts from 2 sesame accessions: $\mathrm{O}$ is original ethanolic extract, AEE is ethanolic extract after extraction with ether, $\mathrm{E}$ is etheric extract.

and therefore, in the effect of plant extracts on fungi growth. Extreme response of fungi before plant extracts from different accessions of the same species can be observed, as in the present study: large stimulatory effect or strong growth inhibition. Fungi growth curves in presence of plant extracts were similar except for F. oxysporum f. sp. sesami on leaf extracts. Strong growth inhibition until 48 hours of incubation was rapidly overcome, suggesting a process of detoxification. Accessions such as Korea 1, India 7, Greece and Japan 1 

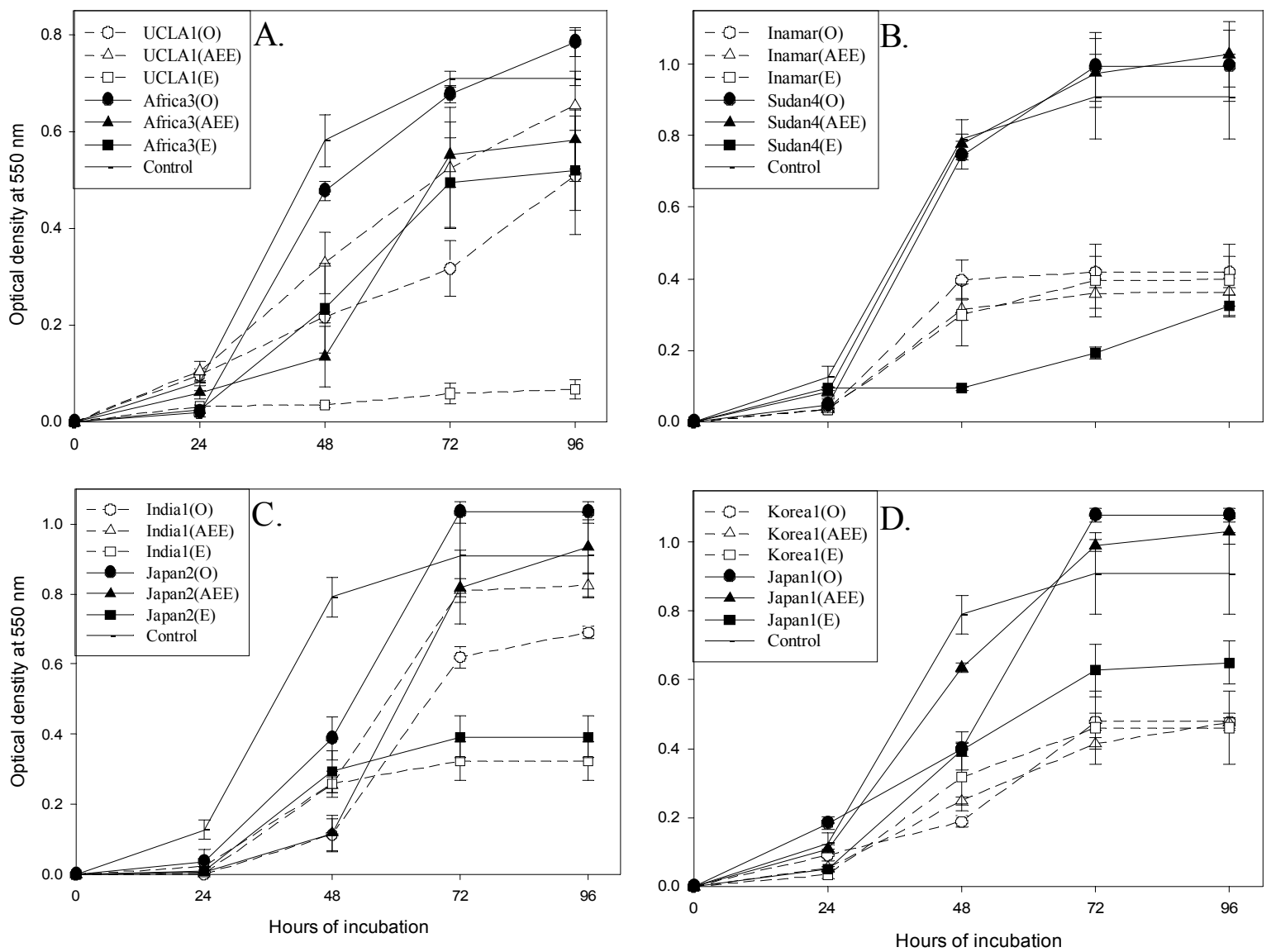

Figure 5. Changes in optical density as consequence of mycelia growth of $F$. oxysporum in presence of fractions of root (A), stem (B), leaf (C) and seed (D) ethanolic extracts from 2 sesame accessions: $\mathrm{O}$ is original ethanolic extract, $\mathrm{AEE}$ is ethanolic extract after extraction with ether, $\mathrm{E}$ is etheric extract.

have special importance for breeding because they have root compounds which inhibit growth of M. phaseolina and F. oxysporum f. sp. sesami, which are soil-borne fungi. These constitutive roots compounds, as well as stem compounds from accessions Africa 1, Africa 3, UCLA1 (against M. phaseolina) and Inamar and Glauca (against $F$. oxysporum f. sp. sesami), suppose to be related to a resistance response. Some sesame root compounds with antifungal properties such as naphthoquinone epoxide (Ogasawara et al., 1993), chlorosesamone (Hasan et al., 2000), hydroxisesamone and 2,3 epoxysesamone (Hasan et al., 2001) have been found 

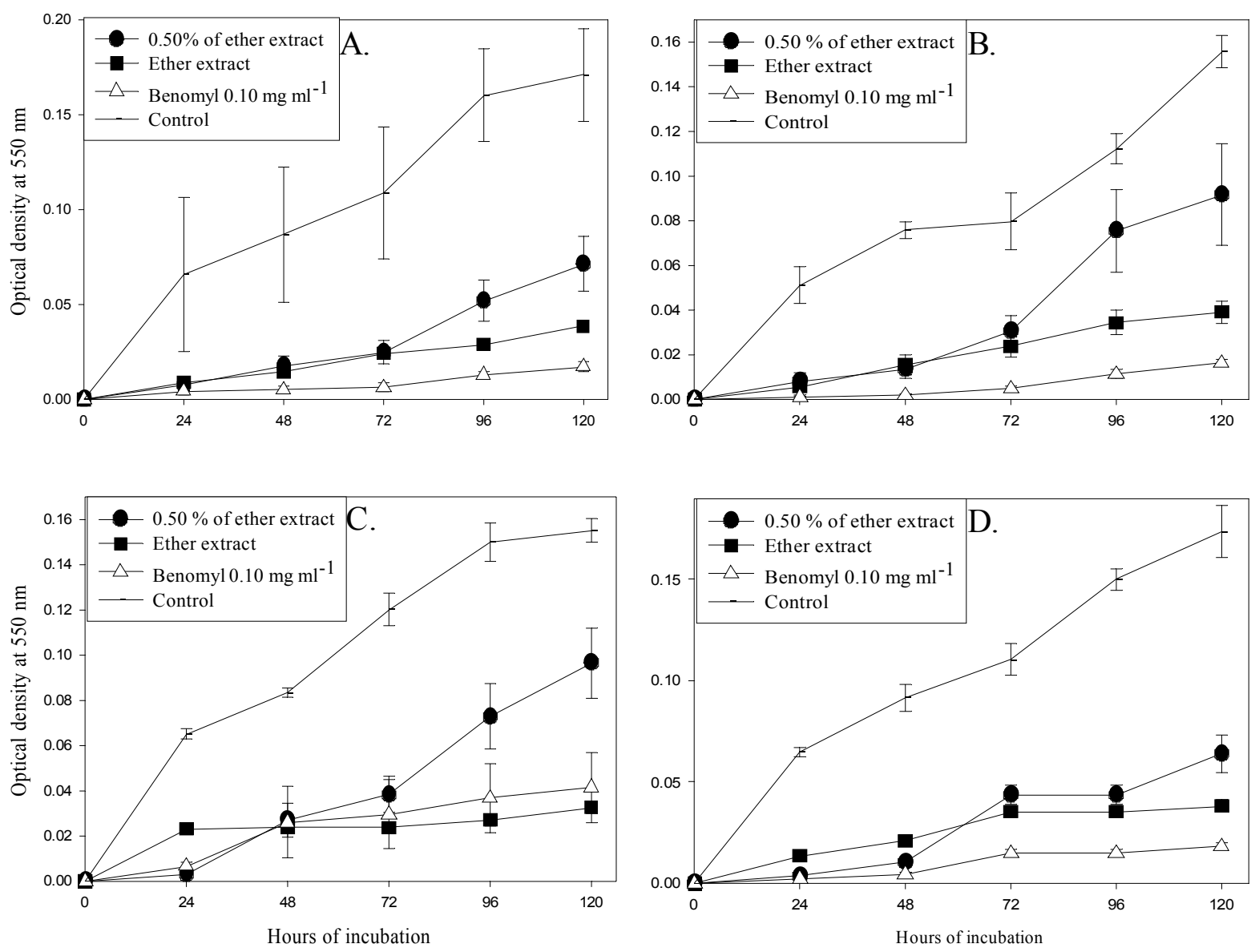

Figure 6. Changes in optical density (mean $\pm \mathrm{SE}$ ) as consequence of mycelia growth of $M$. phaseolina in presence of ether extract and $0.50 \%$ of ether extract from A. Roots of accession Korea 1. B. Stem of accession UCLA1. C. Leaf of accession Greece. D. Seed of accession India 8

in chloroform or ethyl acetate extracts. Sesame leaf extracts, even when they are not related with resistance response to soil-borne fungi, have been reported having antifungal activity, e.g. chloroform fraction against Leucocoprinus gongylophorus (Möller) (fungus cultivated by leaf-cutting ants of the species Atta sexdens rubropilosa Forel (Pagnoca et al., 1990). Sesamol, a major compound of refined sesame oil, of which promoter must be in the seed, has been reported as inhibitory to Fusarium moniliforme (Jacklin et al., 2000) and Macrophomina phaseolina (Brooker et al., 2000). Extracts from other plant species, such as Majorana 

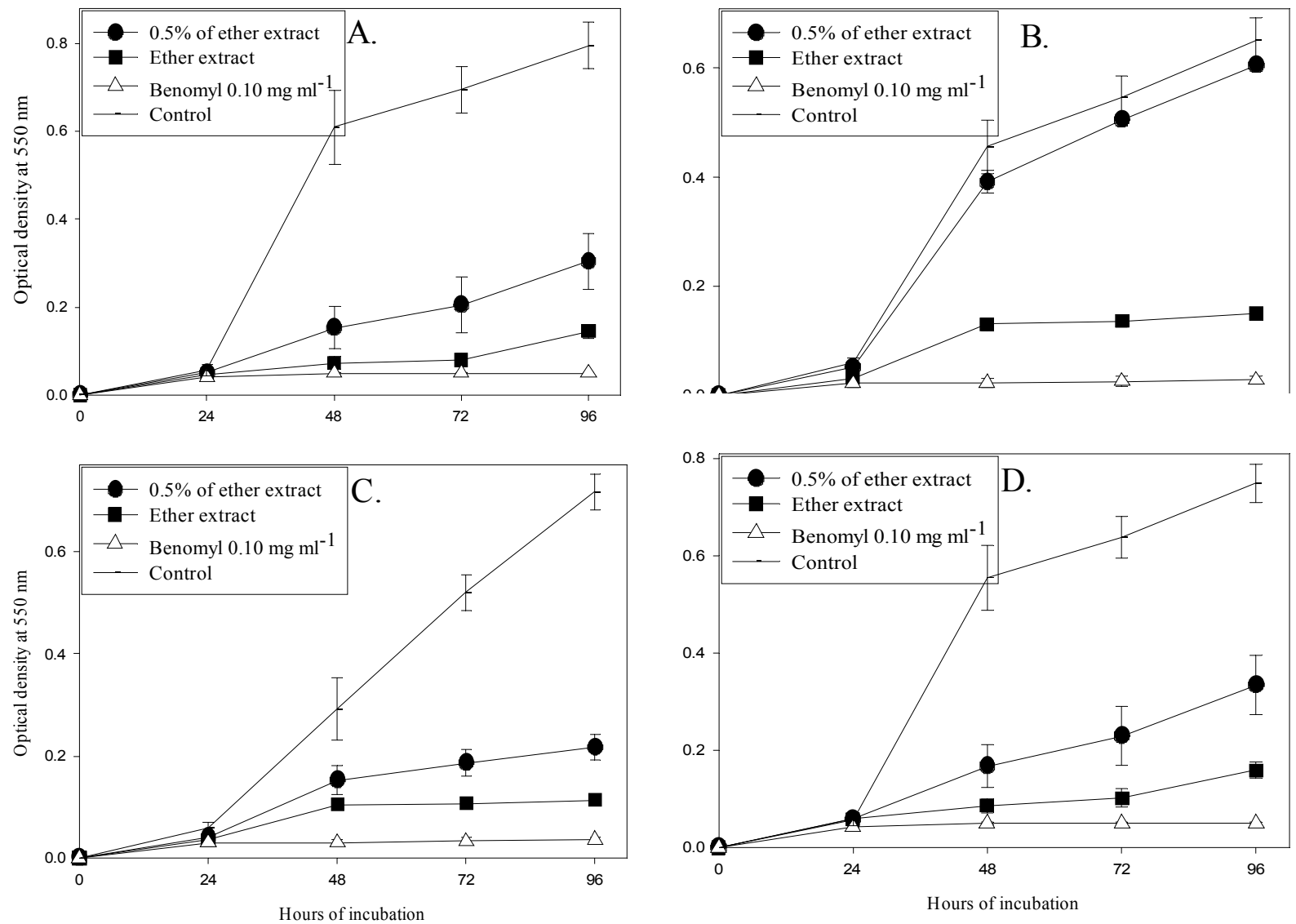

Figure 7. Changes in optical density (mean $\pm \mathrm{SE}$ ) as consequence of mycelia growth of $F$. oxysporum f. sp. sesami in presence of ether extract and $0.50 \%$ of ether extract from A. Roots of accession UCLA1. B. Stem of accession Inamar. C. Leaf of accession India 1. D. Seed of accession Korea 1

syriaca (Shimoni et al., 1993), Tranchyspermum ammi L. (Sprauge) (Dwivedi and Singh, 1998) have been reported to inhibit growth of $M$. phaseolina and/or $F$. oxysporum . Others authors have reported the use of extracts of plant such as pepper/mustard, cassia and clover to control the soil-borne fungi $F$. oxysporum $\mathrm{f}$. sp. chrysantemi and $F$. oxysporum $\mathrm{f}$. sp. melonis (Bowers and Locke, 2000). Results obtained in the present study could be the basis for potential application of sesame extracts to control soil-borne fungi in greenhouse or field.

Traditionally, effect of different plant accessions on pest or microorganism is tried to relate to classifications based on molecular markers or geographical origin. Ordination of the sesame accessions based on effect of plant extracts on growth of two fungi species is quite different to 
the AFLP ordination either the 32 sesame accessions from the Centro Nacional de Investigaciones Agropecuarias (CENIAP) Germplasm Bank (Venezuela) reported by Laurentin and Karlovsky (2006) or the 20 commercial cultivars or elite lines from Venezuelan sesame breeding programs reported by Laurentin and Karlovsky (2007). However, accessions India 2, India 5, India 8, Korea 1 and Greece on one side, and Central Asia accessions by the other side, were grouped in 2 different robust cluster based on AFLP (Laurentin and Karlovsky, 2006) and also were grouped closely based on effect of plant extracts against fungi growth (Figure 3). Additionally, commercial cultivars grouping based on effect of plant extract on fungi growth has some common features to the AFLP ordination reported by Laurentin and Karlovsky (2007), for instance a close grouping among Venezuela 51, Acarigua, Caripucha and 43x32; and among UCLA249, UCLA83, UCLA295 and Fonucla.

The less polar fraction (diethylether) from the partition of ethanolic extracts resulted to possess the most inhibitory effect, not only for ethanolic extracts with the most inhibitory effect, also for those with most stimulatory effect. Fungi-toxic compound reported in sesame extracts, either root or leaf, have been found in non-polar fractions such as chloroform or ethyl acetate (Pagnoca et al., 1990; Ogasawara et al., 1993; Hasan et al., 2000; Hasan et al., 2001). Results of the present study suggest that toxic compounds to fungi are present in all the accessions, but final effect on fungi growth depends on the balance among present compounds. Equivalent weight to $15 \mathrm{mg}$ (fresh weight) of root, stem, leaf or seed were enough to show inhibition in growth of $M$. phaseolina and $F$. oxysporum f. sp. sesami in 30 $\mu \mathrm{L}$. Even this concentration showed less inhibition than Benomyl, and it was 150 fold higher in weight, compounds present in less-polar fraction from ethanolic extracts of sesame organs seem to be promising for controlling these two fungi species.

The findings of this study enhance the idea of screening into the genetic variability of a species when antimicrobial compounds are searched. This intra-species screening in the case of sesame, resulted in identification of accessions possessing promising compounds with 
potential in control of fungal diseases, either by means of resistant cultivar or production of natural fungicides.

\section{Acknowledgments}

This work was supported by the Programme Alban (European Union Programme of High Level Scholarships for Latin America, Identification Number E03D13301VE), International $\mathrm{PhD}$ program for Agricultural Sciences in Göttingen University (IPAG), and Universidad Centroccidental Lisandro Alvarado. 


\section{Literature cited}

Al-Sakeiti, M., A. Al-Subhi, N. Al-Saady and M. Deadman. 2005. First report of witches'-broom disease of sesame (Sesamum indicum) in Oman. Plant Disease 89:530

Aponte, O., E. Gonnella and M. Perez. 1997. Determinación de la preferencia de Antigastra catalaunalis Duponchel (Lepidoptera:Pyralidae) sobre variedades de ajonjoli. Bol Entomol. Venez. 12:135-140

Ashri, A. 1998. Sesame breeding. Plant Breeding Reviews 16:179-228

Avila, J. 2003. Resistance of white seeded sesame (Sesamum indicum L.) cultivars against charcoal rot (Macrophomina phaseolina) in Venezuela. Sesame and Safflower Newsletter 18:72-76

Bedigian, D. and J. Harlan. 1986. Evidence for cultivation on sesame in the ancient world. Economic Botany 40:137-154

Bowers, J., and J. Locke. 2000. Effect of botanical extracts on the population density of Fusarium oxysporum in soil and control of Fusarium wilt in the greenhouse. Plant Dis. 84:300-305

Brooker, N., J. Long and S. Stephan. 2000. Field assessment of plant derivative compounds for managing fungal soybean diseases. Biochemical Society Transactions 28:917-920

De Lucca, A., T. Cleveland and D. Wedge. 2005. Plant-derived antifungal proteins and peptides. Can J Microbiol 51:1001-1014

Dhingra, O. and J.Sinclair. 1978. Biology and pathology of Macrophomina phaseolina. Impresa Universitaria. Universidade Federal de Viçosa. Minas Gerais, Brasil.

Dwivedi, S. and K. Singh. 1998. Fungitoxicity of some higher plant products against Macrophomina phaseolina (Tassi) Goid. Flavour Frag J. 13:397-399

El-Bramawy, M., and A. Wahid. 2006. Field resistance of crosses of sesame (Sesamum indicum L.) to charcoal root rot caused by Macrophomina phaseolina (Tassi) Goid. Plant Protect. Sci. 42:66-72

El-Shazly, M., O. A. Wahid, M. A. El-Ashry, S. M. Ammar, M. A. El-Barmawy. 1999. Evaluation of resistance to Fusarium wilt disease in sesame germplasm. International Journal of Pest Management 45:207-210

Gata-Goncalves, J. Nogueira, O. Matos and R. De Sousa. 2003. Photoactive extracts from Thevetia peruviana with antifungal properties against Cladosporium cucumerinum. Journal of Photochemistry and Photobiology 70:51-54

Ghosh, M. 2006. Antifungal properties of haem peroxidase from Acorus calamus. Annals of Botany 98:1145-1153

Hasan, A., S. Begum, T. Furumoto and H. Fukui. 2000. A new chlorinated red naphthoquinone from roots of Sesamum indicum. Biosci Biotechnol.Biochem. 64:873-874 
Hasan, A., T. Furumoto, S. Begum and H. Fukui. 2001. Hydroxisesamone and 2,3epoxysesamone from roots of Sesamum indicum. Phytochemistry 58:1225-1228

Jacklin, A., C. Ratledge and J. Wynn. 2000. Lipid-to-gibberellin metabolic switching in Fusarium moniliforme via the action of sesamol. Biotechnology Letters 22:1983-1986

Laurentin, H., A. Layrisse and P. Quijada. 2000. Evaluación de dos ciclos de selección recurrente para altos rendimientos de semilla en una población de ajonjolí. Agronomía Tropical (Maracay) 50:521-535.

Laurentin, H. and C. Pereira. 2001. Incidencia de la mosca blanca sobre seis genotipos de ajonjolí. Agronomía Tropical (Maracay) 51(3):319-335

Laurentin, H., and P. Karlovsky. 2006. Genetic relationship and diversity in a sesame (Sesamum indicum L.) germplasm collection using amplified fragment length polymorphism (AFLP).BMCGenetics7:10

Laurentin, H. and P. Karlovsky. 2007. AFLP fingerprinting of sesame (Sesamum indicum L.) cultivars: identification, genetic relationship and comparison of AFLP informativeness parameters. Genetic Resources and Crop Evolution:in press, published on-line under DOI 10.1007/s10722-006-9128-y

Malaguti, G. Una podredumbre del tallo del ajonjolí (Sesamum indicum L.) causada por Phytophthora. Agronomía Tropical (Maracay) 3 (3): 201-204. 1953.

Mazzani, B. 1999. Investigación y tecnología del cultivo del ajonjolí en Venezuela. Ediciones del Consejo Nacional de Investigaciones Cientificas y Tecnológicas. Caracas. Venezuela. 103 pp. http://ajonjoli.sian.info.ve/mazzani.pdf

Nirenberg, H. 1990. Recent advances in the taxonomy of Fusarium. Stud. Mycol. 32:91-101

Nyanapah, J., P. Ayiecho and J. Nyabundi. 1995. Evaluation of sesame cultivars for resistance to Cercospora leaf spot. E. Afr. Agric. For. J. 6:115-121

Ogasawara, T., K. Chiba and M. Tada. 1993. Production in high-yield of a naphthoquinone by a hairy root culture of Sesamum indicum. Phytochemistry 33:1095-1098

Ojiambo, P., P. Ayiecho and R. Narla. 2000. Tolerance level of Alternaria sesami and the effect of seed infection on yield of sesame in Kenya. Expl Agric 36:335-342

Pagnoca, F., O. da Silva, M. Hebling-Beraldo, O. Correa, J. Fernandes and P. Vieira. 1990. Toxicity of sesame extracts to the symbiotic fungus of leaf-cutting ants. Bulletin of Entomological Research 80:349-352

Papavizas, G. 1960. Some factors affecting survival of sclerotia of Macrophomina phaseolina in soil. Soil Biol. Biochem. 9: 337-341

Pathirana, R. 1992. Gamma ray-induced field tolerance to Phytophthora blight in sesame. Plant Breeding 108:314-319

Pineda, J.B. 1987. Macrophomina phaseolina en Ajonjolí. Evaluación de Daños y Pérdidas. 
Fonaiap Divulga (Venezuela) 5(25):25-26.

Pineda, J. and J. Avila. 1988. Alternativas para el control de Macrophomina phaseolina y Fusarium oxysporum patogenos del ajonjoli (Sesamum indicum L.). Agronomia Tropical (Maracay) 38(4-6):79-84

Pineda, J., H. Nass and H. Rodriguez. 1985. Efecto de la densidad de inoculo de Macrophomina phaseolina en la infección de plántulas de ajonjoli. Agronomia Tropical (Maracay) 35(4-6):133-138

Rajput, M., H. Khan, K. Jafri and J. Fazal Ali. 1998. Field Screening of Sesame Germplasm for Resistance against Charcoal Rot (Macrophomina phaseolina). Sesame Safflower Newsl., 13:63-66.

Shimoni, M., E. Putievsky, U. Ravid, and R. Reuveni. 1993. Antifungal activity of volatile fractions of essential oils from four aromatic wild plants in Isarael. Journal of Chemical Ecology 19:1129-1133

Shivas, R.G., C.A. Brockway and V.C. Beilharz. 1996. First record in Australia of Cercospora sesami and Psudocercospora sesami, two important foliar pathogens of sesame. Australasian Plant Pathology 26:212

Simosa, N. and M. Delgado. 1991. Virulence of four isolates of Macrophomina phaseolina on four sesame (Sesamum indicum) cultivars. Fitopatología Venezolana 4: 20-23

Sreenivasulu, P., J. Demski, D. Purcifull, R. Christie and G. Lovell.1994. A potyvirus causing mosaic disease of sesame (Sesamum indicum). Plant Dis 78: 95-99

Treyvaud Amiquet, V., P. Petit, C. Ta, R. Nunez, P. Sanchez-Vindas, L. Alvarez, M. Smith, J. Aranson and T. Durst. 2006. Phytochemistry and antifungal properties of the newly discovered tree Pleodendron costaricense. J Nat Prod 69:1005-1009 


\section{Chapter 7. Concluding summary}

Sesame is an important crop in tropical and subtropical areas. Sesame seed is traditionally used for direct consumption, because of its high nutritional value (50\% oil and $25 \%$ protein), and as a source of oil of excellent quality due to the presence of natural antioxidants such as sesamin and sesamol. Potentially beneficial effects of sesame on human health have recently renewed the interest in this ancient crop. Despite the nutritional value and historic and cultural importance of sesame, the research on this crop has been scarce. For example, no international CGIAR (Consultative Group on International Agricultural Research) agency is mandated to study sesame. Information on the genetic diversity in sesame is limited as well, only some studies about morphological diversity have been carried out, and generally, these studies have been focused on regional interest. To overcome this gap of knowledge in sesame, this research has been achieved in order to know how diverse is a sesame germplasm collection containing accessions from different origin regions. Genetic diversity was assessed at three different levels: DNA (by means of amplified fragment length polymorphism or AFLP), metabolic profiles, and functional metabolites (by means of effect of plant extracts on soilborne pathogenic fungi). Individual outputs for every approach were obtained, but also information about usefulness of AFLP for identifying sesame cultivars, informativeness of parameters used in molecular markers analyses, how to analize relationship between pair of approaches, and identification of sesame accessions potentially valuables for breeding and/or production of natural compounds against soil-borne fungi. These results cover a wide range of issues of knowledge about sesame such as planning of conservation strategies based on genetic diversity, protection of sesame breeders' rights, potential use of specific accessions for breeding or for obtaining natural antifungal compounds, and methodological approaches for obtaining metabolic profiles, and relationship between different ways to assess diversity, or for assessing effect of novel compounds on fungi growth.

These studies were achieved using (totally or partially) 32 accessions from Venezuelan 
Germplasm Bank coming from 5 diversity centres (India, Africa, Central Asia, Wester Asia and China-Korea-Japan) and 20 genotypes cataloged as commercial cultivars of elite lines from Venezuelan breeding programs.

The assessment of genetic diversity in sesame using 32 accessions from different geographical origin resulted in a high level of variability within all diversity centres except Central Asia. Any association between geographic origin and AFLP patterns was found. Most of the variation is explained by genetic diversity within origin regions rather than between origin regions. Practical consequences in conservation and breeding of sesame are derived from these results. Conservation strategies do not need to cover all diversity centres as long as they sample a sufficient number of accessions. Similarly, choosing parent genotypes for breeding programs from many diversity centres as compared to sampling just one centre (except Central Asia) is not likely to increase the variability among progeny significantly, whether the objective is breeding for poligenic traits such as yield. Regardless of how many diversity centres are sampled, both conservation strategies and breeding programs would benefit from using AFLP or another genome fingerprinting technique to maximise the genetic variability covered by the selected genotype set.

AFLP-based fingerprints demonstrated to be useful for identifying unequivocally sesame genotypes, resulting an average and maximum probability of identical match by chance between 2 accessions of $2.7 \times 10^{-7}$ and $5.2 \times 10^{-5}$ respectively. Reliability in cultivar identification by means of molecular markers is needed for protection of breeder's rights, and for assessing genetic variability of breeding stocks. Relationship among accessions by pedigree did not result related to AFLP patterns parent-progeny. By tradition, some parameters such as PIC (polymorphic information content), Rp (resolving power) and MI (marker index) have been used for evaluating usefulness of molecular markers or primers (e.g. when PCR-based techniques are used) in cultivar identification, however, according to the literature and also to present results, they are not useful for this objective. Number of cultivar 
identified by a primer combination (when AFLP are used) seems to be more useful. Similarly, to calculate the maximal, instead of average probability of identical match by chance in the assessment of the informativeness of a marker for cultivar identification seem to be more adequate.

Correlation between AFLP data and metabolic profiles data was not found, but some important consistencies, independently of the similarity level between a pair of accessions were reported. Metabolic profiles were obtained from seeds; and indirect selection on some metabolites at seed by farmers and differences in the sampling on the genome of the two methodologies could explain the results. AFLP sampling is insensitive to gene expression, but metabolic profiles are sampling on biosynthetic genes. This fact suggests that identification of similarity/dissimilarity relationship between pairs based on AFLP and seed metabolic profiles depend on the genotypes under comparison, due to differences in evolutionary history of each genotype. Therefore the assumption that genetic distance between two genotypes is directly proportional to the probability of identifying very different levels in some important agronomic or quality trait is not necessarily true, and is not supported by this work. This approach seems to be more realistic whether poligenic traits such as yield is under consideration. The results suggest that the elucidation of the metabolic diversity in sesame requires recording metabolic profiles from all plant organs (root, stem, leaf, fruit, seed), which are affected by different kinds of phenotypic selection. Metabolic content of seeds as a major quality criterion cannot be predicted from metabolic profiles of other plant organs. Genome diversity revealed by AFLP markers does not mirror the differences in the content of seed metabolites.

Search in plants of novel compounds with antimicrobial properties requires large screening of accessions, not only at inter-species level, but also within species. Adequate system of screening must be available for this goal. The present study report the standardization of a biosassay to test biological activity of novel compounds on growth of M. phaseolina. The 
proposed bioassay has the advantage of being suitable to test small amount of compounds, reducing required laboratory space and therefore being suitable for testing a great amount of sources with several replications. This is especially advantageous for testing natural compounds from plant genetic resources collections, because of the large amount of sources available.

The present study shows the importance of large screening within a species when antifungal activity from plants are being searched. Large within-species genetic variation has been originated by evolutionary forces, which can lead to differentiation at metabolite level and therefore, in the effect of plant extracts on fungi growth. Extreme response of fungi before plant extracts from different accessions of the same species can be observed, as in the present study: large stimulatory effect or strong growth inhibition. Some accessions have been identified as potentially valuable for breeding and/or production of natural products to control soil-borne fungi, not only from root extracts, also from stem, leaf and seed extracts. Ordination of the sesame accessions based on stimulatory or inhibitory effect of plant extracts on growth of two fungi species is quite different to the AFLP ordination either the 32 sesame accessions from the Centro Nacional de Investigaciones Agropecuarias (CENIAP) Germplasm Bank (Venezuela) or the 20 commercial cultivars or elite lines from Venezuelan sesame breeding programs. However, based on effect of plant extracts, accessions India 2, India 5, India 8, Korea 1 and Greece on one side, and Central Asia accessions by the other side, were grouped in 2 different robust cluster based on AFLP and also were grouped closely based on effect of plant extracts against fungi growth. Additionally, commercial cultivars grouping based on effect of plant extract on fungi growth has some common features to the AFLP ordination, for instance a close grouping among Venezuela 51, Acarigua, Caripucha and 43x32; and among UCLA249, UCLA83, UCLA295 and Fonucla. The less polar fraction (diethylether) from the partition of ethanolic extracts resulted to possess the most inhibitory effect, not only for ethanolic extracts with the most inhibitory effect, but also for those with 
most stimulatory effect. Results of the present study suggest that toxic compounds to fungi are present in all the accessions, but final effect on fungi growth depend on its balance respect to other compounds present in the plant organ. 
- Laurentin H and Karlovsky P (2007): AFLP fingerprinting of sesame (Sesamum indicum L.) cultivars: identification, genetic relationship and comparison of AFLP informativeness parameters. Genetic Resources and Crop Evolution, in press and published on-line under DOI 10.1007/s10722-006-9128-y

- Laurentin H and Karlovsky P (2006): Genetic relationship and diversity in sesame (Sesamum indicum L.) germplasm collection using amplified fragments length polymorphisms (AFLP). BMC Genetics 7:10

- Laurentin H, Karlovsky P (2006): Untersuchung der genetischen und metabolischen Diversität in einer Sammlung von Sesam-Akzessionen. 55. Deutsche Pflanzenschutztagung, 25.-28.9.2006. In: Mitteilungen aus der BBA 400:267-268.

- Laurentin H and P Karlovsky (2005) Investigation of genetic relationships in sesame (Sesamum indicum L.) germplasm collection using amplified fragments length polymorphisms (AFLP). DIVERSITAS Open Science Conference"Integrating biodiversity science for human well-being“, Oaxaca, Mexico, November 9-12, 2005. Book of Abstracts

- Laurentin H and Karlovsky P (2005): Investigation of genetic variability among twenty sesame (Sesamum indicum L.) Venezuelan cultivars using amplified fragments length polymorphisms (AFLP). Proceedings of the Deutscher Tropentag, Hohenheim, Germany, October 11-13, 2005.

- Laurentin H, A Ratzinger and P Karlovsky (2005): Relationship between genetic and metabolic diversity in sesame (Sesamum indicum L.) . 2nd International Symposium on Recent Advances in Food Analysis, Prague 2005, Book of Abstracts, Last Minute Posters p. 16.

- Hettwer U, H Laurentin and P Karlovsky (2005): Determination of antioxidative furofuran lignans in sesame seeds by HPLC-MS. 2nd International Symposium on Recent Advances in Food Analysis, Prague 2005, Book of Abstracts, Last Minute Posters p. 15. 


\section{Curriculum vitae}

Personal

Name:

Hernán Laurentin Táriba

Sex:

Male

Date of birth:

November $27^{\text {th }}, 1968$

Place of birth:

Montevideo, Uruguay

Nacionality:

Venezuelan

Marital status:

Married

\section{Education}

1975-1981

1981-1986

1987-1994

1995-1997

2003-2007

\section{Professional career}

1997-present
Elementary School, Valencia, Carabobo state, Venezuela

Secondary School, Valencia, Carabobo state, Venezuela

Universitary degree as Agronomist, at Universidad Centrooccidental Lisandro Alvarado, in Barquisimeto, Lara state, Venezuela

Master of Science in Agronomy, at Universidad Central de Venezuela, Maracay, Aragua state, Venezuela

Ph.D. Student, Georg-August University, Göttingen, Germany

Lecturer of Genetic and Plant Breeding in Universidad Centrooccidental Lisandro Alvarado. Department of Biologic Sciences 